Article

\title{
Novel Fluorinated Indanone, Tetralone and Naphthone Derivatives: Synthesis and Unique Structural Features
}

\author{
Joseph C. Sloop ${ }^{1, *}$, Paul D. Boyle ${ }^{2}$, Augustus W. Fountain ${ }^{3}$, Cristina Gomez ${ }^{4}$, \\ James L. Jackson ${ }^{5}$, William F. Pearman ${ }^{4}$, Robert D. Schmidt ${ }^{2}$ and Jonathan Weyand ${ }^{4}$ \\ 1 School of Science and Technology, Georgia Gwinnett College, 1000 University Center Lane, \\ Lawrenceville, GA 30043, USA \\ 2 Department of Chemistry, North Carolina State University, P.O. Box 8204, Raleigh, NC 27695, \\ USA; E-Mails: boyle@ncsu.edu (P.D.B.); rdschmid@ncsu.edu (R.D.S.) \\ 3 Edgewood Chemical and Biological Center, 5183 Blackhawk Road, Aberdeen Proving Ground, \\ MD 21010, USA; E-Mail: augustus.w.fountain@us.army.mil \\ 4 Department of Chemistry and Life Science, United States Military Academy, 646 Swift Road, West \\ Point, NY 10996, USA; E-Mail: cristina.c.gomez@us.army.mil (C.G.); \\ William.Pearman@usma.edu (W.F.P.); jon.weyand@us.army.mil (J.W.) \\ 5 US Army Corps of Engineers, 101 West Oglethorpe Avenue, Savannah, GA 31401, USA; \\ E-Mail: James.L.Jackson@usace.army.mil \\ * Author to whom correspondence should be addressed; E-Mail: jsloop@ggc.edu; \\ Tel.: +1-678-407-5022; Fax: +1-678-407-5938.
}

Received: 6 December 2011; in revised form: 12 January 2012 / Accepted: 16 January 2012 / Published: 1 February 2012

\begin{abstract}
Several fluorinated and trifluoromethylated indanone, tetralone and naphthone derivatives have been prepared via Claisen condensations and selective fluorinations in yields ranging from $22-60 \%$. In addition, we report the synthesis of new, selectively fluorinated bindones in yields ranging from 72-92\%. Of particular interest is the fluorination and trifluoroacetylation regiochemistry observed in these fluorinated products. We also note unusual transformations including a novel one pot, dual trifluoroacetylation, trifluoroacetylnaphthone synthesis via a deacetylation as well as an acetyl-trifluoroacetyl group exchange. Solid-state structural features exhibited by these compounds were investigated using crystallographic methods. Crystallographic results, supported by spectroscopic data, show that trifluoroacetylated ketones prefer a chelated cis-enol form whereas fluorinated bindone products exist primarily as the cross-conjugated triketo form.
\end{abstract}


Keywords: 2-trifluoroacetyl-1,3-Diketone; 1,3,5-triketone; tautomerism; X-ray crystallography

\section{Introduction}

Molecules which have medicinal, industrial and herbicidal properties are of continued interest to the pharmaceutical, chemical and agrochemical communities. For example, indanone derivatives have anticoagulant properties and are used in elaborating latent fingerprints, bindone variants comprise components of near infrared dyes while certain tetralones and naphthones, ketones similar in structure to those shown in Figure 1, have demonstrated bioactive properties [1-6]. Since bioactivity is known to be enhanced in many classes of fluorinated molecules [3,7], it is desirous to prepare fluorine-containing molecules with similar architecture and gain a better understanding of their structure-property relationships.

Figure 1. Medicinally and industrially important ketones.<smiles>O=C1Cc2ccccc2C1</smiles><smiles>O=C1CC(=O)c2ccccc21</smiles>

indanones<smiles>O=C1CC(=C2C(=O)c3ccccc3C2=O)c2ccccc21</smiles>

bindones<smiles>O=C1CCc2ccccc2C1</smiles>

tetralones<smiles>CC(=O)c1ccc2ccccc2c1O</smiles>

naphthones

Previously, we reported the preparation and structure-property relationships of acyclic fluorinated and trifluoromethylated $\beta$-diketones, precursors to a variety of heterocyclic molecules [8-10]. While the syntheses and properties of these molecules have been investigated thoroughly, the preparation and study of selectively fluorinated, cyclic ketones containing the structural features of the molecules depicted in Figure 1 remains relatively limited [11].

The molecules of interest in this study, shown in Scheme 1, provide this sort of molecular architecture. This paper addresses the design and synthetic approach to prepare these novel molecules, the interesting synthetic results and the unique solid-state structural features that differentiate these molecules.

Scheme 1. Synthesis of fluorinated ketones.

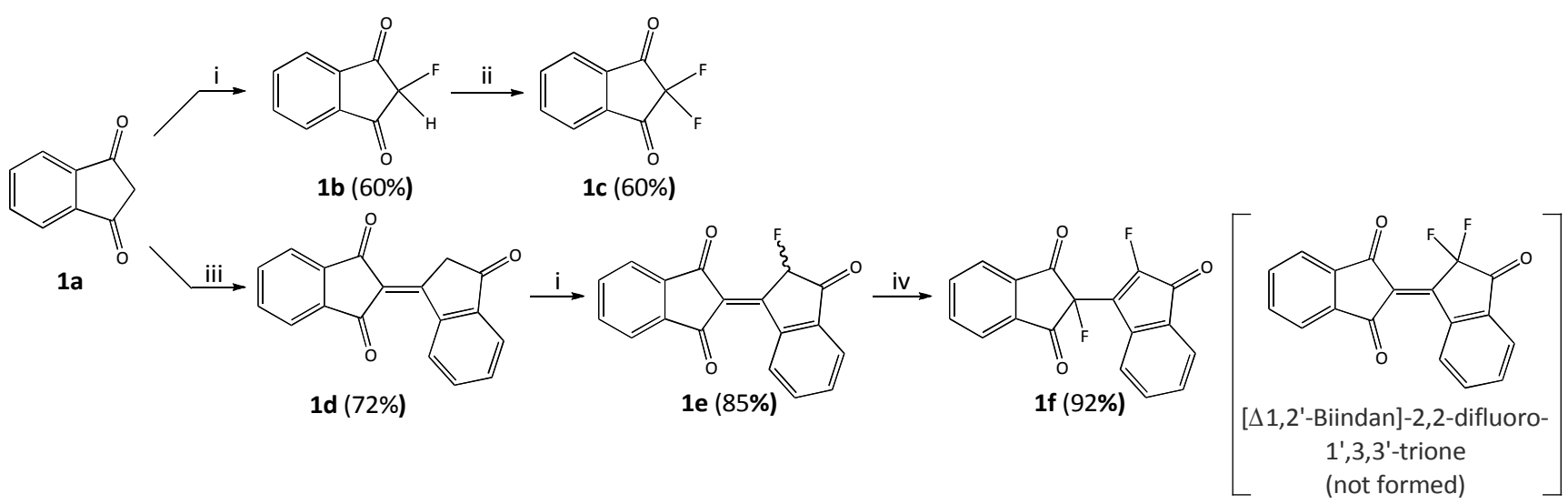


Scheme 1. Cont.

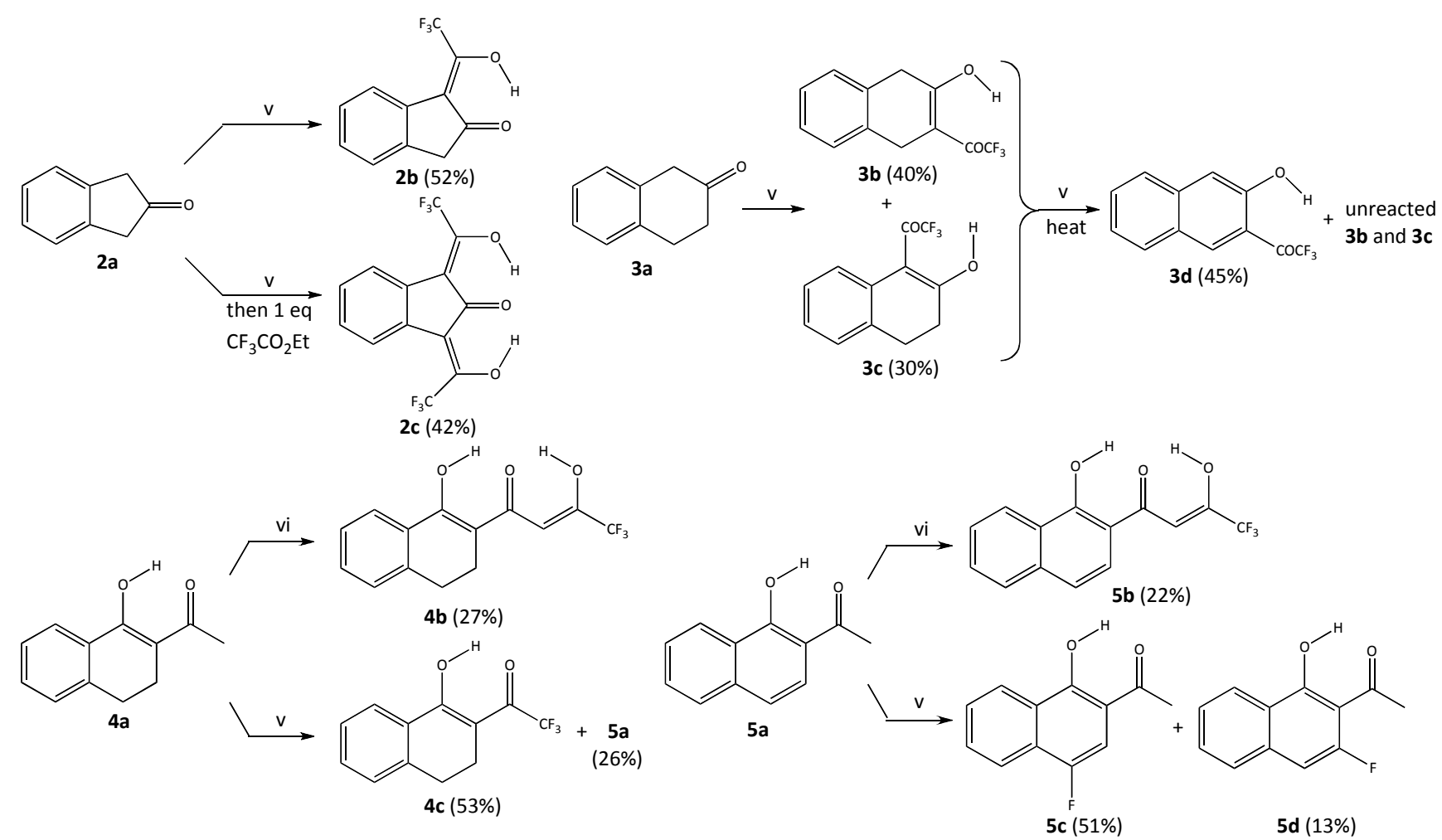

Conditions: i. 1.1 eq Selectfluor ${ }^{\circledR}, \mathrm{MeCN}$, reflux, $10 \mathrm{~h}$; ii. 1.5 eq Selectfluor ${ }^{\circledR}, \mathrm{MeCN}, \mathrm{RT}, 18-30 \mathrm{~h}$; iii. $\mathrm{H}_{2} \mathrm{SO}_{4}$, $\mathrm{MeOH}$, reflux, 24 h; iv. 1.1 eq Selectfluor ${ }^{\circledR}, \mathrm{MeCN}$, reflux, 16 h; v. $\mathrm{CF}_{3} \mathrm{CO}_{2} \mathrm{Et}, \mathrm{NaOMe}, \mathrm{Et}_{2} \mathrm{O}$, rt, 18 h; vi. (1) 3.0 eq LDA, $\mathrm{Et}_{2} \mathrm{O}, 0{ }^{\circ} \mathrm{C}$; (2) 2 eq $\mathrm{CF}_{3} \mathrm{CO}_{2} \mathrm{Et}, 0{ }^{\circ} \mathrm{C} \rightarrow \mathrm{rt}, 24 \mathrm{~h}$; (3) 2 eq $\mathrm{CF}_{3} \mathrm{CO}_{2} \mathrm{Et}$.

\section{Experimental Section}

\subsection{Chemicals}

All chemicals were obtained from the Aldrich Chemical Company, Eastman Kodak, or Fisher Chemical Company. All solvents (spectrophotometric grade) and starting materials were checked for purity by mass spectrometry prior to use.

\subsection{Instrumentation}

Melting points were obtained on a Mel-Temp melting point apparatus and are uncorrected. NMR data were collected using a Varian VXR-200 spectrometer with a broad band probe operating at 200.0 MHz for ${ }^{1} \mathrm{H}, 188.2 \mathrm{MHz}$ for ${ }^{19} \mathrm{~F}$ and $50.3 \mathrm{MHz}$ for ${ }^{13} \mathrm{C}$, and/or a Brüker Avance 300 spectrometer operating at $300.0 \mathrm{MHz}$ for ${ }^{1} \mathrm{H}, 282.0 \mathrm{MHz}$ for ${ }^{19} \mathrm{~F}$ and $75.4 \mathrm{MHz}$ for ${ }^{13} \mathrm{C}$. Unless otherwise noted, $\mathrm{CDCl}_{3}$ was used as the solvent and internal standard for ${ }^{1} \mathrm{H}$ and ${ }^{13} \mathrm{C}$ NMR experiments while $\mathrm{CFCl}_{3}$ served as the internal standard for ${ }^{19} \mathrm{~F}$ NMR experiments. All X-ray measurements were made on a Bruker-Nonius X8 Apex2 diffractometer. See the appendix for complete crystallographic experimental details. 


\subsection{General Procedure for the Preparation of Trifluoromethyl- $\beta$-Diketones and Triketones [12]}

A $100 \mathrm{~mL}$ round bottom flask equipped with a magnetic stirrer is charged with $50 \mathrm{~mL}$ diethyl ether and $60 \mathrm{mmol}$ of sodium methoxide is added slowly. Then, 1eq $(60 \mathrm{mmol})$ of trifluoromethyl ethyl acetate is added dropwise slowly while stirring. After 5 minutes, 1eq $(60 \mathrm{mmol})$ of the ketone is added dropwise and stirred overnight at room temperature under a calcium chloride drying tube. The resulting solution is evaporated to dryness under reduced pressure and the solid residue dissolved in $30 \mathrm{~mL} 3 M$ sulfuric acid. This solution is extracted with ether, and the organic layer dried over $\mathrm{Na}_{2} \mathrm{SO}_{4}$. The solvent is evaporated under reduced pressure and the crude diketone purified by radial chromatography.

\subsection{General Procedure for the Preparation of Selectively Fluorinated Ketones $[10,13]$}

A $100 \mathrm{~mL}$ round bottom flask equipped with a magnetic stirrer is charged with $40 \mathrm{~mL} \mathrm{CH}_{3} \mathrm{CN}$ and the ketone (1 eq: $1-10 \mathrm{mmol})$. Then, Selectfluor ${ }^{\circledR}\left(1-3 \mathrm{eq}(3-30 \mathrm{mmol})\right.$ ) dissolved in $30 \mathrm{~mL} \mathrm{CH}_{3} \mathrm{CN}$ is added slowly while stirring. The solution is either allowed to stir at room temperature or refluxed as required. Times range from 10-30 h. The resulting solution is evaporated to dryness under reduced pressure and the solid residue taken up in distilled water. This solution is extracted with $\mathrm{CH}_{2} \mathrm{Cl}_{2}$, and the organic layer dried over $\mathrm{Na}_{2} \mathrm{SO}_{4}$. The solvent is evaporated under reduced pressure and the crude fluorinated ketone purified by radial chromatography.

2-fluoro-1,3-indanedione (1b). This compound was obtained in $60 \%$ yield as pale yellow crystals (EtOH), m.p. 97-99 ${ }^{\circ} \mathrm{C}$ lit [14] (m.p. 96-98 $\left.{ }^{\circ} \mathrm{C}\right)$. NMR: ${ }^{1} \mathrm{H}: \delta 5.4\left(\mathrm{~d},{ }^{1} \mathrm{~J}_{\mathrm{H}-\mathrm{F}}=51.0 \mathrm{~Hz}, 1 \mathrm{H}\right), 7.65-8.22$ $(\mathrm{m}, 4 \mathrm{H}) .{ }^{13} \mathrm{C}: \delta 90.1\left(\mathrm{~d},{ }^{1} \mathrm{~J}_{\mathrm{C}-\mathrm{F}}=211.2 \mathrm{~Hz}, \mathrm{CF}\right), 125.3,138.9,141.9,193.5\left(\mathrm{~d},{ }^{2} \mathrm{~J}_{\mathrm{C}-\mathrm{F}}=24.0 \mathrm{~Hz}, \mathrm{C}-\mathrm{CF}\right)$. ${ }^{19} \mathrm{~F}: \delta-207.3\left(\mathrm{~d},{ }^{1} \mathrm{~J}_{\mathrm{F}-\mathrm{H}}=51.1 \mathrm{~Hz}, 1 \mathrm{~F}\right)$. HRMS (ESI+) Calcd. for $\mathrm{C}_{9} \mathrm{H}_{5} \mathrm{FO}_{2}:$ 164.02740. Found: 164.027580 .

2,2-difluoro-1,3-indanedione (1c). This compound was obtained in $60 \%$ yield from fluorination of $\mathbf{1 b}$ as described in the general procedure above as yellowish-brown crystals $(\mathrm{EtOH})$, m.p. $116-117^{\circ} \mathrm{C}$, lit [15] (m.p. $\left.117-118{ }^{\circ} \mathrm{C}\right)$. NMR: ${ }^{1} \mathrm{H}: \delta 8.0-8.15(\mathrm{~m}, 4 \mathrm{H}) .{ }^{13} \mathrm{C}: \delta 104.0\left(\mathrm{t},{ }^{1} \mathrm{~J}_{\mathrm{C}-\mathrm{F}}=264 \mathrm{~Hz}, \mathrm{CF}_{2}\right), 128.8$, $138.2,139.3\left(\mathrm{t},{ }^{3} \mathrm{~J}_{\mathrm{C}-\mathrm{F}}=4.3 \mathrm{~Hz}\right), 185.8\left(\mathrm{t},{ }^{2} \mathrm{~J}_{\mathrm{C}-\mathrm{F}}=24.0 \mathrm{~Hz}, \mathrm{C}_{-} \mathrm{CF}_{2}\right) .{ }^{19} \mathrm{~F}: \delta-125.9(\mathrm{~s}, 2 \mathrm{~F})$.

[ $\Delta 1,2^{\prime}$-Biindan]-1',3,3'-trione (1d). This compound was obtained in $72 \%$ yield as orange crystals (EtOH), m.p. 207-209 ${ }^{\circ} \mathrm{C}$, lit [16] (m.p. 205-208 ${ }^{\circ} \mathrm{C}$ ). NMR: ${ }^{1} \mathrm{H}: \delta 4.17$ (s, 2H), 7.74-8.04 (m, 8H), $9.50(\mathrm{~d}, \mathrm{~J}=7.8 \mathrm{~Hz}, 1 \mathrm{H}) .{ }^{13} \mathrm{C}: \delta 43.4,123.0,123.4,123.5,125.8,131.7,134.2,135.3,135.4,140.4$, 141.2, 141.6, 145.9, 155.4, 189.5, 191.0, 201.2.

[ $\Delta 1,2^{\prime}$-Biindan]-2-fluoro-1',3,3'-trione (1e). This compound was obtained was obtained in $85 \%$ yield from fluorination of $\mathbf{1 d}$ as described in the general procedure above as orange crystals $(\mathrm{EtOH})$, m.p. ${ }^{165-168}{ }^{\circ} \mathrm{C}(\mathrm{dec})$. NMR: ${ }^{1} \mathrm{H}: \delta 6.45\left(\mathrm{~d},{ }^{1} \mathrm{~J}_{\mathrm{H}-\mathrm{F}}=46.1 \mathrm{~Hz}, 1 \mathrm{H}\right), 7.75-8.20(\mathrm{~m}, 7 \mathrm{H}), 9.50$ $(\mathrm{d}, \mathrm{J}=7.7 \mathrm{~Hz}, 1 \mathrm{H}) .{ }^{13} \mathrm{C}: \delta 70.8\left(\mathrm{~d},{ }^{1} \mathrm{~J}_{\mathrm{C}-\mathrm{F}}=194 \mathrm{~Hz}, \mathrm{CF}\right), 125.4,126.6,129.3,130.1,132.0,137.7,138.5$, 166.3, 189.3, 191.2, $204.1\left(\mathrm{~d},{ }^{2} \mathrm{~J}_{\mathrm{C}-\mathrm{F}}=24 \mathrm{~Hz}, \mathrm{C}-\mathrm{CF}\right) .{ }^{19} \mathrm{~F}: \delta-182.4\left(\mathrm{~d},{ }^{1} \mathrm{~J}_{\mathrm{F}-\mathrm{H}}=46.0 \mathrm{~Hz}, 1 \mathrm{~F}\right)$. Analysis calcd for $\mathrm{C}_{18} \mathrm{H}_{9} \mathrm{FO}_{3}$ : C, 73.97, H, 3.10. Found: C, 74.06, H, 3.21.

2-fluoro-2-(2'-fluoro-3'-oxoindenyl)-1,3-indanedione (1f). This compound was obtained in $92 \%$ yield from fluorination of $\mathbf{1 e}$ as described in the general procedure above as yellow crystals (EtOH), m.p. ${ }^{126-129}{ }^{\circ} \mathrm{C}$. NMR: ${ }^{1} \mathrm{H}: 7.8-8.25(7 \mathrm{H}, \mathrm{m}), 9.53(1 \mathrm{H}, \mathrm{d}, \mathrm{J}=6.9 \mathrm{~Hz}) .{ }^{13} \mathrm{C}: \delta 89.9,125.1,126.3$, $129.5,130.0,132.2,137.1,138.0\left(\mathrm{~d},{ }^{1} \mathrm{~J}_{\mathrm{C}-\mathrm{F}}=254 \mathrm{~Hz}, \mathrm{CF}\right), 166.1,185.9,189.1 .{ }^{19} \mathrm{~F}: \delta-137.3(\mathrm{~s}, 1 \mathrm{~F})$, 
$-176.7(\mathrm{~s}, 1 \mathrm{~F})$. HRMS (ESI+) calcd for $\mathrm{C}_{18} \mathrm{H}_{8} \mathrm{~F}_{2} \mathrm{O}_{3}$ : 310.04415 . Found: 310.04415 .

1-trifluoroacetyl-2-indanone (2b). This compound was obtained in 52\% yield as a brown oil. NMR: ${ }^{1} \mathrm{H}: \delta 3.73(2 \mathrm{H}, \mathrm{s}), 7.29(2 \mathrm{H}, \mathrm{m}), 7.60(2 \mathrm{H}, \mathrm{m}), 14.19(1 \mathrm{H}, \mathrm{bs}),{ }^{13} \mathrm{C}: \delta 40.9,111.5,120.4\left(\mathrm{CF}_{3}, \mathrm{q}\right.$, $\left.{ }^{1} \mathrm{~J}_{\mathrm{C}-\mathrm{F}}=277 \mathrm{~Hz}\right), 122.9,123.0,124.9,127.7,128.1,128.8,129.6,154.5\left(\mathrm{C}-\mathrm{CF}_{3}, \mathrm{q},{ }^{2} \mathrm{~J}_{\mathrm{C}-\mathrm{F}}=37 \mathrm{~Hz}\right), 203.0$. ${ }^{19} \mathrm{~F}:-68.59(\mathrm{~s}, 3 \mathrm{~F})$. Analysis calcd for $\mathrm{C}_{11} \mathrm{H}_{7} \mathrm{~F}_{3} \mathrm{O}_{2}: \mathrm{C}, 57.90, \mathrm{H}, 3.09$. Found: $\mathrm{C}, 58.04, \mathrm{H}, 3.02$.

1,3-ditrifluoroacetyl-2-indanone $(\mathbf{2 c})$. To $30 \mathrm{~mL}$ dry $\mathrm{Et}_{2} \mathrm{O}$ in a round bottom flask equipped with a magnetic stirrer is added sodium methoxide $(0.449 \mathrm{~g}, 8.32 \mathrm{mmol})$ all at once. Then, trifluoromethyl ethyl acetate $(0.903 \mathrm{~mL}, 7.57 \mathrm{mmol})$ is added dropwise slowly while stirring. After 5 minutes, 2-indanone (1.00 g, $7.57 \mathrm{mmol})$ dissolved in $20 \mathrm{~mL}$ dry $\mathrm{Et}_{2} \mathrm{O}$ is added dropwise and stirred overnight at room temperature under a calcium chloride drying tube. After $24 \mathrm{~h}$, another equivalent of trifluoromethyl ethyl acetate is added dropwise and stirred overnight at room temperature under a calcium chloride drying tube. The reaction mixture is acidifed with $30 \mathrm{~mL} 3 M$ sulfuric acid. The organic layer was separated, washed with deionized water, and the organic layer dried over $\mathrm{Na}_{2} \mathrm{SO}_{4}$. The solvent was evaporated under reduced pressure, providing a yellow solid, which when recrystallized, yielded yellow crystals (cyclohexane), in 42\% yield, m.p. $111-113{ }^{\circ} \mathrm{C}$. NMR: ${ }^{1} \mathrm{H}: \delta 7.34$ $(2 \mathrm{H}, \mathrm{m}), 7.65(2 \mathrm{H}, \mathrm{m}), 13.50(2 \mathrm{H}, \mathrm{bs}) .{ }^{13} \mathrm{C}: \delta 111.5,118.4\left(\mathrm{CF}_{3}, \mathrm{q},{ }^{1} \mathrm{~J}_{\mathrm{C}-\mathrm{F}}=273 \mathrm{~Hz}\right), 119.6,122.9$,

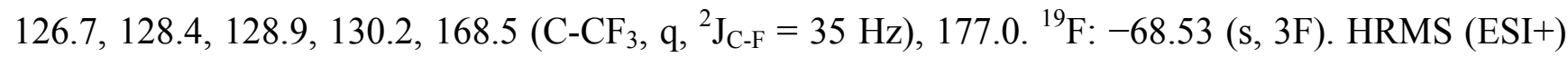
calcd for $\mathrm{C}_{13} \mathrm{H}_{6} \mathrm{~F}_{6} \mathrm{O}_{3}: 324.02211$, found: 324.02158 .

3-trifluoroacetyl-2-tetralone (3b) and 1-trifluoroacetyl-2-tetralone (3c). These compounds were obtained as a 4:3 mixture of 3b:3c. Radial chromatography $\left(100 \% \mathrm{CH}_{2} \mathrm{Cl}_{2}-50 / 50 \mathrm{CH}_{2} \mathrm{Cl}_{2} / \mathrm{MeOH}\right)$ afforded two product fractions. Fraction 1: $\mathbf{3 b}$ as orange crystals (hexane), in $40 \%$ yield, m.p. 123-126 ${ }^{\circ} \mathrm{C}$. NMR: ${ }^{1} \mathrm{H}: \delta, 3.76(2 \mathrm{H}, \mathrm{s}), 3.81(2 \mathrm{H}, \mathrm{s}), 7.25-8.05(4 \mathrm{H}, \mathrm{m}), 15.01(1 \mathrm{H}, \mathrm{bs}) .{ }^{13} \mathrm{C}: \delta 27.8$, 38.3, 103.7, $117.5\left(\mathrm{CF}_{3}, \mathrm{q},{ }^{1} \mathrm{~J}_{\mathrm{C}-\mathrm{F}}=281 \mathrm{~Hz}\right), 127.1,127.3,127.8,127.9,130.5,133.4,157.3,174.8$ $\left(\mathrm{C}-\mathrm{CF}_{3}, \mathrm{q},{ }^{2} \mathrm{~J}_{\mathrm{C}-\mathrm{F}}=35 \mathrm{~Hz}\right), 191.0 .{ }^{19} \mathrm{~F}\left(\mathrm{C}_{6} \mathrm{~F}_{6}\right.$ ext. std.): $\oint^{-70.62}$ (s, 3F). HRMS (ESI+) calcd for $\mathrm{C}_{12} \mathrm{H}_{9} \mathrm{~F}_{3} \mathrm{O}_{2}: 242.04470$, found: 242.04436 . Fraction 2: 3c (30\%) as an orange solid, m.p. 88-91 ${ }^{\circ} \mathrm{C} .3 \mathbf{c}$ : NMR: ${ }^{1} \mathrm{H}: \delta 2.72\left(2 \mathrm{H}, \mathrm{t},{ }^{2} \mathrm{~J}=1.9 \mathrm{~Hz}\right), 3.01\left(2 \mathrm{H}, \mathrm{t},{ }^{2} \mathrm{~J}=1.9 \mathrm{~Hz}\right), 7.25(4 \mathrm{H}, \mathrm{m}), 14.98(1 \mathrm{H}, \mathrm{bs}) .{ }^{13} \mathrm{C}: \delta$ 25.0, 30.3, 102.9, $118.6\left(\mathrm{CF}_{3}, \mathrm{q},{ }^{1} \mathrm{~J}_{\mathrm{C}-\mathrm{F}}=282 \mathrm{~Hz}\right), 126.6,126.9,127.3,128.1,130.2,133.8,158.1,175.4$ $\left(\mathrm{C}-\mathrm{CF}_{3}, \mathrm{q},{ }^{2} \mathrm{~J}_{\mathrm{C}-\mathrm{F}}=35 \mathrm{~Hz}\right), 189.1 .{ }^{19} \mathrm{~F}\left(\mathrm{C}_{6} \mathrm{~F}_{6}\right.$ ext. std.): $\oint^{-67.70}$ (s, 3F). HRMS (ESI+) calcd for $\mathrm{C}_{12} \mathrm{H}_{9} \mathrm{~F}_{3} \mathrm{O}_{2}$ : 242.04470, found: 242.04442.

3-trifluoroacetyl-2-naphthol (3d). A round bottom flask equipped with a magnetic stirrer containing $30 \mathrm{~mL}$ dry $\mathrm{Et}_{2} \mathrm{O}$ is charged with 1 equivalent $\mathrm{NaOCH}_{3}$. Then, 1 equivalent ethyl trifluoroacetate is added dropwise slowly and stirred for $15 \mathrm{~min}$. To this solution is added a 4:3 mixture of compounds 3b:3c dissolved in $20 \mathrm{~mL} \mathrm{Et}_{2} \mathrm{O}$. The reaction mixture is stirred overnight at room temperature under a calcium chloride drying tube. The solvent is removed under reduced pressure while heating at $60{ }^{\circ} \mathrm{C}$ for $20 \mathrm{~min}$. The solid residue is acidified with $30 \mathrm{~mL} 3 M$ sulfuric acid and extracted with $3-15 \mathrm{~mL}$ portions of $\mathrm{Et}_{2} \mathrm{O}$. The organic layers were combined, washed with deionized water, and the organic layer dried over $\mathrm{Na}_{2} \mathrm{SO}_{4}$. The solvent was evaporated under reduced pressure, providing a orange solid, which when subjected to radial chromatography, gave a fraction which upon recrystallization, yielded pale, orange crystals $\left(\mathrm{CH}_{2} \mathrm{Cl}_{2}\right), \mathbf{3 d}$, in $45 \%$ yield, m.p. $80-83{ }^{\circ} \mathrm{C}$. An additional fraction was collected which contained unreacted 3b and 3c. 3d: NMR: ${ }^{1} \mathrm{H}: \delta, 7.25-8.05(6 \mathrm{H}, \mathrm{m}), 14.83(1 \mathrm{H}, \mathrm{bs}) .{ }^{13} \mathrm{C}: \delta$ $119.3\left(\mathrm{CF}_{3}, \mathrm{q},{ }^{1} \mathrm{~J}_{\mathrm{C}-\mathrm{F}}=284 \mathrm{~Hz}\right), 124.9,125.4,126.9,129.9,130.1,130.4,131.4,135.1,139.1,157.3$, $184.6\left(\mathrm{C}-\mathrm{CF}_{3}, \mathrm{q},{ }^{2} \mathrm{~J}_{\mathrm{C}-\mathrm{F}}=35 \mathrm{~Hz}\right) .{ }^{19} \mathrm{~F}\left(\mathrm{C}_{6} \mathrm{~F}_{6}\right.$ ext. std. $): \delta-74.25(\mathrm{~s}, 3 \mathrm{~F})$. Analysis calcd for $\mathrm{C}_{12} \mathrm{H}_{7} \mathrm{~F}_{3} \mathrm{O}_{2}$ : 
C, 60.01, H, 2.94. Found: C, 60.13, H, 2.88.

4,4,4-trifluoro-1-(1-oxotetrahydronaphthyl)-1,3-butanedione (4b) [17]. A $100 \mathrm{~mL}$ round bottom flask is charged with $50 \mathrm{~mL}$ dry $\mathrm{Et}_{2} \mathrm{O}, 5 \mathrm{~mL}$ dry diisopropylamine, equipped with a magnetic stir bar and placed under $\mathrm{N}_{2}$ at $0{ }^{\circ} \mathrm{C}$. To this is added LDA $(6.0 \mathrm{~mL}, 0.0120 \mathrm{~mol})$ and stirred for fifteen minutes. Then, a solution of $4 \mathbf{a}(0.752 \mathrm{~g}, 0.004 \mathrm{~mol})$ in $15 \mathrm{~mL}$ dry $\mathrm{Et}_{2} \mathrm{O}$ is added dropwise slowly via syringe. After $8 \mathrm{~h}$, ethyl trifluoroacetate $(0.96 \mathrm{~mL}, 0.008 \mathrm{~mol})$ is delivered dropwise slowly via syringe, the reaction mixture is stirred overnight and allowed to warm to $\mathrm{rt}$. A third equivalent of ethyl trifluoroacetate $(0.004 \mathrm{~mol})$ is added after 24 hours and the solution is left to stir again overnight. The reaction mixture is acidifed with $30 \mathrm{~mL} 3 M$ sulfuric acid. The organic layer was separated, washed with deionized water, and the organic layer dried over $\mathrm{Na}_{2} \mathrm{SO}_{4}$. The solvent was evaporated under reduced pressure, and subjected to radial chromatography. After recrystallization from cyclohexane, 4b was obtained as reddish-brown crystals in $27 \%$ yield, mp $133-135{ }^{\circ} \mathrm{C} .4 \mathbf{b}$ : NMR: ${ }^{1} \mathrm{H}: \delta 2.85(2 \mathrm{H}$, t, $7.6 \mathrm{~Hz}), 2.93(2 \mathrm{H}, \mathrm{t}, 7.6 \mathrm{~Hz}), 6.76(\mathrm{~s}, 1 \mathrm{H}), 7.37-7.77(4 \mathrm{H}, \mathrm{m}), 15.68(2 \mathrm{H}, \mathrm{bs}) .{ }^{13} \mathrm{C}: \delta 20.9,22.7,104.6$, $118.4\left(\mathrm{CF}_{3}, \mathrm{q},{ }^{1} \mathrm{~J}_{\mathrm{C}-\mathrm{F}}=270 \mathrm{~Hz}\right), 125.9,126.8,127.3,127.4,128.2,128.5,128.6,129.9,133.9,142.8$, $177.0\left(\mathrm{C}_{-} \mathrm{CF}_{3}, \mathrm{q},{ }^{2} \mathrm{~J}_{\mathrm{C}-\mathrm{F}}=36 \mathrm{~Hz}\right), 182.2 .{ }^{19} \mathrm{~F}\left(\mathrm{C}_{6} \mathrm{~F}_{6}\right.$ ext. std. $): \delta-72.04$ (s, 3F). Analysis calcd for $\mathrm{C}_{14} \mathrm{H}_{11} \mathrm{~F}_{3} \mathrm{O}_{3}$ : C, 59.16, H, 3.90. Found: C, 58.99, H, 4.01.

2-trifluoroacetyl-1-tetralone (4c). This compound was obtained as off-white crystals, $\mathbf{4 c}$, in $53 \%$ yield, m.p. $50-52{ }^{\circ} \mathrm{C}$ lit [18] (m.p. $\left.51-52{ }^{\circ} \mathrm{C}\right) .4 \mathrm{c}: \mathrm{NMR}:{ }^{1} \mathrm{H}: \delta 2.75(2 \mathrm{H}, \mathrm{t}, 9.0 \mathrm{~Hz}), 2.88(2 \mathrm{H}, \mathrm{t}, 9.0 \mathrm{~Hz})$, 7.16-7.87 (4H, m), $15.62(1 \mathrm{H}, \mathrm{bs}) .{ }^{13} \mathrm{C}: \delta 21.0,27.8,38.3,103.7,117.5\left(\mathrm{CF}_{3}, \mathrm{q},{ }^{1} \mathrm{~J}_{\mathrm{C}-\mathrm{F}}=285 \mathrm{~Hz}\right), 127.1$,

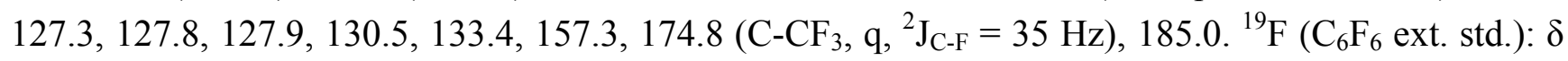
$-70.61(\mathrm{~s}, 3 \mathrm{~F})$. HRMS (ESI+) calcd for $\mathrm{C}_{12} \mathrm{H}_{9} \mathrm{~F}_{3} \mathrm{O}_{2}: 242.04470$, found: 242.04436 .

4,4,4-trifluoro-1-(1-hydroxynaphthyl)-1,3-butanedione (5b) [17]. A $100 \mathrm{~mL}$ RBF equipped with a magnetic stir bar is charged with $50 \mathrm{~mL}$ dry $\mathrm{Et}_{2} \mathrm{O}, 5 \mathrm{~mL}$ dry diisopropylamine (DIPA) and placed under $\mathrm{N}_{2}$ at $0{ }^{\circ} \mathrm{C}$. To this is added LDA $(6.0 \mathrm{~mL}, 0.0120 \mathrm{~mol})$ and stirred for fifteen minutes. Then, a solution of $5 \mathrm{a}(0.740 \mathrm{~g}, 0.004 \mathrm{~mol})$ in $15 \mathrm{~mL}$ dry $\mathrm{Et}_{2} \mathrm{O}$ is added dropwise slowly via syringe. After $8 \mathrm{~h}$, ethyl trifluoroacetate $(0.96 \mathrm{~mL}, 0.008 \mathrm{~mol})$ is delivered dropwise slowly via syringe and the reaction mixture is stirred overnight and allowed to warm to rt. After $24 \mathrm{~h}$, another equivalent of ethyl trifluoroacetate $(0.46 \mathrm{~mL}, 0.004 \mathrm{~mol})$ is added all at once. The reaction is stirred for an additional $24 \mathrm{~h}$. The reaction mixture is acidifed with $30 \mathrm{~mL} 3 M$ sulfuric acid. The organic layer was separated, washed with deionized water, and the organic layer dried over $\mathrm{Na}_{2} \mathrm{SO}_{4}$. The solvent was evaporated under reduced pressure, and subjected to radial chromatography. After recrystallization (cyclohexane) 5b was obtained as brown crystals, in $22 \%$ yield, m.p. $154-157{ }^{\circ} \mathrm{C}$. 5b: NMR: ${ }^{1} \mathrm{H}: \delta 6.90(\mathrm{~s}, 1 \mathrm{H})$, 7.51-8.50 (6H, m), $14.44(1 \mathrm{H}, \mathrm{bs}), 15.70(1 \mathrm{H}, \mathrm{bs}) .{ }^{13} \mathrm{C}: \delta 111.9,115.7\left(\mathrm{CF}_{3}, \mathrm{q},{ }^{1} \mathrm{~J}_{\mathrm{C}-\mathrm{F}}=271 \mathrm{~Hz}\right), 127.1$,

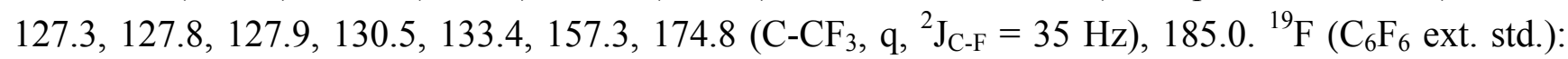
$\delta-71.60$ (s, 3F). Analysis calcd for $\mathrm{C}_{14} \mathrm{H}_{9} \mathrm{~F}_{3} \mathrm{O}_{3}$ : C, 59.59, H, 3.21. Found: C, 59.86, H, 3.16.

2-acetyl-4-fluoro-1-naphthol (5c) and 2-acetyl-3-fluoro-1-naphthol (5d). These compounds were obtained as a 5:1 mixture of 5c:5d. Radial chromatography $\left(100 \% \mathrm{CH}_{2} \mathrm{Cl}_{2}-50 / 50 \mathrm{CH}_{2} \mathrm{Cl}_{2} / \mathrm{MeOH}\right)$ afforded $\mathbf{5 c}$ as brown crystals $\left(51 \%\right.$, m.p. $\left.93-95{ }^{\circ} \mathrm{C}\right)$ and $\mathbf{5 d}$ as a tan solid (13\%, m.p. 88-91 $\left.{ }^{\circ} \mathrm{C}\right) . \mathbf{5 c}$ : NMR: ${ }^{1} \mathrm{H}: \delta 2.71(3 \mathrm{H}, \mathrm{s}), 7.31-8.48(5 \mathrm{H}, \mathrm{m}), 14.01(1 \mathrm{H}, \mathrm{bs}) .{ }^{13} \mathrm{C}: \delta 26.9,113.1,118.3,124.9,126.0$, 127.4, 130.1, 137.4, 150.5 (Ar-F, d, $\left.{ }^{1} \mathrm{~J}_{\mathrm{C}-\mathrm{F}}=243 \mathrm{~Hz}\right), 162.4,204.2 .{ }^{19} \mathrm{~F}\left(\mathrm{C}_{6} \mathrm{~F}_{6}\right.$ ext. std.): $\delta-134.0(\mathrm{~s}, 1 \mathrm{~F})$. Analysis calcd for $\mathrm{C}_{12} \mathrm{H}_{9} \mathrm{FO}_{2}$ : C, 70.59, H, 4.44. Found: $\mathrm{C}, 70.77, \mathrm{H}, 4.31 .5 \mathrm{~d}$ : NMR: ${ }^{1} \mathrm{H}: \delta 2.63$ $(3 \mathrm{H}, \mathrm{s}), 7.40-8.00(5 \mathrm{H}, \mathrm{m}), 13.82(1 \mathrm{H}, \mathrm{bs}) .{ }^{13} \mathrm{C}: \delta 27.6,111.3,120.3,124.6,125.1,126.9,128.6,130.2$, 
130.3, 155.5 (Ar-F, d, $\left.{ }^{1} \mathrm{~J}_{\mathrm{C}-\mathrm{F}}=244 \mathrm{~Hz}\right), 158.7,203.4 .{ }^{19} \mathrm{~F}\left(\mathrm{C}_{6} \mathrm{~F}_{6}\right.$ ext. std.): $\delta-134.2(\mathrm{~s}, 1 \mathrm{~F})$. Analysis calcd for $\mathrm{C}_{12} \mathrm{H}_{9} \mathrm{FO}_{2}$ : C, 70.59, H, 4.44. Found: C, 70.44, H, 4.49.

\section{Results and Discussion}

\subsection{Synthesis}

Compounds 1a-5a are commercially available and were used without further purification. Compounds 1b and 1c have been previously described, but were prepared according to a different method [14,15]. Compound 1d is known and was synthesized via a previously described method [12,16]. The remaining compounds were prepared using a modified Claisen condensation or direct fluorination with Selectfluor ${ }^{\circledR}[10,12,13,18,19]$. See Scheme 1.

Recent work by our group showed that regioselective monofluorination and geminal difluorination of acyclic $\beta$-diketones could be effected with Selectfluor ${ }^{\circledR}$ under mild conditions without the necessity of specialized glassware or safety precautions $[10,14,15]$. The current synthetic investigation sought to take advantage of this earlier work by probing Selectfluor ${ }^{\circledR}$, s efficiency and effectiveness in the monoand difluorination of 1,3-indanedione and bindone. Our efforts revealed some unexpected findings. The monofluorination of 1a proceeded with little difficulty to give 2-fluoro-1,3-indanedione (1b) in the diketonic form (as evidenced by a doublet signal $\left(\mathrm{J}_{\mathrm{F}-\mathrm{H}}=51.1 \mathrm{~Hz}\right.$ ) in the ${ }^{19} \mathrm{~F}$ NMR at $\left.-207.3 \mathrm{ppm}\right)$, albeit in slightly lower yield compared to fluorination achieved with $5 \% \mathrm{~F}_{2}$ in $\mathrm{N}_{2}$ [10]. Diketone $\mathbf{1 b}$ was also successfully fluorinated (as evidenced by a singlet signal in the ${ }^{19} \mathrm{~F}$ NMR at $-125.9 \mathrm{ppm}$ ), delivering the geminally difluorinated product $1 \mathbf{c}$ in good overall yield.

We then examined whether bindone, the aldol self-condensation product of 1,3-indanedione, would react similarly to treatment with Selectfluor ${ }^{\circledR}$. As expected, monofluorination was achieved in high yield to give 1e as an enantiomeric triketone pair $\left({ }^{19} \mathrm{~F}\right.$ NMR: $\left.-182.4 \mathrm{ppm}, \mathrm{J}_{\mathrm{F}-\mathrm{H}}=46.0 \mathrm{~Hz}\right)$, but the site of fluorination was the $\alpha$-carbon adjacent to the isolated ketone rather than fluorination between the 1,3-diketone residue. Subsequent fluorination of 1e likewise yielded interesting results. Particularly noteworthy were the fluorination regioselectivity and alkene rearrangement observed during the formation of triketone 1f. We expected an outcome similar to the fluorination of $\mathbf{1 b}$, but the occurrence of two distinct signals in the ${ }^{19}$ F NMR at $-137.3 \mathrm{ppm}$ and $-176.7 \mathrm{ppm}$ ruled out geminal difluorination. Evidently, the alkene in 1e retains sufficient nucleophilic nature to permit electrophilic fluorination between the $\beta$-dicarbonyl residue. This addition, coupled with a concomitant E1-like elimination leads to $\mathbf{1 f}$, rather than formation of [ $\Delta 1,2^{\prime}$-Biindan]-2,2-difluoro-1',3,3'-trione, shown in Scheme 1.

While preparing $\mathbf{2 b}$ and $\mathbf{2 c}$, the previously undescribed one-pot, twin trifluoroacetylation of 2-indanone gave the dual exocyclic enol $\mathbf{2 c}$ in moderate yield (confirmed by the presence of a single ${ }^{19} \mathrm{~F}$ NMR resonance at $-68.5 \mathrm{ppm}$ ) and no $\mathbf{2 c}$ ', Figure 2 . In this case, the ethoxide base present following the condensation apparently deprotonates the unsubstituted benzylic $\alpha$-hydrogen $\left(\mathrm{H}_{3}\right)$ rather than the more acidic $\alpha$-hydrogen $\mathrm{H}_{1}$.

There are several possible explanations for the formation of $\mathbf{2 c}$ and the failure to obtain $\mathbf{2} \mathbf{c}$ '. The most plausible scenario involves initial formation of $\mathbf{2} \mathbf{c}^{\prime}$. Given the basic reaction conditions, however, we surmise that upon attachment of the second $\mathrm{COCF}_{3}$ group, 2c' may undergo nucleophilic acyl substitution by ethoxide, reverting $2 \mathbf{c}^{\prime}$ back to enolate $\mathbf{A}$. A second possibility for the failure to obtain 
$\mathbf{2} \mathbf{c}^{\prime}$ may be larger steric demands in the transition state leading to enolate $\mathbf{A}$ formation relative to that leading to enolate $\mathbf{B}$. Finally, a base-promoted tautomerization from enolate $\mathbf{A}$ to enolate $\mathbf{B}$ could occur before formation of $\mathbf{2} \mathbf{c}$, ultimately leading to $\mathbf{2 c}$.

Figure 2. Formation of 1,3-ditrifluoroacetyl-2-indanone (2c).

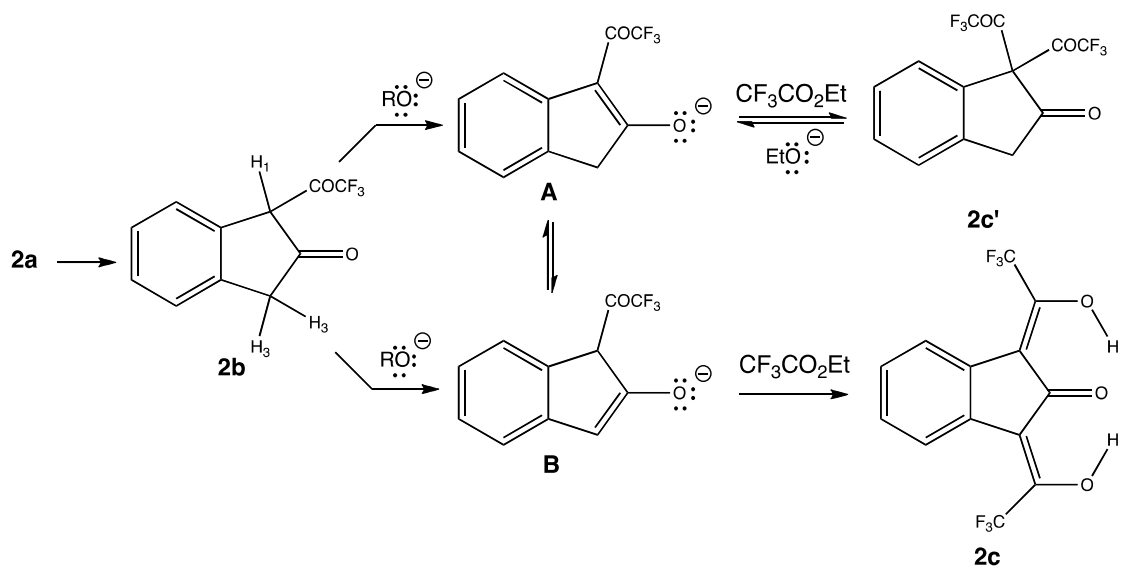

We then attempted a similar strategy with $\beta$-tetralone (3a) to ascertain whether this ditrifluoroacetylation methodology could be generalized to other ketones with two acidic $\alpha$-hydrogen sets. Sequential treatment of $\mathbf{3 a}$ with two equivalents of ethyl trifluoroacetate followed by neutralization at room temperature led to a mixture of the 3- and 1-trifluoroacetyl-2-tetralone endocyclic enols $\mathbf{3 b}$ and 3c, respectively; the formation of 1,3-ditrifluoroacetyl-2-tetralone was not observed. Assignment of the endocyclic enolic structures was based on the observation of a single ${ }^{19} \mathrm{~F}$ NMR resonance at $-70.6 \mathrm{ppm}$ for $\mathbf{3 b}$ and $-67.7 \mathrm{ppm}$ for $\mathbf{3 c}$. When the reaction workup conditions were modified by subjecting the enols $\mathbf{3 b}$ and $\mathbf{3} \mathbf{c}$ to an additional equivalent of base and ethyl trifluoroacetate followed by in vacuo removal of solvent at elevated temperature, we were surprised to find that aromatization occurred to give the trifluoroacetylated naphthol 3d in moderate overall yield. Figure 3 depicts a plausible route to naphthol 3d. We surmise that deprotonation of the less sterically hindered $\alpha$-hydrogen enroute to $\mathbf{3 b}$ occurs rather than abstraction of the more acidic, benzylic $\alpha$-hydrogen. Detrifluoroacetylation of triketone I followed by tautomerization of diketone II under acidic workup provides naphthol 3d.

Figure 3. Formation of 3-trifluoroacetyl-2-tetralone (3b) and 3-trifluoroacetyl-2-naphthol (3d).

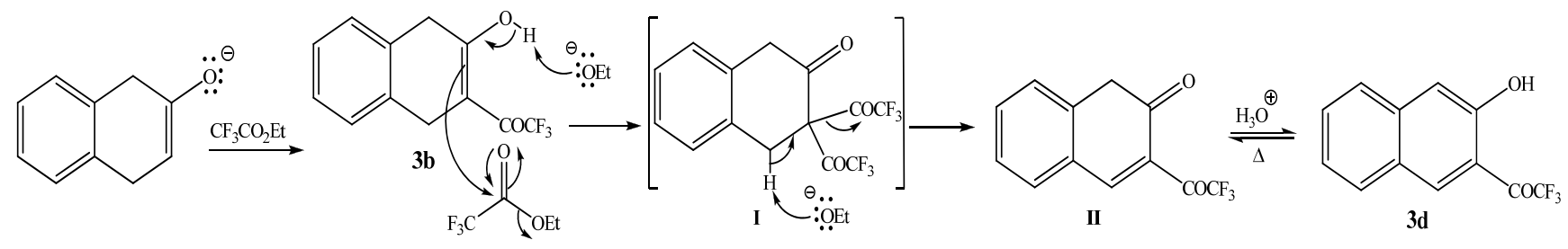

Application of Light and Hauser's method to 4a and 5a produced the cross-conjugated, dienolic 1,3,5-triketones $\mathbf{4} \mathbf{b}$ and $\mathbf{5 b}$ in modest yields [17]. Assignment of the enolic structures was based on a combination of resonances found in their NMR spectra-(4b) ${ }^{1} \mathrm{H}$ : an alkene proton signal @6.76 ppm $(1 \mathrm{H})$, a broad, unresolvable singlet corresponding to the enol protons @ 15.68 ppm $(2 \mathrm{H})$ and ${ }^{19} \mathrm{~F}$ : a 
singlet@-72.0 ppm (3F); for $(\mathbf{5 b}){ }^{1} \mathrm{H}$ : an alkene proton signal @ 6.90 ppm $(1 \mathrm{H})$, a singlet corresponding to the phenolic enol proton@14.44 (1H), a broader singlet @ 15.68 ppm (1H) corresponding to the enol adjacent to the $\mathrm{CF}_{3}$ group and ${ }^{19} \mathrm{~F}$ : a singlet @-71.6 ppm (3F). Addition of $\mathrm{D}_{2} \mathrm{O}$ to the NMR samples of $\mathbf{4} \mathbf{b}$ and $\mathbf{5 b}$ resulted in rapid diminuation of the exchangeable enolic protons in the ${ }^{1} \mathrm{H}$ NMR. Increasing the molar ratio of ethyl trifluoroacetate:diketone to $>2: 1$, although necessary for triketone product formation, also led to $O$-trifluoroacetylated by-products. Fortunately, these were easily separated by chromatography from the desired 1,3,5-triketones. Additionally, we found that when 4a was subjected to standard Claisen reaction conditions, an unintended acetyl-trifluoroacetyl group exchange occurred to give 2-trifluoroacetyl-1-tetralone (4c) in good yield along with, to our surprise, naphthol 5a. A process similar to the detrifluoroacetylation depicted in Figure 2 may be operating in these cases as well.

Treatment of 5a with Selectfluor ${ }^{\circledR}$ demonstrated the fluorination preference of activated aromatic substrates over acetyl groups [19-21]. The fluorinated naphthols 5c and 5d were achieved in good overall yield and a 5:1 ratio of the para:meta isomers, respectively. Ring fluorination was confirmed by the observation of resonances in the ${ }^{19} \mathrm{~F}$ NMR spectra as singlets: $-134.0 \mathrm{ppm}(1 \mathrm{~F})$ and $-134.2 \mathrm{ppm}$ (1F) for 5c and 5d, respectively. Preferential para fluorination is in accord with the $o-p$ directing ability of the hydroxyl group. Use of up to 5 equivalents of Selectfluor ${ }^{\circledR}$ to effect fluorination at the acetyl carbon provided only the monofluorinated naphthols $\mathbf{5 c}$ and $\mathbf{5 d}$.

\subsection{Solid State Structural Features: X-ray Crystallography}

Several of the target molecules (1d, 2c, 3c and 4c) were examined by x-ray crystallography. Crystal data and structure refinement information for $\mathbf{1 d}$ and $\mathbf{2 c}$ are recorded in Figure 4 and Table 1 while Figure 5 and Table 2 contain data for $\mathbf{3 d}$ and $\mathbf{4 c}$. Critical bond information is listed in Table 3. The crystallographic information files for these molecules have been uploaded to the Cambridge Crystallographic Data Center and have the following control numbers: 1d: 854704, 2c: 854697, 3d: 854705 and 4c: 854706.

Figure 4. ORTEP drawings of $1 \mathbf{d}$ and $2 \mathrm{c}$. Ellipsoids are at the 50\% probability level and hydrogen atoms were drawn with arbitrary radii for clarity.

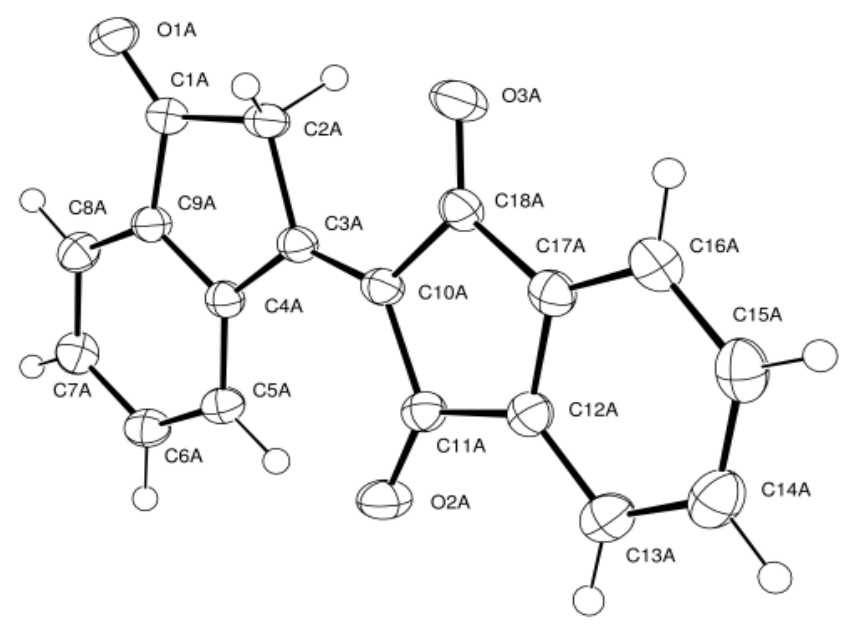

1d

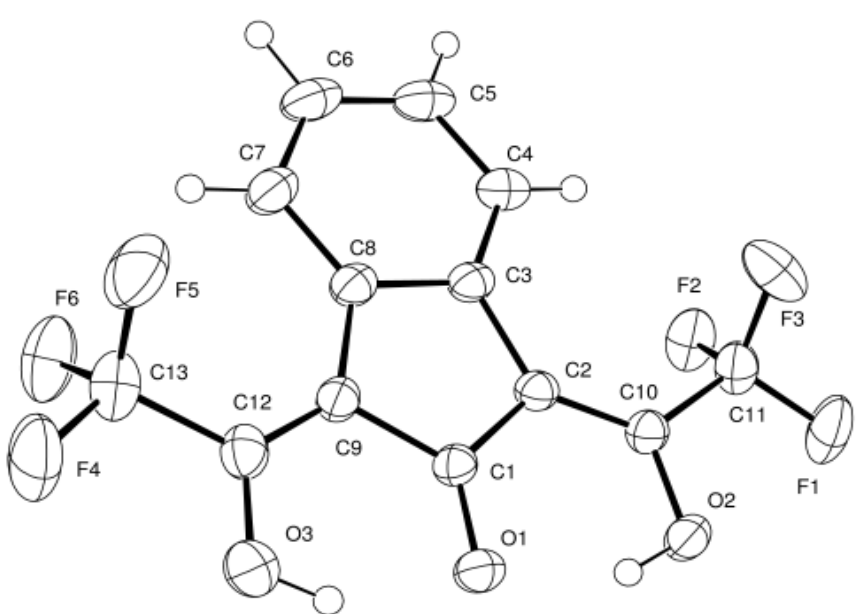

2c 
Table 1. Crystal data and structure refinement for $\mathbf{1 d}$ and $\mathbf{2 c}$.

\begin{tabular}{|c|c|c|}
\hline Compound & 1d & $2 c$ \\
\hline Formula & $\mathrm{C}_{18} \mathrm{H}_{10} \mathrm{O}_{3}$ & $\mathrm{C}_{13} \mathrm{H}_{6} \mathrm{~F}_{6} \mathrm{O}_{3}$ \\
\hline Formula Weight $(\mathrm{g} / \mathrm{mol})$ & 274.26 & 324.18 \\
\hline Crystal Dimensions $(\mathrm{mm})$ & $0.30 \times 0.24 \times 0.20$ & $1.20 \times 0.10 \times 0.06$ \\
\hline Crystal Color and Habit & clear prism & yellow needle \\
\hline Crystal System & orthorhombic & monoclinic \\
\hline Space Group & $\mathrm{Fd} \mathrm{d} 2$ & $\mathrm{P} 2{ }_{1} / \mathrm{c}$ \\
\hline Temperature, $\mathrm{K}$ & 173 & 173 \\
\hline$a, \AA$ & $18.0996(6)$ & \\
\hline$b, \AA$ & $20.9271(7)$ & $18.6978(12)$ \\
\hline$c, \AA$ & $26.0789(8)$ & $13.8431(9)$ \\
\hline$\alpha,{ }^{\circ}$ & 90.00 & 90.0 \\
\hline$\beta,^{\circ}$ & 90.00 & $98.964(3)$ \\
\hline Compound & 1d & $2 \mathrm{c}$ \\
\hline$\gamma,{ }^{\circ}$ & 90.00 & 90.0 \\
\hline $\mathrm{V}, \AA^{3}$ & $9878.0(6)$ & $1218.11(14)$ \\
\hline Reflections to determine final unit cell & 9975 & 9959 \\
\hline $2 \theta$ range, ${ }^{\circ}$ & $5.0,56.84$ & $5.28-57.7$ \\
\hline $\mathrm{Z}$ & 32 & 4 \\
\hline $\mathrm{F}(000)$ & 4544 & 648.71 \\
\hline$\rho(\mathrm{g} / \mathrm{cm})$ & 1.475 & 1.768 \\
\hline$\lambda, \AA,(\operatorname{MoK} \alpha)$ & 0.71070 & 0.71073 \\
\hline$\mu,\left(\mathrm{cm}^{-1}\right)$ & 0.101 & 0.18 \\
\hline Reflections collected & 103146 & 26516 \\
\hline Unique reflections & 6360 & 3195 \\
\hline $\mathrm{R}_{\text {merge }}$ & 0.0403 & 0.027 \\
\hline Cut off Threshold Expression & $>2 \operatorname{sigma}(\mathrm{I})$ & Inet $>1.0$ sigma(Inet) \\
\hline Refinement method & full matrix least-sqs using $\mathrm{F}^{2}$ & full matrix least-sqs using $\mathrm{F}$ \\
\hline Weighting Scheme & $\begin{array}{l}1 /\left[\operatorname{sigma}^{2}\left(\mathrm{Fo}^{2}\right)+(0.0555 \mathrm{P})^{2}+\right. \\
3.0465 \mathrm{P}] \text { where } \\
\mathrm{P}=\left(\mathrm{Fo}^{2}+2 \mathrm{Fc}^{2}\right) / 3\end{array}$ & $1 /\left(\operatorname{sigma}^{2}(F)+0.0005 F^{2}\right)$ \\
\hline $\mathrm{R}_{1}^{\mathrm{a}}$ & 0.0342 & 0.038 \\
\hline $\mathrm{wR}_{2}$ & $0.0846^{\mathrm{b}}$ & $0.053^{\mathrm{c}}$ \\
\hline $\mathrm{R}_{1}$ (all data) & 0.0400 & 0.046 \\
\hline $\mathrm{wR}_{2}$ (all data) & 0.0880 & 0.054 \\
\hline GOF & $1.038^{\mathrm{d}}$ & $1.74^{\mathrm{e}}$ \\
\hline
\end{tabular}

${ }^{\mathrm{a}} \mathrm{R}_{1}=\Sigma\left(\left|\mathrm{F}_{\mathrm{o}}\right|-\mid \mathrm{F}_{\mathrm{c}}\right) / \Sigma \mathrm{F}_{\mathrm{o}} ;{ }^{\mathrm{b}} \mathrm{wR}_{2}=\left[\Sigma\left(w\left(\mathrm{~F}_{\mathrm{o}}{ }^{2}-\mathrm{F}_{\mathrm{c}}{ }^{2}\right)^{2}\right) / \Sigma\left(w \mathrm{~F}_{\mathrm{o}}{ }^{4}\right)\right]^{1 / 2} ;{ }^{\mathrm{c}} \mathrm{wR}_{2}=\left[\Sigma\left(w\left(\mathrm{~F}_{\mathrm{o}}{ }^{2}-\mathrm{F}_{\mathrm{c}}{ }^{2}\right)^{2}\right) / 2\left(w \mathrm{~F}_{\mathrm{o}}{ }^{4}\right)\right]^{1 / 2} ;$ ${ }^{\mathrm{d}} \mathrm{GOF}=\left[\Sigma\left(w\left(\mathrm{~F}_{\mathrm{o}}{ }^{2}-\mathrm{F}_{\mathrm{c}}{ }^{2}\right)^{2}\right) /(\# \text { reflns }-\# \text { params })\right]^{1 / 2} ;{ }^{\mathrm{e}} \mathrm{GOF}=\left[\Sigma\left(w\left(\mathrm{~F}_{\mathrm{o}}{ }^{2}-\mathrm{F}_{\mathrm{c}}{ }^{2}\right)^{2}\right) /(\text { No. reflns. No. params. })\right]^{1 / 2}$. 
Figure 5. ORTEP drawings of $\mathbf{3 d}$ and $\mathbf{4 c}$. Ellipsoids are at the $50 \%$ probability level and hydrogen atoms were drawn with arbitrary radii for clarity.

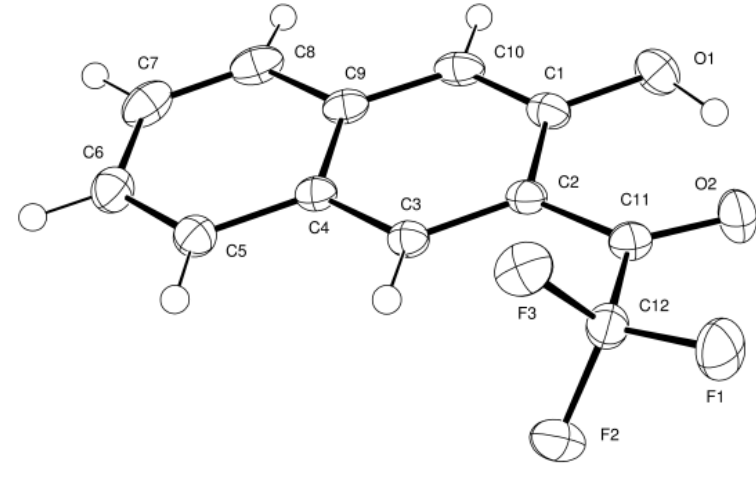

3d

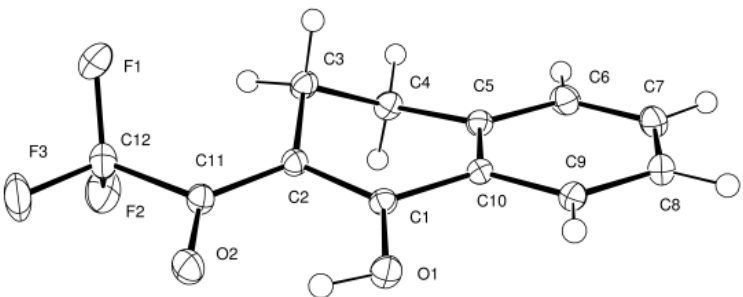

$4 c$

Table 2. Crystal data and structure refinement for $\mathbf{3 d}$ and $\mathbf{4 c .}$

\begin{tabular}{|c|c|c|}
\hline Compound & 3d & $4 c$ \\
\hline Formula & $\mathrm{C}_{12} \mathrm{H}_{7} \mathrm{~F}_{3} \mathrm{O}_{2}$ & $\mathrm{C}_{12} \mathrm{H}_{9} \mathrm{~F}_{3} \mathrm{O}_{2}$ \\
\hline Formula Weight $(\mathrm{g} / \mathrm{mol})$ & 240.18 & 242.19 \\
\hline crystal size $(\mathrm{mm})$ & $0.46 \times 0.08 \times 0.04$ & $0.38 \times 0.28 \times 0.04$ \\
\hline crystal color/shape & orange yellow needle & colourless plate \\
\hline cryst syst & orthorhombic & triclinic \\
\hline space group & $\mathrm{P}$ n a 2 & $\mathrm{P}-1$ \\
\hline temp, $\mathrm{K}$ & 110 & 110 \\
\hline$a, \AA$ & $13.5923(5)$ & $7.3528(2)$ \\
\hline$b, \AA$ & $14.9695(5)$ & $7.9165(2)$ \\
\hline$c, \AA$ & $4.8381(2)$ & $9.7991(2)$ \\
\hline$\alpha,^{\circ}$ & 90.00 & $73.0533(11)$ \\
\hline$\beta,^{\circ}$ & 90.00 & $85.3968(12)$ \\
\hline$\gamma,{ }^{\circ}$ & 90.00 & $68.3581(11)$ \\
\hline $\mathrm{V}, \AA^{3}$ & $984.41(6)$ & $506.92(2)$ \\
\hline Reflections to final unit cell & 5859 & 6416 \\
\hline $2 \theta$ range, $^{\circ}$ & $5.44-52.66$ & $5.78-71.38$ \\
\hline $\mathrm{Z}$ & 4 & 2 \\
\hline $\mathrm{F}(000)$ & 488 & 248 \\
\hline$\rho(\mathrm{g} / \mathrm{cm})$ & 1.621 & 1.587 \\
\hline$\lambda, \AA,(\operatorname{MoK} \alpha)$ & 0.71070 & 0.71073 \\
\hline$\mu,\left(\mathrm{cm}^{-1}\right)$ & 0.147 & 0.143 \\
\hline Reflections collected & 21568 & 20479 \\
\hline Unique reflections & 2632 & 4691 \\
\hline $\mathrm{R}_{\text {merge }}$ & 0.0444 & 0.0265 \\
\hline Cut off Threshold Expression & $>2 \operatorname{sigma}(\mathrm{I})$ & $>2 \operatorname{sigma}(\mathrm{I})$ \\
\hline refinement method & full matrix least-sqs using $\mathrm{F}^{2}$ & full matrix least-sqs using $\mathrm{F}^{2}$ \\
\hline Weighting Scheme & $\begin{array}{l}1 /\left[\operatorname{sigma}^{2}\left(\mathrm{Fo}^{2}\right)+(0.0406 \mathrm{P})^{2}+\right. \\
0.0000 \mathrm{P}] \text { where } \\
\mathrm{P}=\left(\mathrm{Fo}^{2}+2 \mathrm{Fc}^{2}\right) / 3\end{array}$ & $\begin{array}{l}1 /\left[\operatorname{sigma}^{2}\left(\mathrm{Fo}^{2}\right)+(0.0707 \mathrm{P})^{2}+\right. \\
0.0436 \mathrm{P}] \text { where } \mathrm{P}=\left(\mathrm{Fo}^{2}+2 \mathrm{Fc}^{2}\right) / 3\end{array}$ \\
\hline $\mathrm{R}_{1}^{\mathrm{a}}$ & 0.0370 & 0.0382 \\
\hline $\mathrm{wR}_{2}$ & 0.0712 & 0.1082 \\
\hline
\end{tabular}


Table 2. Cont.

\begin{tabular}{lll}
\hline Compound & $\mathbf{3 d}$ & $\mathbf{4 c}$ \\
$\mathrm{R}_{1}(\text { all data })^{\mathrm{b}}$ & 0.0538 & 0.0525 \\
$\mathrm{wR}_{2}(\text { all data })^{\mathrm{a}}$ & 0.0762 & 0.1220 \\
$\mathrm{GOF}$ & 1.035 & 1.048 \\
\hline${ }^{\mathrm{a}} \mathrm{R}_{1}=\Sigma\left(\left|\mathrm{F}_{\mathrm{o}}-\mathrm{F}_{\mathrm{c}}\right|\right) / \Sigma \mathrm{F}_{\mathrm{o}}, w_{2}=\left[\Sigma\left(w\left(\mathrm{~F}_{\mathrm{o}}-\mathrm{F}_{\mathrm{c}}\right)^{2}\right) / \Sigma\left(\mathrm{F}_{\mathrm{o}}{ }^{2}\right)\right]^{1 / 2}, \mathrm{GOF}=\left[\Sigma\left(w\left(\mathrm{~F}_{\mathrm{o}}-\mathrm{F}_{\mathrm{c}}\right)^{2}\right) /(\right.$ No. reflns. - No. \\
params. $)]^{1 / 2} ;$ \\
${ }^{\mathrm{b}} \mathrm{R}_{1}=\Sigma\left(\left|\mathrm{F}_{\mathrm{o}}\right|-\mid \mathrm{F}_{\mathrm{c}}\right) / \Sigma \mathrm{F}_{\mathrm{o}}, \mathrm{wR}_{2}=\left[\Sigma\left(w\left(\mathrm{~F}_{\mathrm{o}}{ }^{2}-\mathrm{F}_{\mathrm{c}}{ }^{2}\right)^{2}\right) / \Sigma\left(w \mathrm{~F}_{\mathrm{o}}{ }^{4}\right)\right]^{1 / 2}, \mathrm{GOF}=\left[\Sigma\left(w\left(\mathrm{~F}_{\mathrm{o}}{ }^{2}-\mathrm{F}_{\mathrm{c}}{ }^{2}\right)^{2}\right) /(\right.$ No. reflns. - No. \\
params. $)]^{1 / 2}$
\end{tabular}

Table 3. Selected interatomic distances and bond lengths of $\mathbf{1 d}, \mathbf{2 c}, \mathbf{3 d}$ and $\mathbf{4 c}$.

\begin{tabular}{|c|c|c|c|c|c|c|}
\hline \multicolumn{3}{|c|}{ Interatomic Distances $(\AA)$} & \multicolumn{3}{|c|}{ Bond Lengths $(\AA \AA)$} & \multirow[t]{2}{*}{ Dihedral $\angle\left({ }^{\circ}\right)$} \\
\hline & $\mathbf{O} \cdots \mathbf{O}$ & $\mathbf{O} \cdots \mathbf{H}$ & O-H & C-O & $\mathrm{C}-\mathrm{C}$ & \\
\hline 1d & NA & NA & NA & $\begin{array}{c}\mathrm{C}_{1 \mathrm{~A}}-\mathrm{O}_{1 \mathrm{~A}} \\
1.2143(17) \\
\mathrm{C}_{11 \mathrm{~A}}-\mathrm{O}_{2 \mathrm{~A}} \\
1.2212(17) \\
\mathrm{C}_{18 \mathrm{~A}}-\mathrm{O}_{3 \mathrm{~A}} \\
1.2143(17)\end{array}$ & $\begin{array}{c}\mathrm{C}_{3 \mathrm{~A}}-\mathrm{C}_{10 \mathrm{~A}} \\
1.3574(19)\end{array}$ & $\begin{array}{c}\mathrm{O}_{3}-\mathrm{C}_{18}-\mathrm{C}_{10}-\mathrm{C}_{3} \\
-2.4(11)\end{array}$ \\
\hline $2 c$ & $\begin{array}{c}\mathrm{O}_{1} \cdots \mathrm{O}_{2} \\
2.5781(13) \\
\mathrm{O}_{1} \cdots \mathrm{O}_{3} \\
2.5926(14)\end{array}$ & $\begin{array}{l}\mathrm{O}_{1} \cdots \cdot \mathrm{H}_{2} \\
1.75(2) \\
\mathrm{O}_{1} \cdots \mathrm{H}_{3} \\
1.81(2)\end{array}$ & $\begin{array}{c}\mathrm{O}_{2}-\mathrm{H}_{2} \\
0.90(2) \\
\mathrm{O}_{3}-\mathrm{H}_{3} \\
0.88(2)\end{array}$ & $\begin{array}{c}\mathrm{C}_{1}-\mathrm{O}_{1} \\
1.2576(15) \\
\mathrm{C}_{10}-\mathrm{O}_{2} \\
1.3308(15) \\
\mathrm{C}_{12}-\mathrm{O}_{3} \\
1.3242(17)\end{array}$ & $\begin{array}{c}\mathrm{C}_{1}-\mathrm{C}_{2} \\
1.4547(15) \\
\mathrm{C}_{2}-\mathrm{C}_{10} \\
1.3593(17) \\
\mathrm{C}_{9}-\mathrm{C}_{12} \\
1.3602(17)\end{array}$ & $\begin{array}{c}\mathrm{O}_{1}-\mathrm{C}_{1}-\mathrm{C}_{2}-\mathrm{C}_{10} \\
-1.91(11)\end{array}$ \\
\hline 3d & $\begin{array}{c}\mathrm{O}_{1}^{\cdots \cdots} \mathrm{O}_{2} \\
2.6142(17)\end{array}$ & $\begin{array}{l}\mathrm{O}_{2} \cdots \cdot \mathrm{H} \\
1.75(3)\end{array}$ & $\begin{array}{c}\mathrm{O}_{1}-\mathrm{H} \\
0.97(3)\end{array}$ & $\begin{array}{c}\mathrm{C}_{1}-\mathrm{O}_{1} \\
1.3588(19) \\
\mathrm{C}_{11}-\mathrm{O}_{2} \\
1.2199(18)\end{array}$ & $\begin{array}{c}\mathrm{C}_{1}-\mathrm{C}_{2} \\
1.438(2) \\
\mathrm{C}_{2}-\mathrm{C}_{11} \\
1.459(2)\end{array}$ & $\begin{array}{c}\mathrm{O}_{1}-\mathrm{C}_{1}-\mathrm{C}_{2}-\mathrm{C}_{11} \\
1.9(2)\end{array}$ \\
\hline $4 c$ & $\begin{array}{c}\mathrm{O}_{1} \cdots \mathrm{O}_{2} \\
2.5063(9)\end{array}$ & $\begin{array}{l}\mathrm{O}_{2} \cdots \mathrm{H} \\
1.72(2)\end{array}$ & $\begin{array}{c}\mathrm{O}_{1}-\mathrm{H} \\
0.855(19)\end{array}$ & $\begin{array}{c}\mathrm{C}_{1}-\mathrm{O}_{1} \\
1.3215(9) \\
\mathrm{C}_{11}-\mathrm{O}_{2} \\
1.2476(10)\end{array}$ & $\begin{array}{c}\mathrm{C}_{1}-\mathrm{C}_{2} \\
1.3895(10) \\
\mathrm{C}_{2}-\mathrm{C}_{11} \\
1.4193(10)\end{array}$ & $\begin{array}{c}\mathrm{O}_{1}-\mathrm{C}_{1}-\mathrm{C}_{2}-\mathrm{C}_{11} \\
-2.04(11)\end{array}$ \\
\hline
\end{tabular}

In the case of compound $\mathbf{1 d}$, the small $\mathrm{O}_{3}-\mathrm{C}_{10}-\mathrm{C}_{18}-\mathrm{C}_{3}$ dihedral angle of $-2.4^{\circ}$ shows bindone to be nearly planar across the ring bridge in the solid state. The $\mathrm{C}-\mathrm{O}$ and $\mathrm{C}_{3}-\mathrm{C}_{10}$ bond lengths are consistent with those of typical carbonyls and alkenes, respectively and identify 1d as a cross-conjugated triketone in the solid state. For 2c, x-ray crystallography confirms the preference of a previously unreported structure in the solid state: a planar, exocyclic dienol shown in Figure 4. The weak intramolecular H-bonding normally observed in cyclic triketones is clearly supported for $\mathbf{2 c}$ by the

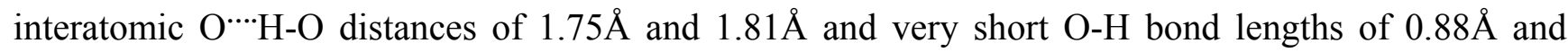
$0.90 \AA[11,22]$. The small $\mathrm{O}_{1}-\mathrm{C}_{1}-\mathrm{C}_{2}-\mathrm{C}_{10}$ dihedral angle of $-1.91^{\circ}$ attests to the planar nature of the cyclopentanone residue.

Likewise, 3-trifluoroacetyl-2-naphthol (3d) and 2-trifluoroacetyl-1-tetralone (4c) show trends consistent with a single endocyclic cis-enol tautomer having weak intramolecular H-bonding, e.g., 
interatomic $\mathrm{O} \cdots \cdot \mathrm{H}-\mathrm{O}$ distances $>1.7 \AA$, $\mathrm{O}-\mathrm{H}$ bond lengths $<1.0 \AA$ and small $\mathrm{O}_{1}-\mathrm{C}_{1}-\mathrm{C}_{2}-\mathrm{C}_{11}$ dihedral angles. For 3d, the aromatic ring introduces an additional structural constraint prohibiting tautomerism to either the diketo form or any other enolic structure.

Spectral data provided in the experimental section supports the solid-state structural data presented herein [8-10,23-28]. A detailed examination of the absorption, vibrational and magnetic resonance spectroscopy of these molecules is underway to discern the keto-enol and enol-enol behavior of these di- and triketones in various solvent systems and where applicable in the solid-state and/or neat liquid. Those results, along with a comparative ab initio component, will be presented in a future communication.

\section{Acknowledgments}

The views expressed in this academic research paper are those of the authors and do not necessarily reflect the official policy or position of the US Government, the Department of Defense, or any of its agencies. The authors wish to thank the NCSU X-ray Facility for crystallographic support and NCSU Mass Spectrometry Facility for high resolution mass spectroscopic support of this work. The authors also wish to thank the Department of Chemistry of NCSU and the State of North Carolina for funding the purchase of the Apex2 diffractometer. Joseph C. Sloop thanks the USMA (C\&LS-02-07) and GGC SST Faculty Research Funds for providing financial support for this work.

\section{References}

1. Nauta, W.T., Rekker, R.F., Eds.; Biological Activities of 1,3-Indandiones. Pharmacochemistry of 1,3-Indanediones; Elsevier Scientific Publishing Co.: New York, NY, USA, 1981; pp. 187-269.

2. Wiesner, S.; Springer, E.; Sasson, Y.; Almog, J. Chemical development of latent fingerprints: 1,2-Indanedione has come of age. J. For. Sci. 2001, 46, 1082-1084.

3. Near-Infrared Dyes for high Technology Applications. In Proceedings of the NATO Advanced Research Workshop on Syntheses, Optical Properties and Applications of Near Infrared (NIR) Dyes in High Technology Fields, Daehne, S., Resch-Genger, U., Wolfbeis, O.S., Eds.; Kluwer Academic Publishers: Dordrecht, The Netherlands, 1997; Volume 52, pp. 363-364.

4. van Klink, J.W.; Larsen, L.; Perry, N.B.; Weavers, R.T.; Cook, G.M.; Bremer, P.J.; MacKenzie, A.D.; Kirikae, T. Triketones active against antibiotic-resistant bacteria: Synthesis, structure-activity relationships, and mode of action. Bioorg. Med. Chem. 2005, 13, 6651-6662.

5. An, T.Y.; Hu, L.H.; Chen, R.M.; Chen, Z.L.; Li, J.; Shen, Q. Anti-diabetes agents-1. Tetralone derivative from Juglans regia. Chin. Chem. Lett. 2003, 14, 489-490.

6. Jain, R.; Jain, S.C.; Arora, R. A new cholestane derivative of Abutilon bidentatum Hochst. And ist bioactivity. Pharmazie 1996, 51, 253-254.

7. Mentré, F.; Pousset, F.; Comets, E.; Plaud, B.; Diquet, B.; Montalescot, G.; Ankri, A.; Mallet, A.; Lechat. P. Population pharmacokinetic-pharmacodynamic analysis of fluindione in patients. Clin. Pharmacol. Ther. 1998, 63, 64-78.

8. Sloop, J.C.; Bumgardner, C.; Washington, G.; Loehle, W.D.; Sankar, S.; Lewis, A. Keto-Enol and Enol-Enol Tautomerism in Trifluoromethyl- $\tilde{\beta}$-Diketones, J. Fluorine Chem. 2006, 127, 780-786.

9. Sloop, J.C.; Bumgardner, C.; Washington, G.; Loehle, W.D. Synthesis of fluorinated heterocycles. J. Fluorine Chem. 2002, 118, 135-147. 
10. Sloop, J.C.; Boyle, P.; Fountain, A.W.; Pearman, W.; Swann, J. Electron deficient aryl $\beta$-diketones: synthesis and novel tautomeric preferences. Eur. J. Org. Chem. 2011, 5, 936-941.

11. Bolvig, S.; Hansen, P.E. Deuterium-Induced Isotope Effects on ${ }^{13} \mathrm{C}$ Chemical Shifts as a Probe for Tautomerism in enolic $\beta$-Diketones. Mag. Res. Chem. 1996, 34, 467-478.

12. Reid, J.C.; Calvin, M. Some New $\beta$-Diketones Containing the Trifluoromethyl Group. J. Am. Chem. Soc. 1950, 72, 2948-2952.

13. Stavber, G.; Zupan, M.; Stavber, S. Micellar-System-Mediated direct fluorination of ketones in water. Synlett 2009, 4, 589-594.

14. Sloop, J.C. Synthesis of Fluorinated Pyrazoles and Isoxazoles. The Effect of 2-Fluoro and 2-Chloro Substituents on the Keto-Enol Equilibria of 1,3-Diketones; DOD Technical Report, Defense Technical Information Center: Fort Belvoir, VA, USA, 18 May 1990; pp. 1-32.

15. Zajc, B.; Zupan, M. Fluorination with xenon difluoride. 27. The effect of catalyst on fluorination of 1,3-diketones and enol acetates. J. Org. Chem. 1982, 47, 573-575.

16. MSDS. Bindone. Available online: http://www.chemcas.org/chemical/msds/cas/AA_M/ AAB24557-03.asp (accessed on 20 November 2011). Mp: 205-208 ${ }^{\circ}$ C. See Carey, F.J.; Sundberg, R.J. Advanced Organic Chemistry, Part B: Reactions and Synthesis, 2nd ed.; Plenum Press: New York, NY, USA, 1983; pp. 43-45.

17. Light, R.J.; Hauser, C.R. Aroylations of $\beta$-diketones at the terminal methyl group to form 1,3,5-Triketones. Cyclizations to 4-Pyrones and 4-Pyridones. J. Org. Chem. 1960, 25, 538-546.

18. Park, J.D.; Brown, H.A.; Lacher, J.R. A Study of Some Fluorine-containing $\beta$-Diketones. J. Am. Chem. Soc. 1953, 75, 4753-4756.

19. Sloop, J.C.; Jackson, J.; Schmidt, R. Microwave-Mediated pyrazole fluorinations using Selectfluor ${ }^{\circledR}$. Heteroatom Chem. 2009, 20, 341-345.

20. Riofski, M.V.; John, J.P.; Zheng, M.M.; Kirshner, J.; Colby, D.A. Exploiting the facile release of trifluoroacetate for the $\alpha$-Methylation of the sterically hindered carbonyl groups on (+)-Sclareolide and (-)-Eburnamonine. J. Org. Chem. 2011, 76, 3676-3683.

21. Kirsch, P. Modern Fluoroorganic Chemistry: Synthesis, Reactivity, Applications; Wiley-VCH VerlagGmbH \& Co.: Darmstadt, Germany, 2004; pp. 78-79.

22. Crouse, D.J.; Hurlbut, S.L.; Wheeler, D.M. Photo Fries rearrangements of 1-naphthyl esters in the synthesis of 2-acylnaphthoquinones. J. Org. Chem. 1981, 46, 374-378.

23. Murdock, K.C. Triacylhalomethanes: 2-Halo-2-acyl-1,3-indanediones. J. Org. Chem. 1959, 24, 845-849.

24. Forsen, S.; Nilsson, M. Proton magnetic resonance studies of enolised $\beta$-Triketones. Acta Chem. Scand. 1959, 13, 1383-1394.

25. Hunig, S.; Hoch, H. 2-Acetyl-cyclanone und Cyclandione-(1,3), ein Vergleich. Justus Liebigs Ann. Chem. 1968, 716, 68-77.

26. Ebraheem, K.A. ${ }^{1} \mathrm{H},{ }^{13} \mathrm{C}$ and ${ }^{19} \mathrm{~F}$ NMR Studies on the Structure of the Intramolecularly Hydrogen Bonded cis-Enols of 2-Trifluoroacetylcycloalkanones. Monatsh. Chem. 1991, 122, 157-163.

27. Hansen, P.E.; Ibsen, S.N.; Kristensen, T.; Bolvig, S. Deuterium and ${ }^{18} \mathrm{O}$ Isotope Effects on ${ }^{13} \mathrm{C}$ Chemical Shifts of Sterically Hindered and/or Intramolecularly Hydrogen-Bonded $o$-Hydroxy Acyl Aromatics. Mag. Res. Chem. 1994, 32, 399-408.

28. Dolbier, W.R. Guide to Fluorine NMR for Organic Chemists; John Wiley and Sons, Inc.: Hoboken, NJ, USA, 2009; Volume 70-81, pp. 152-158. 
29. Bruker-Nonius, SAINT version 7.34A; Bruker-Nonius: Madison, WI, USA, 2006.

30. Bruker-Nonius, SADABS version 2.10; Bruker-Nonius: Madison, WI, USA, 2004.

31. Altomare, A.; Cascarano, G.; Giacovazzo, C.; Guagliardi, A.; Burla, M. C.; Polidori, G.; Camalli, M. SIR92-a program for automatic solution of crystal structures by direct methods. J. Appl. Cryst. 1994, 27, 435.

32. Bruker-AXS, XL version 6.12; Bruker-AXS: Madison, WI, USA.

33. Gabe, E.J.; Le Page, Y.; Charland, J.P.; Lee, F.L.; White, P.S. NCRVAX-an interactive program system for structure analysis. J. Appl. Cryst. 1989, 22, 384-387.

\section{Appendix. X-Ray Experimental Procedures and Data}

\section{Compound 1d}

\section{Experimental for $\mathrm{C}_{18} \mathrm{H}_{10} \mathrm{O}_{3}(1 \mathrm{~d})$}

Data Collection and Processing. The sample 1d was submitted by Joseph Sloop of the Sloop research group at Georgia Gwinnett College. The sample was mounted on a nylon loop with a small amount of NVH immersion oil. All X-ray measurements were made on a Bruker-Nonius X8 Apex2 diffractometer at a temperature of $173 \mathrm{~K}$. The unit cell dimensions were determined from a symmetry constrained fit of 9975 reflections with $5.0^{\circ}<2 \theta<56.84^{\circ}$. The data collection strategy was a number of $\omega$ and $\varphi$ scans which collected data up to $58.24^{\circ}(2 \theta)$. The frame integration was performed using SAINT [29]. The resulting raw data was scaled and absorption corrected using a multi-scan averaging of symmetry equivalent data using SADABS [30].

Structure Solution and Refinement. The structure was solved by direct methods using the SIR92 program [31]. All non-hydrogen atoms were obtained from the initial E-map. The hydrogen atoms were introduced at idealized positions and were allowed to refine isotropically. The structural model was fit to the data using full matrix least-squares based on $\mathrm{F}^{2}$. The calculated structure factors included corrections for anomalous dispersion from the usual tabulation. The structure was refined using the XL program from SHELXTL [32], graphic plots were produced using the NRCVAX crystallographic program suite. Additional information and other relevant literature references can be found in the reference section of the Facility's Web page (http://www.xray.ncsu.edu). 
Figure 6. ORTEP drawing of $\boldsymbol{1 d}$ molecule $\boldsymbol{A}$ showing naming and numbering scheme. Ellipsoids are at the $50 \%$ probability level and hydrogen atoms were drawn with arbitrary radii for clarity.

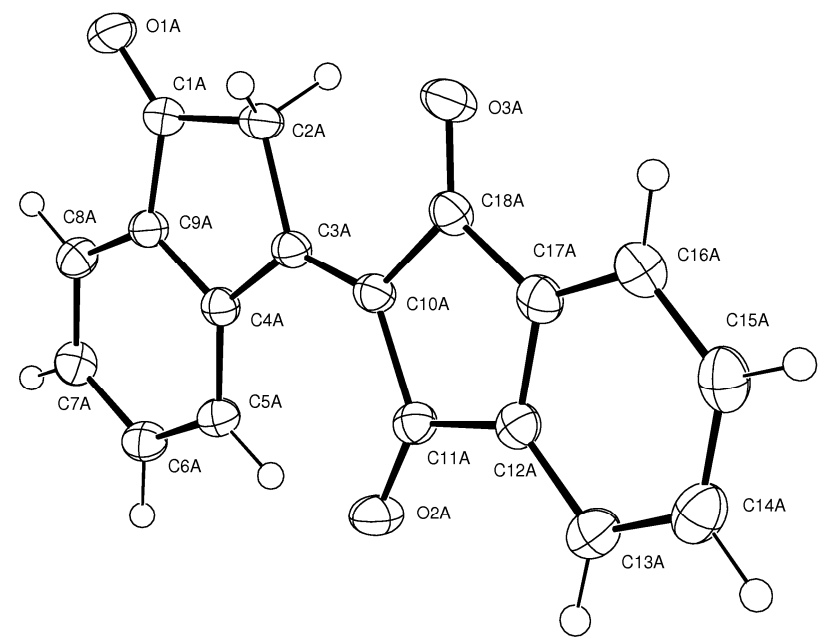

Figure 7. ORTEP drawing of $1 \boldsymbol{d}$ molecule $\boldsymbol{A}$. Ellipsoids are at the $50 \%$ probability level and hydrogen atoms were drawn with arbitrary radii for clarity.

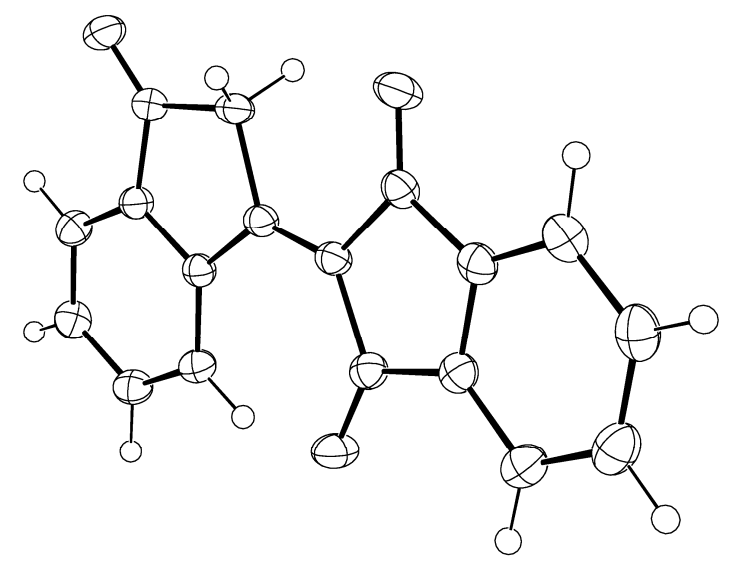

Figure 8. Stereoscopic ORTEP drawing of $1 d$ molecule A. Ellipsoids are at the $50 \%$ probability level and hydrogen atoms were drawn with arbitrary radii for clarity.
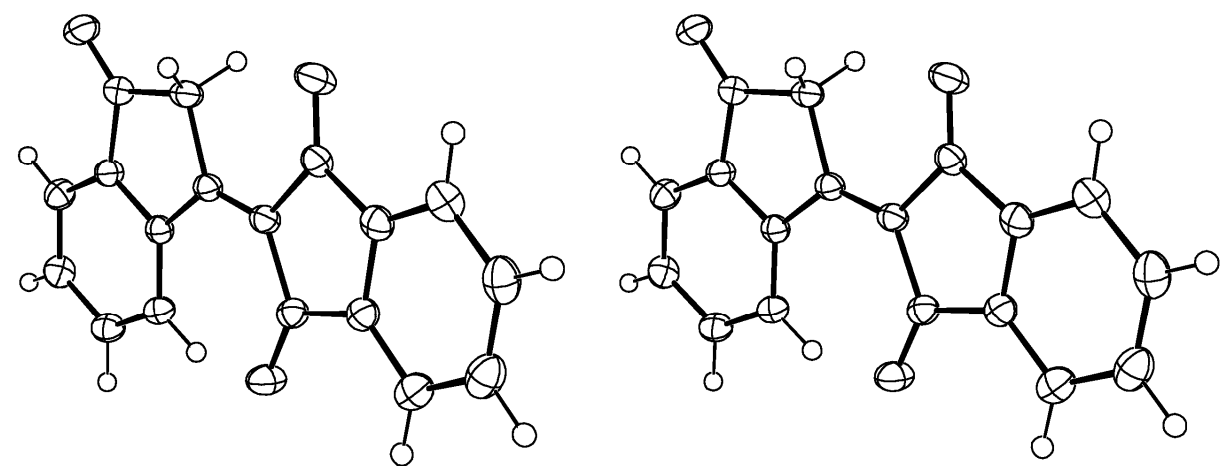
Figure 9. ORTEP drawing of $\boldsymbol{1} \boldsymbol{d}$ molecule $\boldsymbol{B}$ showing naming and numbering scheme. Ellipsoids are at the $50 \%$ probability level and hydrogen atoms were drawn with arbitrary radii for clarity.

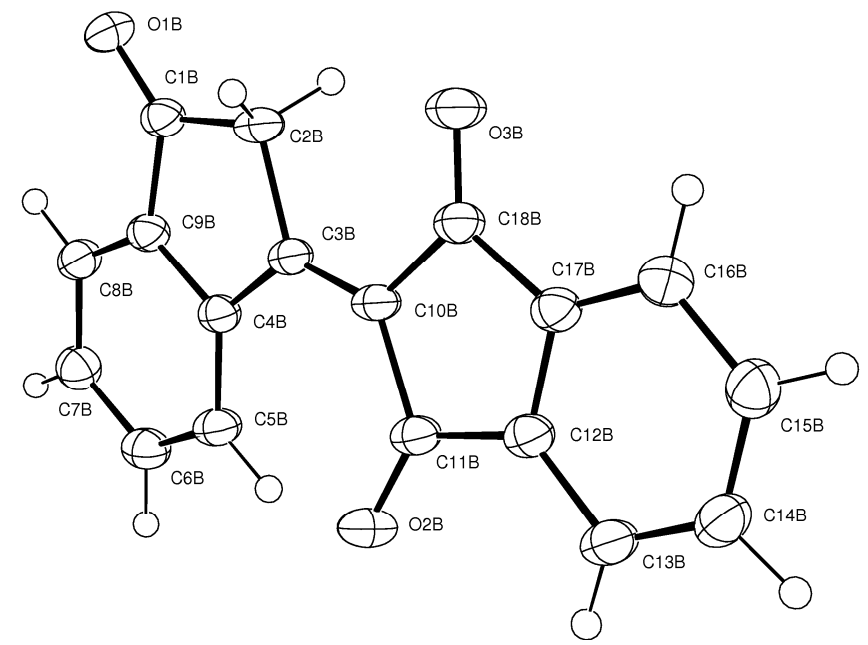

Figure 10. ORTEP drawing of $1 \boldsymbol{d}$ molecule $\boldsymbol{B}$. Ellipsoids are at the $50 \%$ probability level and hydrogen atoms were drawn with arbitrary radii for clarity.

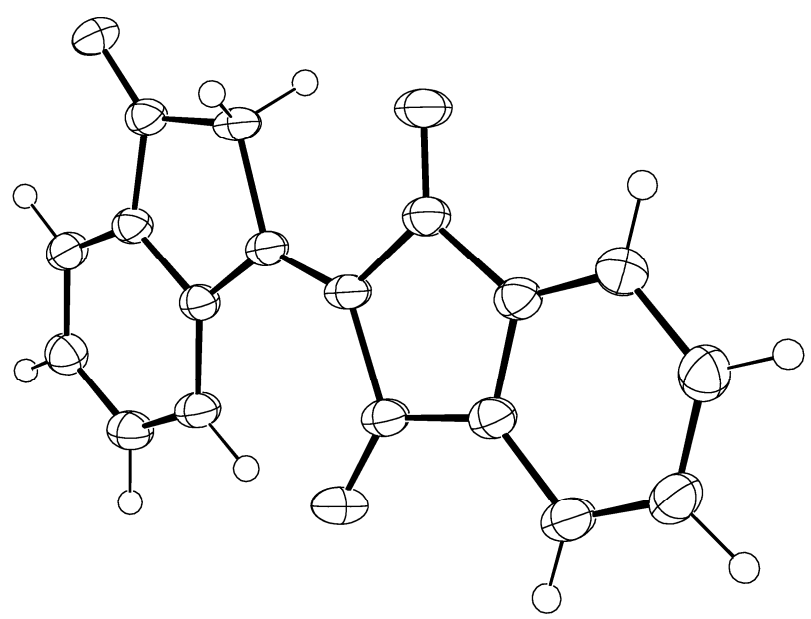

Figure 11. Stereoscopic ORTEP drawing of 1 d molecule B. Ellipsoids are at the 50\% probability level and hydrogen atoms were drawn with arbitrary radii for clarity.

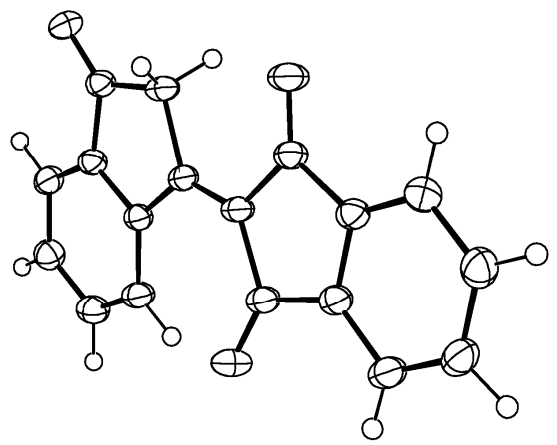

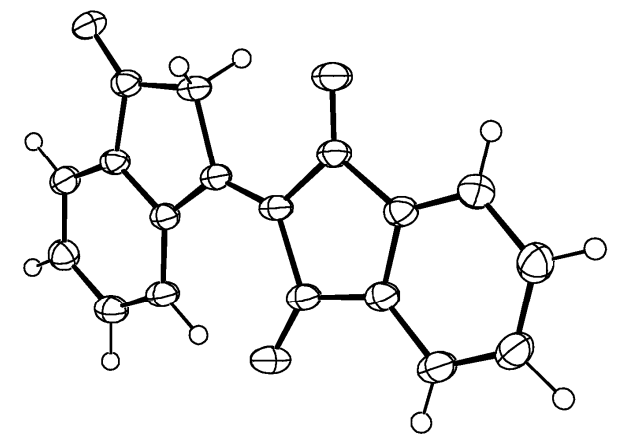


Table 4. Summary of Crystal Data for $\mathbf{1 d}$.

\section{Formula}

Formula Weight $(\mathrm{g} / \mathrm{mol})$

Crystal Dimensions $(\mathrm{mm}$ )

Crystal Color and Habit

Crystal System

Space Group

Temperature, $\mathrm{K}$

$a, \AA$

$b, \AA$

$c, \AA$

$\alpha,{ }^{\circ}$

$\beta,{ }^{\circ}$

$\gamma,{ }^{\circ}$

$\mathrm{V}, \AA^{3}$

Number of reflections to determine final unit cell

Min and Max $2 \theta$ for cell determination, ${ }^{\circ}$

Z

$\mathrm{F}(000)$

$\rho(\mathrm{g} / \mathrm{cm})$

$\lambda, \AA,(\mathrm{MoK} \alpha)$

$\mu,\left(\mathrm{cm}^{-1}\right)$

Diffractometer Type

Scan Type(s)

Max $2 \theta$ for data collection, ${ }^{\circ}$

Measured fraction of data

Number of reflections measured

Unique reflections measured

$\mathrm{R}_{\text {merge }}$

Number of reflections included in refinement

Cut off Threshold Expression

Structure refined using

Weighting Scheme

Number of parameters in least-squares

$\mathrm{R}_{1}$

$w_{2}$

$\mathrm{R}_{1}$ (all data)

$\mathrm{wR}_{2}$ (all data)

GOF

Maximum shift/error

Min \& Max peak heights on final $\Delta \mathrm{F}$ Map $\left(e^{-/} \AA\right)$
$\mathrm{C}_{18} \mathrm{H}_{10} \mathrm{O}_{3}$

274.26

$0.30 \times 0.24 \times 0.20$

clear prism

orthorhombic

F d d 2

173

18.0996(6)

20.9271(7)

$26.0789(8)$

90.00

90.00

90.00

$9878.0(6)$

9975

$5.0,56.84$

32

4544

1.475

0.71070

0.101

Bruker-Nonius X8 Apex2

omega and phi scans

58.24

1.000

103146

6360

0.0403

6360

$>2$ sigma(I)

full matrix least-squares using $\mathrm{F}^{2}$ calc $\mathrm{w}=1 /\left[\operatorname{sigma}^{2}\left(\mathrm{Fo}^{2}\right)+(0.0555 \mathrm{P})^{2}+\right.$ 3.0465P] where $\mathrm{P}=\left(\mathrm{Fo}^{2}+2 \mathrm{Fc}^{2}\right) / 3$ 458

0.0342

0.0846

0.0400

0.0880

1.038

0.000

$-0.219,0.216$

$$
\begin{aligned}
& \text { Where: } \\
& \mathrm{R}_{1}=\Sigma\left(\left|\mathrm{F}_{\mathrm{O}}\right|-\left|\mathrm{F}_{\mathrm{c}}\right|\right) / \Sigma \mathrm{F}_{\mathrm{O}} \\
& \mathrm{wR}_{2}=\left[\Sigma\left(w\left(\mathrm{~F}_{\mathrm{O}}{ }^{2}-\mathrm{F}_{\mathrm{c}}{ }^{2}\right)^{2}\right) / \Sigma\left(w \mathrm{~F}_{\mathrm{O}}{ }^{4}\right)\right]^{1 / 2} \\
& \mathrm{GOF}=\left[\Sigma\left(w\left(\mathrm{~F}_{\mathrm{O}}{ }^{2}-\mathrm{F}_{\mathrm{c}}{ }^{2}\right)^{2}\right) /(\text { No. of reflns. - No. of params. })\right]^{1 / 2}
\end{aligned}
$$


Table 5. Atomic Coordinates for $\mathbf{1 d}$.

\begin{tabular}{|c|c|c|c|c|}
\hline Atom & $\mathrm{x}$ & $\mathrm{y}$ & z & $\mathrm{U}_{\text {iso/equiv }}$ \\
\hline O1A & $0.20028(6)$ & $0.13639(6)$ & $0.62634(6)$ & $0.0362(3)$ \\
\hline $\mathrm{O} 2 \mathrm{~A}$ & $0.36237(6)$ & $0.01557(5)$ & 0.4220 & $0.0310(2)$ \\
\hline $\mathrm{O} 3 \mathrm{~A}$ & $0.40033(6)$ & $-0.02683(5)$ & $0.59892(6)$ & $0.0329(2)$ \\
\hline $\mathrm{C} 1 \mathrm{~A}$ & $0.23461(8)$ & $0.12010(7)$ & $0.58853(6)$ & $0.0257(3)$ \\
\hline $\mathrm{C} 2 \mathrm{~A}$ & $0.29550(8)$ & $0.07078(7)$ & $0.58765(6)$ & $0.0265(3)$ \\
\hline $\mathrm{C} 3 \mathrm{~A}$ & $0.31404(7)$ & $0.06171(6)$ & $0.53149(6)$ & $0.0215(2)$ \\
\hline $\mathrm{C} 4 \mathrm{~A}$ & $0.27141(7)$ & $0.10937(6)$ & $0.50228(6)$ & $0.0214(2)$ \\
\hline C5A & $0.27082(8)$ & $0.12548(7)$ & $0.45022(6)$ & $0.0246(3)$ \\
\hline C6A & $0.22256(8)$ & $0.17252(7)$ & $0.43340(7)$ & $0.0271(3)$ \\
\hline C7A & $0.17513(8)$ & $0.20411(7)$ & $0.46700(7)$ & $0.0283(3)$ \\
\hline C8A & $0.17630(8)$ & $0.19033(7)$ & $0.51873(7)$ & $0.0279(3)$ \\
\hline C9A & $0.22477(7)$ & $0.14322(7)$ & $0.53572(6)$ & $0.0234(3)$ \\
\hline C10A & $0.36116(7)$ & $0.01514(6)$ & $0.51589(6)$ & $0.0217(2)$ \\
\hline C11A & $0.38319(7)$ & $-0.00519(6)$ & $0.46328(6)$ & $0.0228(3)$ \\
\hline C12A & $0.43567(7)$ & $-0.05931(6)$ & $0.46890(7)$ & $0.0231(3)$ \\
\hline C13A & $0.47199(8)$ & $-0.09342(7)$ & $0.43109(7)$ & $0.0289(3)$ \\
\hline C14A & $0.51888(9)$ & $-0.14212(8)$ & $0.44613(8)$ & $0.0328(3)$ \\
\hline C15A & $0.52844(9)$ & $-0.15676(8)$ & $0.49786(8)$ & $0.0331(3)$ \\
\hline C16A & $0.49169(8)$ & $-0.12272(7)$ & $0.53601(7)$ & $0.0293(3)$ \\
\hline C17A & $0.44557(7)$ & $-0.07332(6)$ & $0.52064(7)$ & $0.0242(3)$ \\
\hline C18A & $0.40165(7)$ & $-0.02813(7)$ & $0.55238(7)$ & $0.0237(3)$ \\
\hline $\mathrm{O} 1 \mathrm{~B}$ & $0.14120(7)$ & $0.04113(5)$ & $0.35875(6)$ & $0.0349(2)$ \\
\hline $\mathrm{O} 2 \mathrm{~B}$ & $0.25973(7)$ & $-0.11687(6)$ & $0.56110(5)$ & $0.0351(2)$ \\
\hline O3B & $0.29954(7)$ & $-0.15569(6)$ & $0.38414(6)$ & $0.0367(3)$ \\
\hline $\mathrm{C} 1 \mathrm{~B}$ & $0.15538(8)$ & $0.00789(7)$ & $0.39573(6)$ & $0.0270(3)$ \\
\hline $\mathrm{C} 2 \mathrm{~B}$ & $0.20581(8)$ & $-0.04922(7)$ & $0.39627(6)$ & $0.0267(3)$ \\
\hline $\mathrm{C} 3 \mathrm{~B}$ & $0.21160(8)$ & $-0.06899(7)$ & $0.45205(6)$ & $0.0233(3)$ \\
\hline C4B & $0.16128(8)$ & $-0.02763(7)$ & $0.48137(7)$ & $0.0241(3)$ \\
\hline C5B & $0.14109(8)$ & $-0.02690(8)$ & $0.53345(7)$ & $0.0286(3)$ \\
\hline C6B & $0.09013(9)$ & $0.01792(8)$ & $0.54976(7)$ & $0.0314(3)$ \\
\hline C7B & $0.05876(9)$ & $0.06238(8)$ & $0.51670(7)$ & $0.0318(3)$ \\
\hline $\mathrm{C} 8 \mathrm{~B}$ & $0.07692(9)$ & $0.06178(7)$ & $0.46499(7)$ & $0.0298(3)$ \\
\hline C9B & $0.12772(8)$ & $0.01681(7)$ & $0.44855(6)$ & $0.0255(3)$ \\
\hline C10B & $0.25683(8)$ & $-0.11716(7)$ & $0.46724(6)$ & $0.0245(3)$ \\
\hline C11B & $0.27541(8)$ & $-0.14057(7)$ & $0.52003(7)$ & $0.0259(3)$ \\
\hline C12B & $0.32241(8)$ & $-0.19790(7)$ & $0.51345(7)$ & $0.0262(3)$ \\
\hline C13B & $0.35157(9)$ & $-0.23821(8)$ & $0.55099(7)$ & $0.0322(3)$ \\
\hline C14B & $0.39368(10)$ & $-0.28954(8)$ & $0.53526(8)$ & $0.0352(3)$ \\
\hline C15B & $0.40794(9)$ & $-0.30056(8)$ & $0.48342(8)$ & $0.0352(3)$ \\
\hline C16B & $0.37983(9)$ & $-0.25975(7)$ & $0.44609(7)$ & $0.0322(3)$ \\
\hline C17B & $0.33643(8)$ & $-0.20886(7)$ & $0.46172(7)$ & $0.0264(3)$ \\
\hline C18B & $0.29790(8)$ & $-0.15934(7)$ & $0.43065(7)$ & $0.0269(3)$ \\
\hline H2A1 & $0.2800(10)$ & $0.0306(10)$ & $0.6041(7)$ & $0.038(5)$ \\
\hline $\mathrm{H} 2 \mathrm{~A} 2$ & $0.3395(11)$ & $0.0877(9)$ & $0.6072(7)$ & $0.037(5)$ \\
\hline
\end{tabular}


Table 5. Cont.

\begin{tabular}{lllll}
\hline H5A & $0.3041(10)$ & $0.1074(9)$ & $0.4261(8)$ & $0.033(4)$ \\
H6A & $0.2211(10)$ & $0.1858(9)$ & $0.3965(7)$ & $0.034(5)$ \\
H7A & $0.1431(11)$ & $0.2367(9)$ & $0.4567(7)$ & $0.036(5)$ \\
H8A & $0.1442(12)$ & $0.2130(10)$ & $0.5435(9)$ & $0.045(6)$ \\
H13A & $0.4637(10)$ & $-0.0835(9)$ & $0.3957(8)$ & $0.036(5)$ \\
H14A & $0.5436(10)$ & $-0.1635(9)$ & $0.4193(8)$ & $0.035(5)$ \\
H15A & $0.5585(12)$ & $-0.1908(10)$ & $0.5071(8)$ & $0.044(6)$ \\
H16A & $0.4962(11)$ & $-0.1324(10)$ & $0.5727(8)$ & $0.041(5)$ \\
H2B1 & $0.2541(12)$ & $-0.0384(10)$ & $0.3821(9)$ & $0.052(6)$ \\
H2B2 & $0.1831(10)$ & $-0.0855(9)$ & $0.3765(8)$ & $0.035(5)$ \\
H5B & $0.1623(10)$ & $-0.0581(9)$ & $0.5574(7)$ & $0.033(5)$ \\
H6B & $0.0744(12)$ & $0.0181(10)$ & $0.5865(9)$ & $0.049(6)$ \\
H7B & $0.0234(10)$ & $0.0921(9)$ & $0.5291(8)$ & $0.035(5)$ \\
H8B & $0.0572(10)$ & $0.0917(9)$ & $0.4398(8)$ & $0.038(5)$ \\
H13B & $0.3432(11)$ & $-0.2287(9)$ & $0.5847(8)$ & $0.036(5)$ \\
H14B & $0.4143(11)$ & $-0.3227(10)$ & $0.5586(8)$ & $0.039(5)$ \\
H15B & $0.4354(11)$ & $-0.3383(9)$ & $0.4722(8)$ & $0.043(5)$ \\
H16B & $0.3894(10)$ & $-0.2680(9)$ & $0.4103(7)$ & $0.029(4)$ \\
\hline
\end{tabular}

Table 6. Anisotropic Displacement Parameters for $1 \boldsymbol{d}$.

\begin{tabular}{lllllll}
\hline Atom & $\mathrm{u}^{11}$ & $\mathrm{u}^{22}$ & $\mathrm{u}^{33}$ & $\mathrm{u}^{12}$ & $\mathrm{u}^{13}$ & $\mathrm{u}^{23}$ \\
O1A & $0.0362(6)$ & $0.0485(7)$ & $0.0238(5)$ & $0.0094(5)$ & $0.0051(4)$ & $-0.0015(5)$ \\
O2A & $0.0394(6)$ & $0.0338(6)$ & $0.0198(5)$ & $0.0040(4)$ & $0.0011(4)$ & $0.0012(4)$ \\
O3A & $0.0398(6)$ & $0.0369(6)$ & $0.0221(5)$ & $0.0069(5)$ & $-0.0075(4)$ & $-0.0029(4)$ \\
C1A & $0.0256(6)$ & $0.0301(7)$ & $0.0215(6)$ & $0.0000(5)$ & $-0.0008(5)$ & $-0.0014(5)$ \\
C2A & $0.0291(7)$ & $0.0326(7)$ & $0.0179(6)$ & $0.0040(6)$ & $-0.0015(5)$ & $-0.0015(5)$ \\
C3A & $0.0217(6)$ & $0.0238(6)$ & $0.0191(6)$ & $-0.0048(5)$ & $-0.0004(4)$ & $-0.0006(5)$ \\
C4A & $0.0218(6)$ & $0.0212(6)$ & $0.0213(6)$ & $-0.0030(5)$ & $-0.0006(4)$ & $-0.0007(5)$ \\
C5A & $0.0276(7)$ & $0.0253(7)$ & $0.0210(6)$ & $-0.0012(5)$ & $0.0020(5)$ & $0.0006(5)$ \\
C6A & $0.0332(7)$ & $0.0251(7)$ & $0.0230(6)$ & $-0.0029(5)$ & $0.0008(5)$ & $0.0032(5)$ \\
C7A & $0.0299(7)$ & $0.0245(7)$ & $0.0306(7)$ & $0.0028(5)$ & $-0.0008(6)$ & $0.0047(6)$ \\
C8A & $0.0283(7)$ & $0.0272(7)$ & $0.0282(7)$ & $0.0019(5)$ & $0.0025(5)$ & $-0.0001(6)$ \\
C9A & $0.0244(6)$ & $0.0250(6)$ & $0.0209(6)$ & $-0.0010(5)$ & $0.0003(5)$ & $-0.0001(5)$ \\
C10A & $0.0227(6)$ & $0.0235(6)$ & $0.0190(6)$ & $-0.0021(5)$ & $-0.0016(5)$ & $-0.0008(5)$ \\
C11A & $0.0232(6)$ & $0.0235(6)$ & $0.0217(6)$ & $-0.0034(5)$ & $0.0019(5)$ & $-0.0011(5)$ \\
C12A & $0.0223(6)$ & $0.0225(6)$ & $0.0247(6)$ & $-0.0031(5)$ & $0.0014(5)$ & $-0.0011(5)$ \\
C13A & $0.0300(7)$ & $0.0286(7)$ & $0.0282(7)$ & $-0.0032(6)$ & $0.0055(5)$ & $-0.0030(5)$ \\
C14A & $0.0305(7)$ & $0.0284(7)$ & $0.0396(8)$ & $-0.0010(6)$ & $0.0067(6)$ & $-0.0076(6)$ \\
C15A & $0.0266(7)$ & $0.0284(7)$ & $0.0443(9)$ & $0.0033(6)$ & $-0.0025(6)$ & $-0.0028(6)$ \\
C16A & $0.0279(7)$ & $0.0279(7)$ & $0.0321(8)$ & $0.0000(5)$ & $-0.0052(6)$ & $-0.0001(6)$ \\
C17A & $0.0225(6)$ & $0.0235(6)$ & $0.0264(6)$ & $-0.0046(5)$ & $-0.0021(5)$ & $-0.0016(5)$ \\
C18A & $0.0225(6)$ & $0.0249(7)$ & $0.0237(6)$ & $-0.0015(5)$ & $-0.0034(5)$ & $-0.0017(5)$ \\
O1B & $0.0463(6)$ & $0.0351(6)$ & $0.0235(5)$ & $-0.0023(5)$ & $-0.0037(4)$ & $0.0079(4)$ \\
O2B & $0.0415(6)$ & $0.0444(6)$ & $0.0192(5)$ & $0.0011(5)$ & $-0.0023(4)$ & $0.0013(4)$ \\
O3B & $0.0480(6)$ & $0.0425(6)$ & $0.0196(5)$ & $0.0073(5)$ & $-0.0015(4)$ & $0.0010(4)$ \\
\hline & & & & & &
\end{tabular}


Table 6. Cont.

\begin{tabular}{lllllll}
\hline C1B & $0.0292(7)$ & $0.0303(7)$ & $0.0214(6)$ & $-0.0089(5)$ & $-0.0038(5)$ & $0.0019(5)$ \\
C2B & $0.0287(7)$ & $0.0344(7)$ & $0.0168(6)$ & $-0.0024(6)$ & $-0.0015(5)$ & $0.0028(5)$ \\
C3B & $0.0240(6)$ & $0.0277(7)$ & $0.0181(6)$ & $-0.0080(5)$ & $-0.0024(5)$ & $0.0031(5)$ \\
C4B & $0.0252(6)$ & $0.0271(6)$ & $0.0200(6)$ & $-0.0078(5)$ & $-0.0020(5)$ & $0.0014(5)$ \\
C5B & $0.0309(7)$ & $0.0349(8)$ & $0.0200(6)$ & $-0.0068(6)$ & $-0.0009(5)$ & $0.0039(5)$ \\
C6B & $0.0326(8)$ & $0.0379(8)$ & $0.0238(7)$ & $-0.0048(6)$ & $0.0018(5)$ & $-0.0002(6)$ \\
C7B & $0.0329(7)$ & $0.0330(7)$ & $0.0296(7)$ & $-0.0032(6)$ & $0.0011(6)$ & $-0.0008(6)$ \\
C8B & $0.0328(7)$ & $0.0306(7)$ & $0.0261(7)$ & $-0.0037(6)$ & $-0.0026(6)$ & $0.0045(6)$ \\
C9B & $0.0270(7)$ & $0.0288(7)$ & $0.0207(6)$ & $-0.0068(5)$ & $-0.0034(5)$ & $0.0014(5)$ \\
C10B & $0.0261(7)$ & $0.0310(7)$ & $0.0163(6)$ & $-0.0071(5)$ & $-0.0015(5)$ & $0.0022(5)$ \\
C11B & $0.0273(7)$ & $0.0313(7)$ & $0.0190(6)$ & $-0.0078(5)$ & $-0.0020(5)$ & $0.0040(5)$ \\
C12B & $0.0268(6)$ & $0.0289(7)$ & $0.0227(7)$ & $-0.0089(5)$ & $-0.0046(5)$ & $0.0034(5)$ \\
C13B & $0.0367(8)$ & $0.0351(8)$ & $0.0247(7)$ & $-0.0091(6)$ & $-0.0067(6)$ & $0.0076(6)$ \\
C14B & $0.0410(9)$ & $0.0304(8)$ & $0.0344(8)$ & $-0.0063(6)$ & $-0.0125(7)$ & $0.0085(6)$ \\
C15B & $0.0378(8)$ & $0.0293(7)$ & $0.0386(9)$ & $-0.0001(6)$ & $-0.0093(6)$ & $0.0010(6)$ \\
C16B & $0.0373(8)$ & $0.0315(8)$ & $0.0279(8)$ & $-0.0012(6)$ & $-0.0054(6)$ & $-0.0008(6)$ \\
C17B & $0.0284(7)$ & $0.0281(7)$ & $0.0228(6)$ & $-0.0064(5)$ & $-0.0043(5)$ & $0.0020(5)$ \\
C18B & $0.0301(7)$ & $0.0304(7)$ & $0.0203(6)$ & $-0.0048(6)$ & $-0.0030(5)$ & $0.0016(5)$ \\
\hline
\end{tabular}

Table 7. Bond Lengths for $1 d$.

\begin{tabular}{llll}
\hline O1A-C1A & $1.2143(17)$ & O1B-C1B & $1.2166(17)$ \\
O2A-C11A & $1.2212(17)$ & O2B-C11B & $1.2140(18)$ \\
O3A-C18A & $1.2143(17)$ & O3B-C18B & $1.2159(17)$ \\
C1A-C9A & $1.4705(19)$ & C1B-C9B & $1.4775(19)$ \\
C1A-C2A & $1.510(2)$ & C1B-C2B & $1.504(2)$ \\
C2A-C3A & $1.5145(18)$ & C2B-C3B & $1.5159(17)$ \\
C2A-H2A1 & $0.99(2)$ & C2B-H2B1 & $0.98(2)$ \\
C2A-H2A2 & $1.01(2)$ & C2B-H2B2 & $1.006(19)$ \\
C3A-C10A & $1.3574(19)$ & C3B-C10B & $1.358(2)$ \\
C3A-C4A & $1.4733(19)$ & C3B-C4B & $1.471(2)$ \\
C4A-C5A & $1.3989(18)$ & C4B-C9B & $1.4025(19)$ \\
C4A-C9A & $1.4052(19)$ & C4B-C5B & $1.4065(19)$ \\
C5A-C6A & $1.387(2)$ & C5B-C6B & $1.383(2)$ \\
C5A-H5A & $0.95(2)$ & C5B-H5B & $0.982(19)$ \\
C6A-C7A & $1.394(2)$ & C6B-C7B & $1.390(2)$ \\
C6A-H6A & $1.001(19)$ & C6B-H6B & $1.00(2)$ \\
C7A-C8A & $1.380(2)$ & C7B-C8B & $1.388(2)$ \\
C7A-H7A & $0.94(2)$ & C7B-H7B & $0.95(2)$ \\
C8A-C9A & $1.392(2)$ & C8B-C9B & $1.384(2)$ \\
C8A-H8A & $0.99(2)$ & C8B-H8B & $0.98(2)$ \\
C10A-C11A & $1.4908(18)$ & C10B-C18B & $1.497(2)$ \\
C10A-C18A & $1.5043(19)$ & C10B-C11B & $1.4995(18)$ \\
C11A-C12A & $1.4855(19)$ & C11B-C12B & $1.481(2)$ \\
C12A-C13A & $1.383(2)$ & C12B-C17B & $1.3916(19)$ \\
C12A-C17A & $1.3924(19)$ & C12B-C13B & $1.396(2)$ \\
\hline
\end{tabular}


Table 7. Cont

\begin{tabular}{llll}
\hline C13A-C14A & $1.383(2)$ & C13B-C14B & $1.379(3)$ \\
C13A-H13A & $0.96(2)$ & C13B-H13B & $0.91(2)$ \\
C14A-C15A & $1.394(2)$ & C14B-C15B & $1.395(2)$ \\
C14A-H14A & $0.94(2)$ & C14B-H14B & $1.00(2)$ \\
C15A-C16A & $1.393(2)$ & C15B-C16B & $1.392(2)$ \\
C15A-H15A & $0.93(2)$ & C15B-H15B & $0.98(2)$ \\
C16A-C17A & $1.388(2)$ & C16B-C17B & $1.385(2)$ \\
C16A-H16A & $0.98(2)$ & C16B-H16B & $0.965(19)$ \\
C17A-C18A & $1.4870(19)$ & C17B-C18B & $1.489(2)$ \\
\hline
\end{tabular}

Table 8. Bond Angles for 1d.

\begin{tabular}{|c|c|c|c|}
\hline O1A-C1A-C9A & $127.32(14)$ & O1B-C1B-C9B & $126.54(14)$ \\
\hline O1A-C1A-C2A & $125.28(13)$ & O1B-C1B-C2B & $126.15(13)$ \\
\hline C9A-C1A-C2A & $107.40(11)$ & C9B-C1B-C2B & $107.30(11)$ \\
\hline C1A-C2A-C3A & $105.20(11)$ & C1B-C2B-C3B & $105.54(11)$ \\
\hline C1A-C2A-H2A1 & $111.6(11)$ & $\mathrm{C} 1 \mathrm{~B}-\mathrm{C} 2 \mathrm{~B}-\mathrm{H} 2 \mathrm{~B} 1$ & $110.9(13)$ \\
\hline C3A-C2A-H2A1 & $112.2(11)$ & C3B-C2B-H2B1 & $111.4(13)$ \\
\hline C1A-C2A-H2A2 & $109.2(11)$ & C1B-C2B-H2B2 & $110.3(11)$ \\
\hline C3A-C2A-H2A2 & $110.9(11)$ & $\mathrm{C} 3 \mathrm{~B}-\mathrm{C} 2 \mathrm{~B}-\mathrm{H} 2 \mathrm{~B} 2$ & $108.3(11)$ \\
\hline $\mathrm{H} 2 \mathrm{~A} 1-\mathrm{C} 2 \mathrm{~A}-\mathrm{H} 2 \mathrm{~A} 2$ & $107.7(16)$ & H2B1-C2B-H2B2 & $110.2(18)$ \\
\hline C10A-C3A-C4A & $131.31(12)$ & C10B-C3B-C4B & $131.19(12)$ \\
\hline $\mathrm{C} 10 \mathrm{~A}-\mathrm{C} 3 \mathrm{~A}-\mathrm{C} 2 \mathrm{~A}$ & $121.27(12)$ & C10B-C3B-C2B & $121.63(13)$ \\
\hline C4A-C3A-C2A & $107.40(11)$ & C4B-C3B-C2B & $107.18(12)$ \\
\hline C5A-C4A-C9A & $118.44(12)$ & C9B-C4B-C5B & $118.01(13)$ \\
\hline C5A-C4A-C3A & $131.98(13)$ & C9B-C4B-C3B & $109.95(12)$ \\
\hline C9A-C4A-C3A & $109.58(12)$ & C5B-C4B-C3B & $132.01(13)$ \\
\hline C6A-C5A-C4A & $118.86(13)$ & C6B-C5B-C4B & $118.54(14)$ \\
\hline C6A-C5A-H5A & $118.3(12)$ & C6B-C5B-H5B & $121.1(11)$ \\
\hline C4A-C5A-H5A & $122.8(12)$ & C4B-C5B-H5B & $120.3(11)$ \\
\hline C5A-C6A-C7A & $121.72(13)$ & C5B-C6B-C7B & $122.40(14)$ \\
\hline C5A-C6A-H6A & $121.2(11)$ & C5B-C6B-H6B & $119.2(12)$ \\
\hline C7A-C6A-H6A & $117.1(11)$ & C7B-C6B-H6B & $118.4(12)$ \\
\hline C8A-C7A-C6A & $120.41(14)$ & C8B-C7B-C6B & $120.00(15)$ \\
\hline C8A-C7A-H7A & $116.4(12)$ & C8B-C7B-H7B & $119.7(12)$ \\
\hline C6A-C7A-H7A & $123.2(12)$ & C6B-C7B-H7B & $120.2(12)$ \\
\hline C7A-C8A-C9A & $117.96(14)$ & C9B-C8B-C7B & $117.68(14)$ \\
\hline C7A-C8A-H8A & $121.9(13)$ & C9B-C8B-H8B & $118.1(12)$ \\
\hline C9A-C8A-H8A & $120.2(13)$ & C7B-C8B-H8B & $124.2(12)$ \\
\hline C8A-C9A-C4A & $122.55(13)$ & C8B-C9B-C4B & $123.35(13)$ \\
\hline C8A-C9A-C1A & $127.40(13)$ & C8B-C9B-C1B & $126.87(13)$ \\
\hline C4A-C9A-C1A & $110.03(12)$ & C4B-C9B-C1B & $109.78(13)$ \\
\hline C3A-C10A-C11A & $130.45(12)$ & C3B-C10B-C18B & $123.44(12)$ \\
\hline C3A-C10A-C18A & $123.28(12)$ & C3B-C10B-C11B & $130.22(13)$ \\
\hline C11A-C10A-C18A & $106.27(11)$ & C18B-C10B-C11B & $106.33(12)$ \\
\hline $\mathrm{O} 2 \mathrm{~A}-\mathrm{C} 11 \mathrm{~A}-\mathrm{C} 12 \mathrm{~A}$ & $123.76(13)$ & $\mathrm{O} 2 \mathrm{~B}-\mathrm{C} 11 \mathrm{~B}-\mathrm{C} 12 \mathrm{~B}$ & $124.59(13)$ \\
\hline
\end{tabular}


Table 8. Cont.

\begin{tabular}{llll}
\hline O2A-C11A-C10A & $128.89(12)$ & O2B-C11B-C10B & $128.62(14)$ \\
C12A-C11A-C10A & $107.32(11)$ & C12B-C11B-C10B & $106.68(12)$ \\
C13A-C12A-C17A & $121.39(13)$ & C17B-C12B-C13B & $120.75(14)$ \\
C13A-C12A-C11A & $128.82(13)$ & C17B-C12B-C11B & $110.53(12)$ \\
C17A-C12A-C11A & $109.79(11)$ & C13B-C12B-C11B & $128.72(14)$ \\
C14A-C13A-C12A & $118.02(15)$ & C14B-C13B-C12B & $118.09(15)$ \\
C14A-C13A-H13A & $121.9(11)$ & C14B-C13B-H13B & $123.2(12)$ \\
C12A-C13A-H13A & $120.1(11)$ & C12B-C13B-H13B & $118.7(12)$ \\
C13A-C14A-C15A & $120.83(14)$ & C13B-C14B-C15B & $121.28(15)$ \\
C13A-C14A-H14A & $115.4(12)$ & C13B-C14B-H14B & $124.6(12)$ \\
C15A-C14A-H14A & $123.7(12)$ & C15B-C14B-H14B & $114.1(12)$ \\
C16A-C15A-C14A & $121.30(15)$ & C16B-C15B-C14B & $120.57(16)$ \\
C16A-C15A-H15A & $119.2(13)$ & C16B-C15B-H15B & $118.2(12)$ \\
C14A-C15A-H15A & $119.5(13)$ & C14B-C15B-H15B & $121.2(12)$ \\
C17A-C16A-C15A & $117.51(15)$ & C17B-C16B-C15B & $118.27(15)$ \\
C17A-C16A-H16A & $119.1(12)$ & C17B-C16B-H16B & $121.7(11)$ \\
C15A-C16A-H16A & $123.4(12)$ & C15B-C16B-H16B & $120.0(11)$ \\
C16A-C17A-C12A & $120.94(13)$ & C16B-C17B-C12B & $121.03(14)$ \\
C16A-C17A-C18A & $129.38(13)$ & C16B-C17B-C18B & $129.85(14)$ \\
C12A-C17A-C18A & $109.68(11)$ & C12B-C17B-C18B & $109.11(13)$ \\
O3A-C18A-C17A & $125.54(13)$ & O3B-C18B-C17B & $125.12(14)$ \\
O3A-C18A-C10A & $127.53(13)$ & O3B-C18B-C10B & $127.65(14)$ \\
C17A-C18A-C10A & $106.93(11)$ & C17B-C18B-C10B & $107.22(11)$ \\
\hline
\end{tabular}

Table 9. Torsion Angles for $\mathbf{1 d}$.

\begin{tabular}{llll}
\hline O1A-C1A-C2A-C3A & $173.35(14)$ & O1B-C1B-C2B-C3B & $173.77(14)$ \\
C9A-C1A-C2A-C3A & $-5.93(15)$ & C9B-C1B-C2B-C3B & $-5.04(14)$ \\
C1A-C2A-C3A-C10A & $-172.45(12)$ & C1B-C2B-C3B-C10B & $-175.90(12)$ \\
C1A-C2A-C3A-C4A & $6.20(14)$ & C1B-C2B-C3B-C4B & $4.41(14)$ \\
C10A-C3A-C4A-C5A & $-6.6(2)$ & C10B-C3B-C4B-C9B & $178.21(14)$ \\
C2A-C3A-C4A-C5A & $174.97(14)$ & C2B-C3B-C4B-C9B & $-2.13(15)$ \\
C10A-C3A-C4A-C9A & $174.20(13)$ & C10B-C3B-C4B-C5B & $-3.9(2)$ \\
C2A-C3A-C4A-C9A & $-4.26(15)$ & C2B-C3B-C4B-C5B & $175.74(14)$ \\
C9A-C4A-C5A-C6A & $-2.2(2)$ & C9B-C4B-C5B-C6B & $-0.83(19)$ \\
C3A-C4A-C5A-C6A & $178.62(13)$ & C3B-C4B-C5B-C6B & $-178.57(14)$ \\
C4A-C5A-C6A-C7A & $0.3(2)$ & C4B-C5B-C6B-C7B & $-0.5(2)$ \\
C5A-C6A-C7A-C8A & $1.6(2)$ & C5B-C6B-C7B-C8B & $1.6(2)$ \\
C6A-C7A-C8A-C9A & $-1.5(2)$ & C6B-C7B-C8B-C9B & $-1.3(2)$ \\
C7A-C8A-C9A-C4A & $-0.5(2)$ & C7B-C8B-C9B-C4B & $0.0(2)$ \\
C7A-C8A-C9A-C1A & $-179.00(14)$ & C7B-C8B-C9B-C1B & $-179.50(14)$ \\
C5A-C4A-C9A-C8A & $2.4(2)$ & C5B-C4B-C9B-C8B & $1.1(2)$ \\
C3A-C4A-C9A-C8A & $-178.25(13)$ & C3B-C4B-C9B-C8B & $179.32(13)$ \\
C5A-C4A-C9A-C1A & $-178.91(12)$ & C5B-C4B-C9B-C1B & $-179.32(12)$ \\
C3A-C4A-C9A-C1A & $0.45(15)$ & C3B-C4B-C9B-C1B & $-1.12(15)$ \\
O1A-C1A-C9A-C8A & $2.9(3)$ & O1B-C1B-C9B-C8B & $4.7(2)$ \\
\hline
\end{tabular}


Table 9. Cont.

\begin{tabular}{|c|c|c|c|}
\hline C2A-C1A-C9A-C8A & $-177.83(14)$ & $\mathrm{C} 2 \mathrm{~B}-\mathrm{C} 1 \mathrm{~B}-\mathrm{C} 9 \mathrm{~B}-\mathrm{C} 8 \mathrm{~B}$ & $-176.51(14)$ \\
\hline O1A-C1A-C9A-C4A & $-175.70(15)$ & O1B-C1B-C9B-C4B & $-174.87(14)$ \\
\hline C2A-C1A-C9A-C4A & $3.56(15)$ & C2B-C1B-C9B-C4B & $3.94(15)$ \\
\hline C4A-C3A-C10A-C11A & $-2.9(2)$ & C4B-C3B-C10B-C18B & $172.57(13)$ \\
\hline $\mathrm{C} 2 \mathrm{~A}-\mathrm{C} 3 \mathrm{~A}-\mathrm{C} 10 \mathrm{~A}-\mathrm{C} 11 \mathrm{~A}$ & $175.35(13)$ & C2B-C $3 B-C 10 B-C 18 B$ & $-7.0(2)$ \\
\hline C4A-C3A-C10A-C18A & $178.09(13)$ & C4B-C3B-C10B-C11B & $-6.0(2)$ \\
\hline C2A-C3A-C10A-C18A & $-3.6(2)$ & C2B-C $3 \mathrm{~B}-\mathrm{C} 10 \mathrm{~B}-\mathrm{C} 11 \mathrm{~B}$ & $174.40(13)$ \\
\hline C3A-C10A-C11A-O2A & $-1.1(2)$ & C3B-C10B-C11B-O2B & $-8.6(2)$ \\
\hline C18A-C10A-C11A-O2A & $177.98(14)$ & C18B-C10B-C11B-O2B & $172.65(15)$ \\
\hline C3A-C10A-C11A-C12A & $-179.17(13)$ & C3B-C10B-C11B-C12B & $175.12(14)$ \\
\hline C18A-C10A-C11A-C12A & $-0.06(14)$ & C18B-C10B-C11B-C12B & $-3.62(14)$ \\
\hline $\mathrm{O} 2 \mathrm{~A}-\mathrm{C} 11 \mathrm{~A}-\mathrm{C} 12 \mathrm{~A}-\mathrm{C} 13 \mathrm{~A}$ & $2.9(2)$ & $\mathrm{O} 2 \mathrm{~B}-\mathrm{C} 11 \mathrm{~B}-\mathrm{C} 12 \mathrm{~B}-\mathrm{C} 17 \mathrm{~B}$ & $-173.55(14)$ \\
\hline C10A-C11A-C12A-C13A & $-178.90(13)$ & C10B-C11B-C12B-C17B & $2.91(15)$ \\
\hline $\mathrm{O} 2 \mathrm{~A}-\mathrm{C} 11 \mathrm{~A}-\mathrm{C} 12 \mathrm{~A}-\mathrm{C} 17 \mathrm{~A}$ & $-177.23(13)$ & O2B-C11B-C12B-C13B & $6.2(2)$ \\
\hline $\mathrm{C} 10 \mathrm{~A}-\mathrm{C} 11 \mathrm{~A}-\mathrm{C} 12 \mathrm{~A}-\mathrm{C} 17 \mathrm{~A}$ & $0.94(15)$ & $\mathrm{C} 10 \mathrm{~B}-\mathrm{C} 11 \mathrm{~B}-\mathrm{C} 12 \mathrm{~B}-\mathrm{C} 13 \mathrm{~B}$ & $-177.33(14)$ \\
\hline C17A-C12A-C13A-C14A & $-0.1(2)$ & C17B-C12B-C13B-C14B & $-0.9(2)$ \\
\hline C11A-C12A-C13A-C14A & $179.72(14)$ & C11B-C12B-C13B-C14B & $179.39(14)$ \\
\hline C12A-C13A-C14A-C15A & $0.7(2)$ & C12B-C13B-C14B-C15B & $1.0(2)$ \\
\hline C13A-C14A-C15A-C16A & $-0.5(2)$ & C13B-C14B-C15B-C16B & $0.0(3)$ \\
\hline C14A-C15A-C16A-C17A & $-0.5(2)$ & C14B-C15B-C16B-C17B & $-1.2(2)$ \\
\hline C15A-C16A-C17A-C12A & $1.1(2)$ & C15B-C16B-C17B-C12B & $1.3(2)$ \\
\hline C15A-C16A-C17A-C18A & $-177.97(13)$ & C15B-C16B-C17B-C18B & $-178.14(15)$ \\
\hline C13A-C12A-C17A-C16A & $-0.8(2)$ & C13B-C12B-C17B-C16B & $-0.3(2)$ \\
\hline $\mathrm{C} 11 \mathrm{~A}-\mathrm{C} 12 \mathrm{~A}-\mathrm{C} 17 \mathrm{~A}-\mathrm{C} 16 \mathrm{~A}$ & $179.30(13)$ & C11B-C12B-C17B-C16B & $179.50(13)$ \\
\hline C13A-C12A-C17A-C18A & $178.41(12)$ & C13B-C12B-C17B-C18B & $179.26(13)$ \\
\hline C11A-C12A-C17A-C18A & $-1.45(15)$ & C11B-C12B-C17B-C18B & $-0.96(16)$ \\
\hline C16A-C17A-C18A-O3A & $1.4(2)$ & C16B-C17B-C18B-O3B & $-0.8(2)$ \\
\hline C12A-C17A-C18A-O3A & $-177.79(14)$ & C12B-C17B-C18B-O3B & $179.73(14)$ \\
\hline C16A-C17A-C18A-C10A & $-179.45(13)$ & C16B-C17B-C18B-C10B & $178.11(15)$ \\
\hline C12A-C17A-C18A-C10A & $1.39(15)$ & C12B-C17B-C18B-C10B & $-1.38(15)$ \\
\hline C3A-C10A-C18A-O3A & $-2.4(2)$ & C3B-C10B-C18B-O3B & $3.1(2)$ \\
\hline C11A-C10A-C18A-O3A & $178.39(14)$ & C11B-C10B-C18B-O3B & $-178.05(15)$ \\
\hline C3A-C10A-C18A-C17A & $178.42(12)$ & C3B-C10B-C18B-C17B & $-175.76(12)$ \\
\hline C11A-C10A-C18A-C17A & $-0.77(14)$ & $\mathrm{C} 11 \mathrm{~B}-\mathrm{C} 10 \mathrm{~B}-\mathrm{C} 18 \mathrm{~B}-\mathrm{C} 17 \mathrm{~B}$ & $3.10(14)$ \\
\hline
\end{tabular}

2. Compound 2c

\section{Experimental for $\mathrm{C}_{13} \mathrm{H}_{6} \mathrm{~F}_{6} \mathrm{O}_{3}(2 \mathrm{c})$}

Data Collection and Processing. The sample 2c was submitted by Joseph Sloop of the Sloop research group at Georgia Gwinnett College. The sample was mounted on a nylon loop with a small amount of NVH immersion oil. All X-ray measurements were made on a Bruker-Nonius X8 Apex2 diffractometer at a temperature of $173 \mathrm{~K}$. The unit cell dimensions were determined from a symmetry constrained fit of 9959 reflections with $5.28^{\circ}<2 \theta<57.7^{\circ}$. The data collection strategy was a number of $\omega$ and $\varphi$ scans which collected data up to $57.74^{\circ}(2 \theta)$. The frame integration was performed using 
SAINT+ [29]. The resulting raw data was scaled and absorption corrected using a multi-scan averaging of symmetry equivalent data using SADABS [30].

Structure Solution and Refinement. The structure was solved by direct methods using the SIR92 program [31]. All non-hydrogen atoms were obtained from the initial E-map. The hydrogen atoms were introduced at idealized positions and were allowed to refine isotropically. The structural model was fit to the data using full matrix least-squares based on F. The calculated structure factors included corrections for anomalous dispersion from the usual tabulation. The structure was refined using the LSTSQ program from NRCVAX [33], graphic plots were produced using the NRCVAX crystallographic program suite. Additional information and other relevant literature references can be found in the reference section of the Facility's Web page (http://www.xray.ncsu.edu).

Figure 12. ORTEP drawing of $2 c$ showing naming and numbering scheme. Ellipsoids are at the $50 \%$.

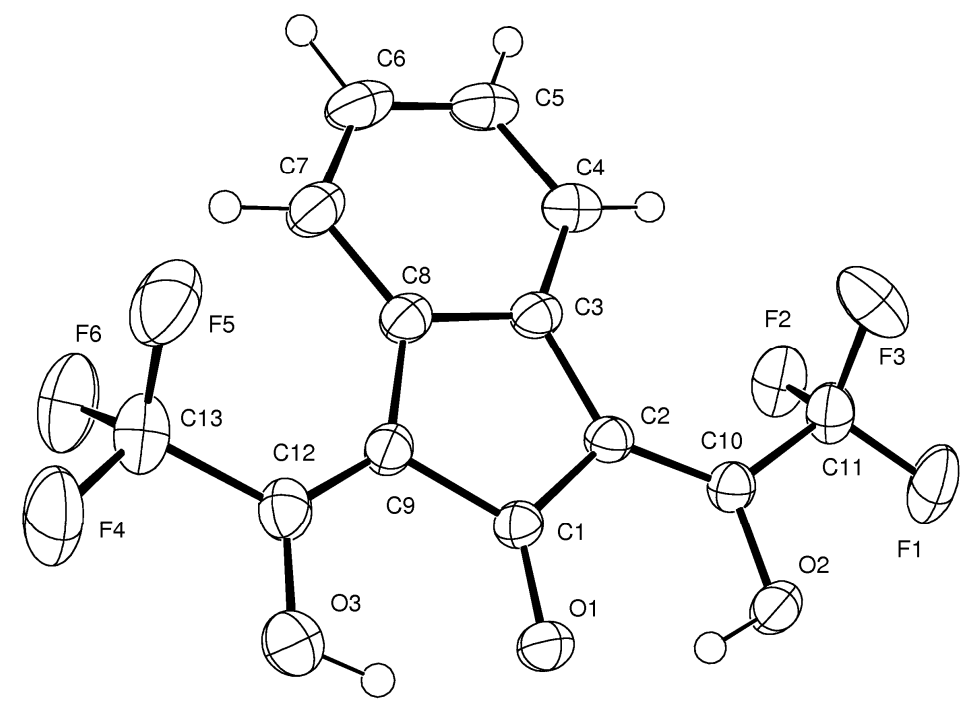

Figure 13. ORTEP drawing of $2 c$. Ellipsoids are at the $50 \%$ probability level and hydrogen atoms were drawn with arbitrary radii for clarity.

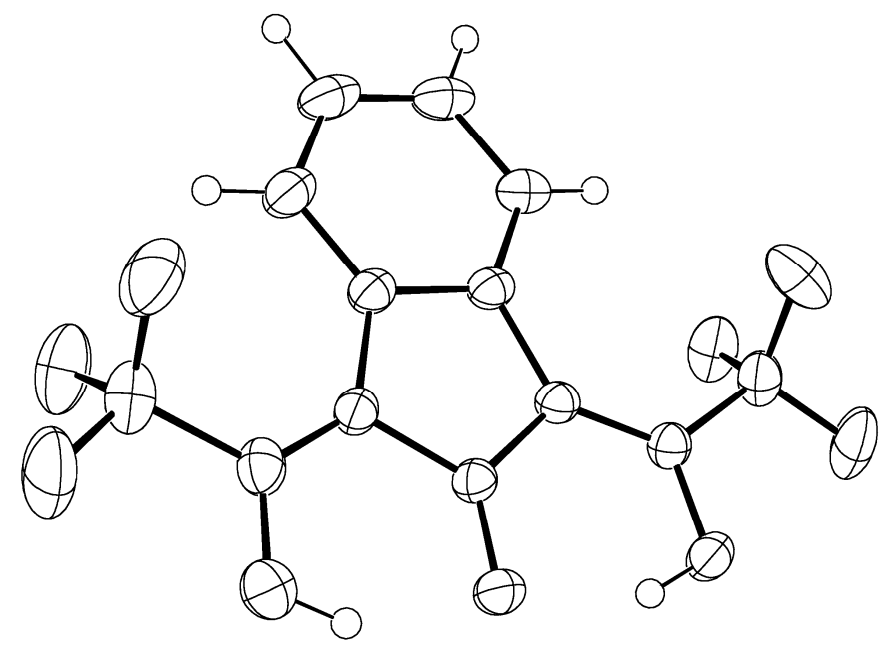


Figure 14. Stereoscopic ORTEP drawing of $2 c$. Ellipsoids are at the 50\% probability level and hydrogen atoms were drawn with arbitrary radii for clarity.
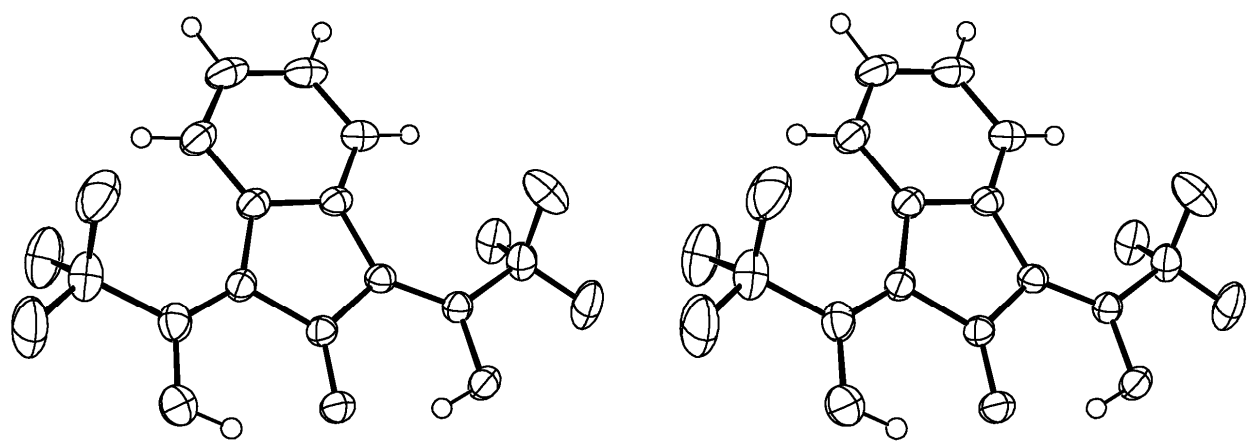

Table 10. Summary of Crystal Data for $2 c$.

\section{Formula}

Formula Weight $(\mathrm{g} / \mathrm{mol})$

Crystal Dimensions $(\mathrm{mm})$

Crystal Color and Habit

Crystal System

Space Group

Temperature, $\mathrm{K}$

$a, \AA$

$b, \AA$

$c, \AA$

$\alpha,{ }^{\circ}$

$\beta,{ }^{\circ}$

$\gamma^{\circ}$

$\mathrm{V}, \AA^{3}$

Number of reflections to determine final unit cell

Min and Max $2 \theta$ for cell determination, ${ }^{\circ}$

$\mathrm{Z}$

$\mathrm{F}(000)$

$\rho(\mathrm{g} / \mathrm{cm})$

$\lambda, \AA,(\mathrm{MoK} \alpha)$

$\mu,\left(\mathrm{cm}^{-1}\right)$

Diffractometer Type

Scan Type(s)

Max $2 \theta$ for data collection, ${ }^{\circ}$

Measured fraction of data

Number of reflections measured

Unique reflections measured

$\mathrm{R}_{\text {merge }}$

Number of reflections included in refinement

Cut off Threshold Expression

Structure refined using

Weighting Scheme
$\mathrm{C}_{13} \mathrm{H}_{6} \mathrm{~F}_{6} \mathrm{O}_{3}$

324.18

$1.20 \times 0.10 \times 0.06$

yellow needle

monoclinic

P $21 / \mathrm{c}$

173

4.7643(3)

$18.6978(12)$

13.8431(9)

90.0

98.964(3)

90.0

1218.11(14)

9959

$5.28,57.7$

4

648.71

1.768

0.71073

0.18

Bruker-Nonius X8 Apex2

omega and phi scans

57.74

0.98

26516

3195

0.027

2755

Inet $>1.0$ sigma(Inet)

full matrix least-squares using $\mathrm{F}$

$1 /\left(\operatorname{sigma}^{2}(\mathrm{~F})+0.0005 \mathrm{~F}^{2}\right)$ 
Table 10. Cont.

\begin{tabular}{ll}
\hline Number of parameters in least-squares & 223 \\
$\mathrm{R}_{\mathrm{f}}$ & 0.038 \\
$\mathrm{R}_{\mathrm{w}}$ & 0.053 \\
$\mathrm{R}_{\mathrm{f}}$ (all data) & 0.046 \\
$\mathrm{R}_{\mathrm{w}}$ (all data) & 0.054 \\
$\mathrm{GOF}$ & 1.74 \\
Maximum shift/error & 0.003 \\
Min \& Max peak heights on final $\Delta \mathrm{F}$ Map $\left(e^{-} / \AA\right)$ & $-0.30,0.35$ \\
\hline Where: & \\
$\mathrm{R}_{\mathrm{f}}=\Sigma\left(\left|\mathrm{F}_{\mathrm{O}}-\mathrm{F}_{\mathrm{c}}\right|\right) / \Sigma \mathrm{F}_{\mathrm{O}}$ & \\
$\mathrm{R}_{\mathrm{W}}=\left[\Sigma\left(w\left(\mathrm{~F}_{\mathrm{O}}-\mathrm{F}_{\mathrm{C}}\right)^{2}\right) / \Sigma\left(\mathrm{F}_{\mathrm{O}}{ }^{2}\right)\right]^{1 / 2}$ & \\
$\mathrm{GOF}=\left[\Sigma\left(w\left(\mathrm{~F}_{\mathrm{O}}-\mathrm{F}_{\mathrm{C}}\right)^{2}\right) /(\text { No. of reflns. }- \text { No. of params. })\right]^{1 / 2}$
\end{tabular}

Table 11. Atomic Coordinates for $2 c$.

\begin{tabular}{|c|c|c|c|c|}
\hline Atom & $\mathrm{x}$ & $\mathrm{y}$ & $\mathrm{z}$ & $\mathrm{U}_{\text {iso/equiv }}$ \\
\hline $\mathrm{O} 1$ & $0.81730(18)$ & $0.99675(5)$ & $0.07954(6)$ & $0.0316(4)$ \\
\hline $\mathrm{O} 2$ & $0.77456(19)$ & $1.10306(5)$ & $-0.04046(7)$ & $0.0328(5)$ \\
\hline $\mathrm{O} 3$ & $0.8507(2)$ & $0.90513(5)$ & $0.22145(8)$ & $0.0392(5)$ \\
\hline $\mathrm{C} 1$ & $0.6645(2)$ & $1.03312(6)$ & $0.12739(8)$ & $0.0244(5)$ \\
\hline $\mathrm{C} 2$ & $0.5495(2)$ & $1.10365(6)$ & $0.10029(9)$ & $0.0243(5)$ \\
\hline $\mathrm{C} 3$ & $0.3836(2)$ & $1.12503(7)$ & $0.17672(8)$ & $0.0257(5)$ \\
\hline $\mathrm{C} 4$ & $0.2245(3)$ & $1.18602(8)$ & $0.18650(10)$ & $0.0319(6)$ \\
\hline $\mathrm{C} 5$ & $0.0812(3)$ & $1.19205(8)$ & $0.26621(11)$ & $0.0377(7)$ \\
\hline C6 & $0.0964(3)$ & $1.13855(8)$ & $0.33508(11)$ & $0.0396(7)$ \\
\hline $\mathrm{C} 7$ & $0.2560(3)$ & $1.07730(8)$ & $0.32738(10)$ & $0.0352(6)$ \\
\hline $\mathrm{C} 8$ & $0.4020(2)$ & $1.07009(7)$ & $0.24809(9)$ & $0.0270(5)$ \\
\hline $\mathrm{C} 9$ & $0.5808(2)$ & $1.01187(6)$ & $0.22025(8)$ & $0.0263(5)$ \\
\hline $\mathrm{C} 10$ & $0.6161(2)$ & $1.13484(7)$ & $0.01809(9)$ & $0.0259(5)$ \\
\hline C11 & $0.5253(3)$ & $1.20877(7)$ & $-0.01820(11)$ & $0.0337(6)$ \\
\hline $\mathrm{C} 12$ & $0.6894(3)$ & $0.95005(7)$ & $0.26242(9)$ & $0.0311(6)$ \\
\hline $\mathrm{C} 13$ & $0.6515(3)$ & $0.92528(8)$ & $0.36396(11)$ & $0.0401(7)$ \\
\hline $\mathrm{F} 1$ & $0.61454(20)$ & $1.22376(5)$ & $-0.10179(7)$ & $0.0526(5)$ \\
\hline $\mathrm{F} 2$ & $0.24328(16)$ & $1.21541(5)$ & $-0.03293(6)$ & $0.0430(4)$ \\
\hline F3 & $0.62851(20)$ & $1.25846(5)$ & $0.04657(7)$ & $0.0526(5)$ \\
\hline $\mathrm{F} 4$ & $0.8000(2)$ & $0.86675(5)$ & $0.39034(7)$ & $0.0592(6)$ \\
\hline F5 & $0.7410(2)$ & $0.97545(6)$ & $0.43055(6)$ & $0.0548(5)$ \\
\hline F6 & $0.38149(19)$ & $0.91237(6)$ & $0.37079(7)$ & $0.0579(5)$ \\
\hline $\mathrm{H} 2$ & $0.822(4)$ & $1.0603(13)$ & $-0.0133(14)$ & $0.064(6)$ \\
\hline $\mathrm{H} 3$ & $0.877(5)$ & $0.9223(11)$ & $0.1643(16)$ & $0.072(6)$ \\
\hline $\mathrm{H} 4$ & $0.213(3)$ & $1.2212(8)$ & $0.1414(11)$ & $0.030(4)$ \\
\hline H5 & $-0.019(3)$ & $1.2318(8)$ & $0.2728(11)$ & $0.035(4)$ \\
\hline H6 & $-0.004(4)$ & $1.1455(9)$ & $0.3899(12)$ & $0.045(4)$ \\
\hline $\mathrm{H} 7$ & $0.272(3)$ & $1.0418(9)$ & $0.3767(12)$ & $0.039(4)$ \\
\hline
\end{tabular}


Table 12. Anisotropic Displacement Parameters for $2 c$.

\begin{tabular}{lllllll}
\hline Atom & $\mathrm{u}^{11}$ & $\mathrm{u}^{22}$ & $\mathrm{u}^{33}$ & $\mathrm{u}^{12}$ & $\mathrm{u}^{13}$ & $\mathrm{u}^{23}$ \\
O1 & $0.0384(5)$ & $0.0291(5)$ & $0.0291(5)$ & $0.0065(4)$ & $0.0112(4)$ & $0.0003(4)$ \\
O2 & $0.0380(5)$ & $0.0333(5)$ & $0.0302(5)$ & $0.0053(4)$ & $0.0146(4)$ & $0.0045(4)$ \\
O3 & $0.0482(6)$ & $0.0321(5)$ & $0.0380(6)$ & $0.0067(4)$ & $0.0085(5)$ & $0.0061(4)$ \\
C1 & $0.0264(5)$ & $0.0255(6)$ & $0.0214(5)$ & $-0.0027(5)$ & $0.0040(4)$ & $-0.0019(4)$ \\
C2 & $0.0245(5)$ & $0.0243(6)$ & $0.0243(5)$ & $-0.0014(5)$ & $0.0042(4)$ & $-0.0029(4)$ \\
C3 & $0.0230(5)$ & $0.0294(6)$ & $0.0248(6)$ & $-0.0045(5)$ & $0.0042(4)$ & $-0.0063(5)$ \\
C4 & $0.0303(6)$ & $0.0330(7)$ & $0.0321(6)$ & $0.0012(5)$ & $0.0041(5)$ & $-0.0072(5)$ \\
C5 & $0.0313(6)$ & $0.0419(8)$ & $0.0407(7)$ & $0.0023(6)$ & $0.0084(6)$ & $-0.0160(6)$ \\
C6 & $0.0341(6)$ & $0.0531(9)$ & $0.0343(7)$ & $-0.0067(6)$ & $0.0139(6)$ & $-0.0166(7)$ \\
C7 & $0.0358(7)$ & $0.0441(8)$ & $0.0275(6)$ & $-0.0092(6)$ & $0.0112(5)$ & $-0.0064(6)$ \\
C8 & $0.0255(5)$ & $0.0316(6)$ & $0.0242(6)$ & $-0.0068(5)$ & $0.0051(4)$ & $-0.0053(5)$ \\
C9 & $0.0290(5)$ & $0.0282(6)$ & $0.0222(6)$ & $-0.0067(5)$ & $0.0054(5)$ & $-0.0015(4)$ \\
C10 & $0.0241(5)$ & $0.0270(6)$ & $0.0271(6)$ & $-0.0010(5)$ & $0.0051(4)$ & $0.0005(5)$ \\
C11 & $0.0293(6)$ & $0.0323(7)$ & $0.0409(7)$ & $0.0007(5)$ & $0.0096(5)$ & $0.0079(5)$ \\
C12 & $0.0324(6)$ & $0.0314(7)$ & $0.0291(6)$ & $-0.0071(5)$ & $0.0031(5)$ & $0.0023(5)$ \\
C13 & $0.0380(7)$ & $0.0444(8)$ & $0.0374(7)$ & $-0.0058(6)$ & $0.0045(6)$ & $0.0128(6)$ \\
F1 & $0.0516(5)$ & $0.0533(6)$ & $0.0594(6)$ & $0.0131(4)$ & $0.0287(5)$ & $0.0306(5)$ \\
F2 & $0.0296(4)$ & $0.0493(5)$ & $0.0507(5)$ & $0.0088(4)$ & $0.0084(4)$ & $0.0178(4)$ \\
F3 & $0.0538(5)$ & $0.0258(4)$ & $0.0750(7)$ & $0.0008(4)$ & $0.0006(5)$ & $-0.0021(4)$ \\
F4 & $0.0650(6)$ & $0.0577(6)$ & $0.0569(6)$ & $0.0082(5)$ & $0.0154(5)$ & $0.0322(5)$ \\
F5 & $0.0661(6)$ & $0.0702(7)$ & $0.0276(4)$ & $-0.0148(5)$ & $0.0057(4)$ & $0.0044(4)$ \\
F6 & $0.0427(5)$ & $0.0755(7)$ & $0.0574(6)$ & $-0.0133(5)$ & $0.0133(4)$ & $0.0236(5)$ \\
\hline & & & & & &
\end{tabular}

Table 13. Bond Lengths for $2 c$.

\begin{tabular}{llll}
\hline O1-C1 & $1.2576(15)$ & C6-C7 & $1.388(2)$ \\
O2-C10 & $1.3308(15)$ & C6-H6 & $0.967(18)$ \\
O2-H2 & $0.90(2)$ & C7-C8 & $1.3944(18)$ \\
O3-C12 & $1.3242(17)$ & C7-H7 & $0.947(17)$ \\
O3-H3 & $0.88(2)$ & C8-C9 & $1.4703(18)$ \\
C1-C2 & $1.4547(17)$ & C9-C12 & $1.3602(18)$ \\
C1-C9 & $1.4590(17)$ & C10-C11 & $1.5108(18)$ \\
C2-C3 & $1.4714(17)$ & C11-F1 & $1.3235(16)$ \\
C2-C10 & $1.3593(17)$ & C11-F2 & $1.3329(15)$ \\
C3-C4 & $1.3876(18)$ & C11-F3 & $1.3311(17)$ \\
C3-C8 & $1.4186(18)$ & C12-C13 & $1.5173(19)$ \\
C4-C5 & $1.3893(20)$ & C13-F4 & $1.3233(18)$ \\
C4-H4 & $0.903(15)$ & C13-F5 & $1.3375(18)$ \\
C5-C6 & $1.376(2)$ & C13-F6 & $1.3267(17)$ \\
C5-H5 & $0.896(17)$ & & \\
\hline
\end{tabular}

Table 14. Bond Angles for 2c.

\begin{tabular}{llll}
\hline C10-O2-H2 & $105.8(12)$ & C3-C8-C9 & $109.21(10)$ \\
C12-O3-H3 & $109.1(14)$ & C7-C8-C9 & $131.18(12)$ \\
O1-C1-C2 & $125.45(11)$ & C1-C9-C8 & $106.17(10)$ \\
O1-C1-C9 & $125.23(11)$ & C1-C9-C12 & $118.14(11)$ \\
C2-C1-C9 & $109.30(10)$ & C8-C9-C12 & $135.54(12)$ \\
\hline
\end{tabular}


Table 14. Cont.

\begin{tabular}{llll}
\hline C1-C2-C3 & $106.48(10)$ & O2-C10-C2 & $123.15(11)$ \\
C1-C2-C10 & $118.51(11)$ & O2-C10-C11 & $111.48(11)$ \\
C3-C2-C10 & $134.99(11)$ & C2-C10-C11 & $125.36(11)$ \\
C2-C3-C4 & $131.02(12)$ & C10-C11-F1 & $111.72(11)$ \\
C2-C3-C8 & $108.80(10)$ & C10-C11-F2 & $111.45(10)$ \\
C4-C3-C8 & $120.17(11)$ & C10-C11-F3 & $110.99(11)$ \\
C3-C4-C5 & $119.18(14)$ & F1-C11-F2 & $107.46(11)$ \\
C3-C4-H4 & $120.4(9)$ & F1-C11-F3 & $107.80(11)$ \\
C5-C4-H4 & $120.4(9)$ & F2-C11-F3 & $107.21(11)$ \\
C4-C5-C6 & $120.80(14)$ & O3-C12-C9 & $124.23(12)$ \\
C4-C5-H5 & $119.0(10)$ & O3-C12-C13 & $111.34(12)$ \\
C6-C5-H5 & $120.2(10)$ & C9-C12-C13 & $124.39(13)$ \\
C5-C6-C7 & $121.13(13)$ & C12-C13-F4 & $111.87(13)$ \\
C5-C6-H6 & C12-C13-F5 & $110.68(11)$ \\
C7-C6-H6 & $117.8(10)$ & C12-C13-F6 & $112.22(11)$ \\
C6-C7-C8 & $121.0(10)$ & F4-C13-F5 & $106.89(12)$ \\
C6-C7-H7 & $119.11(14)$ & F4-C13-F6 & $108.20(12)$ \\
C8-C7-H7 & $120.5(9)$ & F5-C13-F6 & $106.69(13)$ \\
C3-C8-C7 & $120.3(9)$ & & \\
\hline
\end{tabular}

Table 15. Torsion Angles for $2 c$.

\begin{tabular}{llll}
\hline O1-C1-C2-C3 & $179.6(2)$ & C8-C3-C4-C5 & $-0.78(13)$ \\
O1-C1-C2-C10 & $-1.91(11)$ & C2-C3-C8-C7 & $-178.6(3)$ \\
C9-C1-C2-C3 & $-1.90(11)$ & C2-C3-C8-C9 & $0.26(11)$ \\
C9-C1-C2-C10 & $176.6(2)$ & C4-C3-C8-C7 & $0.88(13)$ \\
O1-C1-C9-C8 & $-179.4(3)$ & C4-C3-C8-C9 & $179.7(3)$ \\
O1-C1-C9-C12 & $4.37(11)$ & C3-C4-C5-C6 & $0.17(13)$ \\
C2-C1-C9-C8 & $2.04(11)$ & C4-C5-C6-C7 & $0.35(13)$ \\
C2-C1-C9-C12 & $-174.2(3)$ & C5-C6-C7-C8 & $-0.25(13)$ \\
C1-C2-C3-C4 & $-178.4(2)$ & C6-C7-C8-C3 & $-0.36(13)$ \\
C1-C2-C3-C8 & $1.00(11)$ & C6-C7-C8-C9 & $-178.9(3)$ \\
C10-C2-C3-C4 & $3.44(12)$ & C3-C8-C9-C1 & $-1.41(11)$ \\
C10-C2-C3-C8 & $-177.2(3)$ & C3-C8-C9-C12 & $173.8(3)$ \\
C1-C2-C10-O2 & $2.08(10)$ & C7-C8-C9-C1 & $177.3(3)$ \\
C1-C2-C10-C11 & $-177.3(2)$ & C7-C8-C9-C12 & $-7.50(13)$ \\
C3-C2-C10-O2 & $-179.9(2)$ & C1-C9-C12-O3 & $-4.98(11)$ \\
C3-C2-C10-C11 & $0.67(11)$ & C1-C9-C12-C13 & $172.4(3)$ \\
C2-C3-C4-C5 & $178.6(3)$ & & \\
\hline
\end{tabular}

3. Compound 3d

\section{Experimental for $\mathrm{C}_{12} \mathrm{H}_{7} \mathrm{~F}_{3} \mathrm{O}_{2}(3 \mathrm{~d})$}

Data Collection and Processing. The sample 3d was submitted by Joseph Sloop of the Sloop research group at Georgia Gwinnett College. The sample was mounted on a nylon loop with a small 
amount of NVH immersion oil. All X-ray measurements were made on a Bruker-Nonius X8 Apex2 diffractometer at a temperature of $110 \mathrm{~K}$. The unit cell dimensions were determined from a symmetry constrained fit of 5859 reflections with $5.44^{\circ}<2 \theta<52.66^{\circ}$. The data collection strategy was a number of $\omega$ and $\varphi$ scans which collected data up to $62.92^{\circ}(2 \theta)$. The frame integration was performed using SAINT [29]. The resulting raw data was scaled and absorption corrected using a multi-scan averaging of symmetry equivalent data using SADABS [30].

Structure Solution and Refinement. The structure was solved by direct methods using the SIR92 program [31]. All non-hydrogen atoms were obtained from the initial solution. The carbon bound hydrogen atoms were introduced at idealized positions while the hydroxy hydrogen atom position was obtained from a diffeence Fourier map. All hydrogen atoms were allowed to refine isotropically. The structural model was fit to the data using full matrix least-squares based on $\mathrm{F}^{2}$. The calculated structure factors included corrections for anomalous dispersion from the usual tabulation. The space group is achiral, therefore the structure has an absolute sense to it. However, the anomalous scattering signal is weak due to the absence of any atoms heavier than F, and the absolute structure could not be definitively determined. The structure was refined using the XL program from SHELXTL [32], graphic plots were produced using the NRCVAX crystallographic program suite. Additional information and other relevant literature references can be found in the reference section of the Facility's Web page (http://www.xray.ncsu.edu).

Figure 15. ORTEP drawing of $3 \boldsymbol{d}$ showing naming and numbering scheme. Ellipsoids are at the $50 \%$ probability level and hydrogen atoms were drawn with arbitrary radii for clarity.

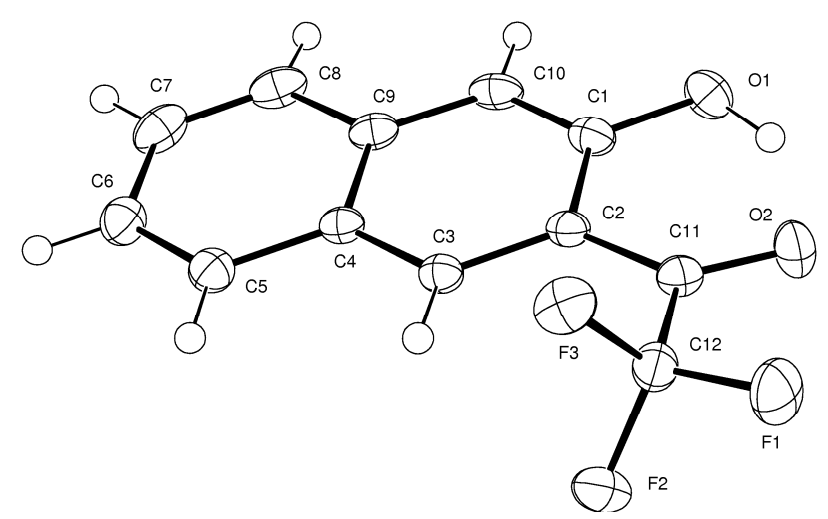

Figure 16. ORTEP drawing of $3 \boldsymbol{d}$. Ellipsoids are at the $50 \%$ probability level and hydrogen atoms were drawn with arbitrary radii for clarity.

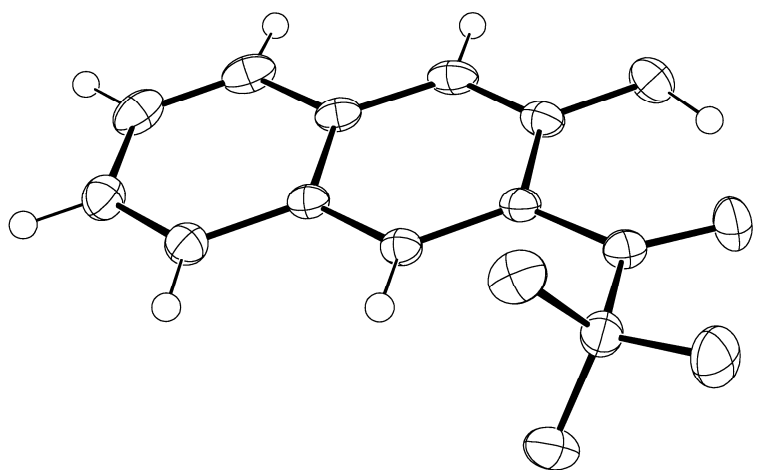


Figure 17. Stereoscopic ORTEP drawing of $3 \boldsymbol{d}$. Ellipsoids are at the 50\% probability level and hydrogen atoms were drawn with arbitrary radii for clarity.
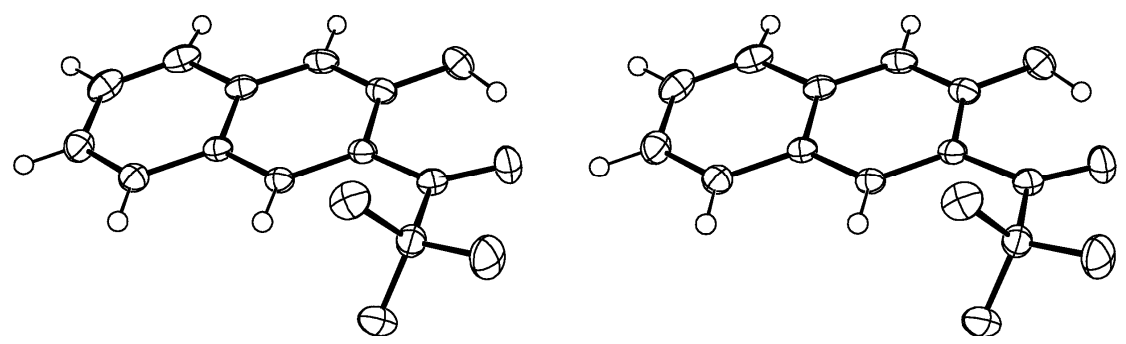

Table 16. Summary of Crystal Data for $\mathbf{3 d}$.

\begin{tabular}{|c|c|}
\hline Formula & $\mathrm{C}_{12} \mathrm{H}_{7} \mathrm{~F}_{3} \mathrm{O}_{2}$ \\
\hline Formula Weight $(\mathrm{g} / \mathrm{mol})$ & 240.18 \\
\hline Crystal Dimensions $(\mathrm{mm})$ & $0.46 \times 0.08 \times 0.04$ \\
\hline Crystal Color and Habit & orange yellow needle \\
\hline Crystal System & orthorhombic \\
\hline Space Group & $\mathrm{P}$ n a $2_{1}$ \\
\hline Temperature, $\mathrm{K}$ & 110 \\
\hline$a, \AA$ & $13.5923(5)$ \\
\hline$b, \AA$ & $14.9695(5)$ \\
\hline$c, \AA$ & $4.8381(2)$ \\
\hline$\alpha,{ }^{\circ}$ & 90.00 \\
\hline$\beta, \circ$ & 90.00 \\
\hline$\gamma{ }^{\circ}$ & 90.00 \\
\hline $\mathrm{V}, \AA^{3}$ & $984.41(6)$ \\
\hline Number of reflections to determine final unit cell & 5859 \\
\hline Min and Max $2 \theta$ for cell determination, ${ }^{\circ}$ & $5.44,52.66$ \\
\hline $\mathrm{Z}$ & 4 \\
\hline $\mathrm{F}(000)$ & 488 \\
\hline$\rho(\mathrm{g} / \mathrm{cm})$ & 1.621 \\
\hline$\lambda, \AA,(\mathrm{MoK} \alpha)$ & 0.71070 \\
\hline$\mu,\left(\mathrm{cm}^{-1}\right)$ & 0.147 \\
\hline Diffractometer Type & Bruker-Nonius X8 Apex2 \\
\hline Scan Type(s) & omega and phi scans \\
\hline Max $2 \theta$ for data collection, ${ }^{\circ}$ & 62.92 \\
\hline Measured fraction of data & 0.874 \\
\hline Number of reflections measured & 21568 \\
\hline Unique reflections measured & 2632 \\
\hline $\mathrm{R}_{\text {merge }}$ & 0.0444 \\
\hline Number of reflections included in refinement & 2632 \\
\hline Cut off Threshold Expression & $>2 \operatorname{sigma}(\mathrm{I})$ \\
\hline Structure refined using & full matrix least-squares using $\mathrm{F}^{2}$ \\
\hline Weighting Scheme & $\begin{array}{l}\text { calc } \mathrm{w}=1 /\left[\operatorname{sigma}^{2}\left(\mathrm{Fo}^{2}\right)+(0.0406 \mathrm{P})^{2}+\right. \\
0.0000 \mathrm{P}] \text { where } \mathrm{P}=\left(\mathrm{Fo}^{2}+2 \mathrm{Fc}^{2}\right) / 3\end{array}$ \\
\hline Number of parameters in least-squares & 182 \\
\hline
\end{tabular}


Table 16. Cont.

\begin{tabular}{ll}
\hline $\mathrm{R}_{1}$ & 0.0370 \\
$\mathrm{wR}_{2}$ & 0.0712 \\
$\mathrm{R}_{1}$ (all data) & 0.0538 \\
$\mathrm{wR}_{2}$ (all data) & 0.0762 \\
$\mathrm{GOF}$ & 1.035 \\
Maximum shift/error & 0.000 \\
Min \& Max peak heights on final $\Delta \mathrm{F}$ Map $\left(e^{-/ \AA}\right)$ & $-0.229,0.183$ \\
\hline
\end{tabular}

Where:

$\mathrm{R}_{1}=\Sigma\left(\left|\mathrm{F}_{\mathrm{O}}\right|-\left|\mathrm{F}_{\mathrm{c}}\right|\right) / \Sigma \mathrm{F}_{\mathrm{O}}$

$\mathrm{wR}_{2}=\left[\Sigma\left(w\left(\mathrm{~F}_{\mathrm{O}}{ }^{2}-\mathrm{F}_{\mathrm{c}^{2}}\right)^{2}\right) / \Sigma\left(w \mathrm{~F}_{\mathrm{O}}{ }^{4}\right)\right]^{1 / 2}$

$\mathrm{GOF}=\left[\Sigma\left(w\left(\mathrm{~F}_{\mathrm{O}}{ }^{2}-\mathrm{F}_{\mathrm{c}}{ }^{2}\right)^{2}\right) /(\text { No. of reflns. }- \text { No. of params. })\right]^{1 / 2}$

Table 17. Atomic Coordinates for $3 \boldsymbol{d}$.

\begin{tabular}{lllll}
\hline Atom & $\mathrm{x}$ & $\mathrm{y}$ & $\mathrm{z}$ & $\mathrm{U}_{\text {iso/equiv }}$ \\
$\mathrm{O} 1$ & $0.11391(8)$ & $0.26937(8)$ & $0.6424(3)$ & $0.0315(3)$ \\
$\mathrm{O} 2$ & $0.22469(8)$ & $0.37533(7)$ & $0.3464(3)$ & $0.0294(3)$ \\
$\mathrm{C} 1$ & $0.19885(11)$ & $0.24126(10)$ & $0.7623(4)$ & $0.0227(3)$ \\
$\mathrm{C} 2$ & $0.29250(11)$ & $0.27865(9)$ & $0.6863(4)$ & $0.0190(3)$ \\
$\mathrm{C} 3$ & $0.37673(11)$ & $0.24539(9)$ & $0.8101(4)$ & $0.0193(3)$ \\
C4 & $0.37205(11)$ & $0.17792(10)$ & $1.0120(4)$ & $0.0192(3)$ \\
C5 & $0.45775(12)$ & $0.14260(10)$ & $1.1386(4)$ & $0.0230(3)$ \\
C6 & $0.45137(13)$ & $0.07873(10)$ & $1.3373(4)$ & $0.0269(3)$ \\
C7 & $0.35837(14)$ & $0.04578(11)$ & $1.4184(4)$ & $0.0300(4)$ \\
C8 & $0.27466(13)$ & $0.07695(10)$ & $1.3003(4)$ & $0.0275(4)$ \\
C9 & $0.27804(11)$ & $0.14416(10)$ & $1.0917(4)$ & $0.0213(3)$ \\
C10 & $0.19325(12)$ & $0.17720(11)$ & $0.9629(4)$ & $0.0247(3)$ \\
C11 & $0.29517(12)$ & $0.35023(10)$ & $0.4818(4)$ & $0.0217(3)$ \\
C12 & $0.39217(11)$ & $0.40275(10)$ & $0.4367(4)$ & $0.0224(3)$ \\
F1 & $0.37724(7)$ & $0.47125(6)$ & 0.2675 & $0.0341(3)$ \\
F2 & $0.46266(6)$ & $0.35198(6)$ & $0.3256(3)$ & $0.0286(2)$ \\
F3 & $0.42682(6)$ & $0.43562(6)$ & $0.6742(3)$ & $0.0297(2)$ \\
H1 & $0.1301(19)$ & $0.3131(16)$ & $0.500(7)$ & $0.079(9)$ \\
H3 & $0.4391(12)$ & $0.2686(10)$ & $0.766(4)$ & $0.022(4)$ \\
H5 & $0.5197(14)$ & $0.1674(10)$ & $1.079(4)$ & $0.033(5)$ \\
H6 & $0.5078(13)$ & $0.0544(10)$ & $1.422(4)$ & $0.026(4)$ \\
H7 & $0.3543(13)$ & $0.0040(11)$ & $1.553(4)$ & $0.030(5)$ \\
H8 & $0.2120(15)$ & $0.0566(12)$ & $1.334(5)$ & $0.053(6)$ \\
\hline & & & & \\
\hline
\end{tabular}

Table 18. Anisotropic Displacement Parameters for $\mathbf{3 d}$.

\begin{tabular}{lllllll}
\hline Atom & $\mathrm{u}^{11}$ & $\mathrm{u}^{22}$ & $\mathrm{u}^{33}$ & $\mathrm{u}^{12}$ & $\mathrm{u}^{13}$ & $\mathrm{u}^{23}$ \\
$\mathrm{O} 1$ & $0.0164(6)$ & $0.0433(7)$ & $0.0347(7)$ & $0.0007(5)$ & $-0.0018(5)$ & $0.0012(6)$ \\
$\mathrm{O} 2$ & $0.0251(6)$ & $0.0319(6)$ & $0.0312(6)$ & $0.0036(5)$ & $-0.0074(6)$ & $0.0048(6)$ \\
$\mathrm{C} 1$ & $0.0174(8)$ & $0.0271(8)$ & $0.0236(8)$ & $-0.0003(6)$ & $0.0012(6)$ & $-0.0060(7)$ \\
\hline
\end{tabular}


Table 18. Cont.

\begin{tabular}{lllllll}
\hline C2 & $0.0180(8)$ & $0.0211(7)$ & $0.0178(7)$ & $0.0006(6)$ & $0.0021(6)$ & $-0.0031(6)$ \\
C3 & $0.0174(8)$ & $0.0209(7)$ & $0.0196(7)$ & $-0.0016(6)$ & $0.0019(6)$ & $-0.0013(7)$ \\
C4 & $0.0199(8)$ & $0.0195(7)$ & $0.0182(7)$ & $-0.0011(6)$ & $0.0023(6)$ & $-0.0032(6)$ \\
C5 & $0.0249(9)$ & $0.0212(8)$ & $0.0229(8)$ & $0.0011(6)$ & $0.0005(7)$ & $-0.0006(6)$ \\
C6 & $0.0338(9)$ & $0.0226(8)$ & $0.0245(8)$ & $0.0051(7)$ & $-0.0020(7)$ & $0.0001(7)$ \\
C7 & $0.0471(11)$ & $0.0208(8)$ & $0.0223(9)$ & $-0.0038(7)$ & $0.0034(7)$ & $0.0020(7)$ \\
C8 & $0.0324(9)$ & $0.0256(8)$ & $0.0247(9)$ & $-0.0107(7)$ & $0.0084(8)$ & $-0.0037(7)$ \\
C9 & $0.0249(8)$ & $0.0193(7)$ & $0.0198(7)$ & $-0.0031(6)$ & $0.0041(6)$ & $-0.0060(6)$ \\
C10 & $0.0178(8)$ & $0.0300(8)$ & $0.0264(8)$ & $-0.0068(7)$ & $0.0072(7)$ & $-0.0062(7)$ \\
C11 & $0.0226(9)$ & $0.0230(8)$ & $0.0195(8)$ & $0.0020(6)$ & $0.0017(6)$ & $-0.0026(6)$ \\
C12 & $0.0238(8)$ & $0.0226(8)$ & $0.0208(7)$ & $0.0010(6)$ & $-0.0013(7)$ & $0.0006(6)$ \\
F1 & $0.0369(6)$ & $0.0279(5)$ & $0.0375(6)$ & $-0.0005(4)$ & $-0.0013(5)$ & $0.0126(5)$ \\
F2 & $0.0238(5)$ & $0.0291(5)$ & $0.0329(5)$ & $0.0011(4)$ & $0.0082(4)$ & $-0.0003(4)$ \\
F3 & $0.0309(5)$ & $0.0300(5)$ & $0.0282(5)$ & $-0.0080(4)$ & $-0.0005(4)$ & $-0.0051(4)$ \\
\hline
\end{tabular}

Table 19. Bond Lengths for $3 \boldsymbol{d}$.

\begin{tabular}{llll}
\hline O1-C1 & $1.3588(19)$ & $\mathrm{C} 6-\mathrm{C} 7$ & $1.412(2)$ \\
O1-H1 & $0.97(3)$ & $\mathrm{C} 6-\mathrm{H} 6$ & $0.941(18)$ \\
O2-C11 & $1.2199(18)$ & $\mathrm{C} 7-\mathrm{C} 8$ & $1.356(2)$ \\
$\mathrm{C} 1-\mathrm{C} 10$ & $1.367(2)$ & $\mathrm{C} 7-\mathrm{H} 7$ & $0.905(18)$ \\
$\mathrm{C} 1-\mathrm{C} 2$ & $1.438(2)$ & $\mathrm{C} 8-\mathrm{C} 9$ & $1.426(2)$ \\
$\mathrm{C} 2-\mathrm{C} 3$ & $1.385(2)$ & $\mathrm{C} 8-\mathrm{H} 8$ & $0.92(2)$ \\
$\mathrm{C} 2-\mathrm{C} 11$ & $1.459(2)$ & $\mathrm{C} 9-\mathrm{C} 10$ & $1.400(2)$ \\
$\mathrm{C} 3-\mathrm{C} 4$ & $1.406(2)$ & $\mathrm{C} 10-\mathrm{H} 10$ & $0.939(18)$ \\
C3-H3 & $0.941(16)$ & $\mathrm{C} 11-\mathrm{C} 12$ & $1.551(2)$ \\
C4-C5 & $1.418(2)$ & $\mathrm{C} 12-\mathrm{F} 1$ & $1.3278(18)$ \\
C4-C9 & $1.427(2)$ & $\mathrm{C} 12-\mathrm{F} 3$ & $1.3356(19)$ \\
C5-C6 & $1.359(2)$ & $\mathrm{C} 12-\mathrm{F} 2$ & $1.3359(18)$ \\
C5-H5 & $0.963(19)$ & & \\
\hline
\end{tabular}

Table 20. Bond Angles for $3 \boldsymbol{d}$.

\begin{tabular}{llll}
\hline C1-O1-H1 & $108.5(16)$ & C8-C7-H7 & $119.3(12)$ \\
O1-C1-C10 & $118.24(14)$ & C6-C7-H7 & $119.8(12)$ \\
O1-C1-C2 & $121.49(14)$ & C7-C8-C9 & $120.94(15)$ \\
C10-C1-C2 & $120.25(14)$ & C7-C8-H8 & $126.2(13)$ \\
C3-C2-C1 & $118.78(13)$ & C9-C8-H8 & $112.8(13)$ \\
C3-C2-C11 & $122.46(13)$ & C10-C9-C8 & $122.53(15)$ \\
C1-C2-C11 & $118.76(13)$ & C10-C9-C4 & $119.43(15)$ \\
C2-C3-C4 & $121.41(13)$ & C8-C9-C4 & $118.04(15)$ \\
C2-C3-H3 & $121.0(10)$ & C1-C10-C9 & $121.21(15)$ \\
C4-C3-H3 & $117.5(10)$ & C1-C10-H10 & $116.9(11)$ \\
C3-C4-C5 & $122.04(13)$ & C9-C10-H10 & $121.8(11)$ \\
C3-C4-C9 & $118.85(13)$ & O2-C11-C2 & $124.81(14)$ \\
C5-C4-C9 & $119.11(14)$ & O2-C11-C12 & $115.85(13)$ \\
\hline
\end{tabular}


Table 20. Cont.

\begin{tabular}{llll}
\hline C6-C5-C4 & $121.03(15)$ & C2-C11-C12 & $119.28(13)$ \\
C6-C5-H5 & $122.5(11)$ & F1-C12-F3 & $107.45(12)$ \\
C4-C5-H5 & $116.5(11)$ & F1-C12-F2 & $107.51(13)$ \\
C5-C6-C7 & $119.96(16)$ & F3-C12-F2 & $107.63(12)$ \\
C5-C6-H6 & $121.7(10)$ & F1-C12-C11 & $110.39(12)$ \\
C7-C6-H6 & $118.3(10)$ & F3-C12-C11 & $111.44(13)$ \\
C8-C7-C6 & $120.91(16)$ & F2-C12-C11 & $112.21(12)$ \\
\hline
\end{tabular}

Table 21. Torsion Angles for 3d.

\begin{tabular}{llll}
\hline O1-C1-C2-C3 & $-178.15(14)$ & C3-C4-C9-C8 & $-178.87(13)$ \\
C10-C1-C2-C3 & $3.2(2)$ & C5-C4-C9-C8 & $1.1(2)$ \\
O1-C1-C2-C11 & $1.9(2)$ & O1-C1-C10-C9 & $178.95(14)$ \\
C10-C1-C2-C11 & $-176.80(13)$ & C2-C1-C10-C9 & $-2.3(2)$ \\
C1-C2-C3-C4 & $-1.6(2)$ & C8-C9-C10-C1 & $-179.58(14)$ \\
C11-C2-C3-C4 & $178.34(13)$ & C4-C9-C10-C1 & $-0.1(2)$ \\
C2-C3-C4-C5 & $179.37(14)$ & C3-C2-C11-O2 & $171.95(15)$ \\
C2-C3-C4-C9 & $-0.7(2)$ & C1-C2-C11-O2 & $-8.1(2)$ \\
C3-C4-C5-C6 & $178.62(14)$ & C3-C2-C11-C12 & $-11.0(2)$ \\
C9-C4-C5-C6 & $-1.3(2)$ & C1-C2-C11-C12 & $168.99(13)$ \\
C4-C5-C6-C7 & $0.7(2)$ & O2-C11-C12-F1 & $4.49(18)$ \\
C5-C6-C7-C8 & $0.1(2)$ & C2-C11-C12-F1 & $-172.83(12)$ \\
C6-C7-C8-C9 & $-0.3(2)$ & O2-C11-C12-F3 & $123.80(14)$ \\
C7-C8-C9-C10 & $179.23(15)$ & C2-C11-C12-F3 & $-53.51(17)$ \\
C7-C8-C9-C4 & $-0.3(2)$ & O2-C11-C12-F2 & $-115.41(15)$ \\
C3-C4-C9-C10 & $1.6(2)$ & C2-C11-C12-F2 & $67.28(18)$ \\
C5-C4-C9-C10 & $-178.48(14)$ & & \\
\hline
\end{tabular}

\section{Compound 4c}

\section{Experimental for $\mathrm{C}_{12} \mathrm{H}_{9} \mathrm{~F}_{3} \mathrm{O}_{2}$ (4c)}

Data Collection and Processing. The sample $\mathbf{4 c}$ was submitted by Joseph Sloop of the Sloop research group at Georgia Gwinnett College. The sample was mounted on a nylon loop with a small amount of Paratone $\mathrm{N}$ oil. All X-ray measurements were made on a Bruker-Nonius Kappa Axis X8 Apex 2 diffractometer at a temperature of $110 \mathrm{~K}$. The unit cell dimensions were determined from a symmetry constrained fit of 6416 reflections with $5.78^{\circ}<2 \theta<71.38^{\circ}$. The data collection strategy was a number of $\omega$ and $\varphi$ scans which collected data up to $71.58^{\circ}(2 \theta)$. The frame integration was performed using SAINT [29]. The resulting raw data was scaled and absorption corrected using a multi-scan averaging of symmetry equivalent data using SADABS [30].

Structure Solution and Refinement. The structure was solved by direct methods using the XS program [31]. All non-hydrogen atoms were obtained from the initial solution. The hydrogen atoms were located from a difference Fourier map and were allowed to refine isotropically. The structural model was fit to the data using full matrix least-squares based on $\mathrm{F}^{2}$. The calculated structure factors included corrections for anomalous dispersion from the usual tabulation. The structure was refined 
using the XL program from SHELXTL [32], graphic plots were produced using the NRCVAX crystallographic program suite. Additional information and other relevant literature references can be found in the reference section of the Facility's Web page (http://www.xray.ncsu.edu).

Figure 18. ORTEP drawing of $4 c$ showing naming and numbering scheme. Ellipsoids are at the $50 \%$ probability level and hydrogen atoms were drawn with arbitrary radii for clarity.

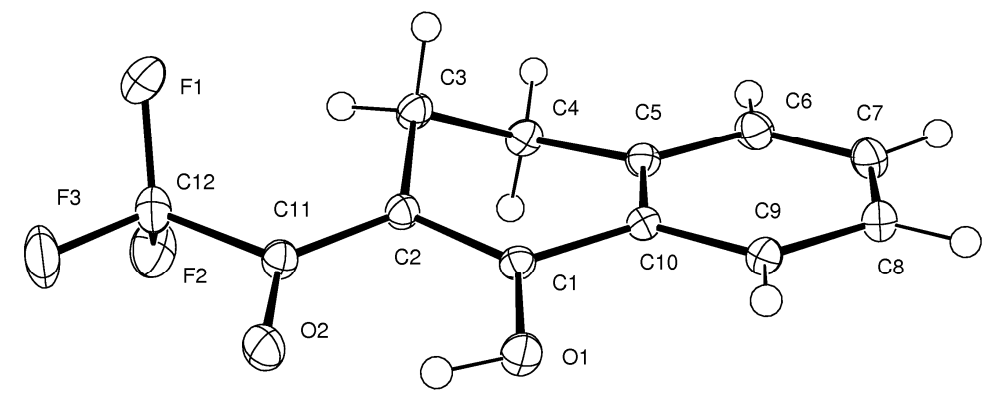

Figure 19. ORTEP drawing of $4 c$. Ellipsoids are at the 50\% probability level and hydrogen atoms were drawn with arbitrary radii for clarity.

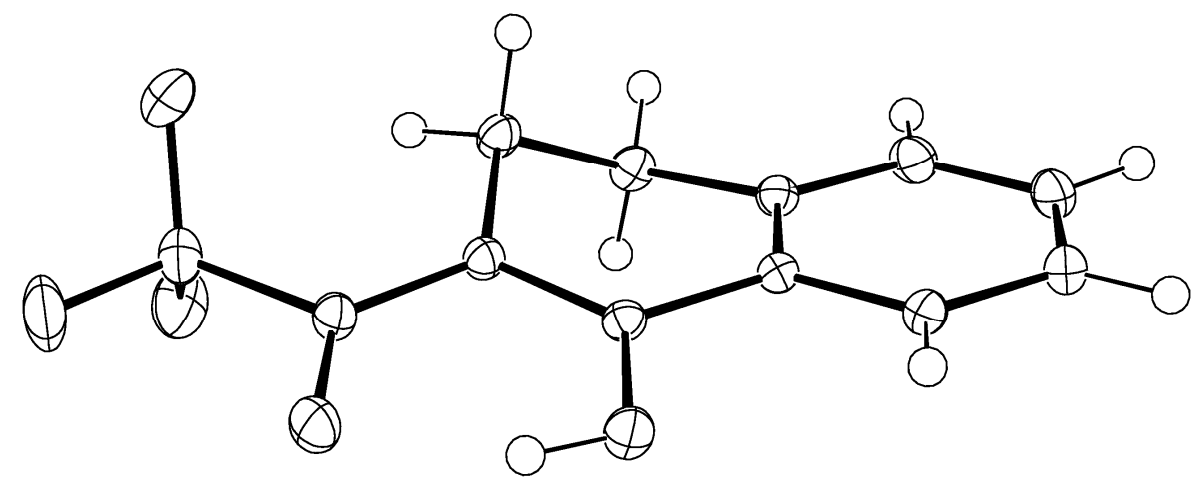

Figure 20. Stereoscopic ORTEP drawing of $4 c$. Ellipsoids are at the 50\% probability level and hydrogen atoms were drawn with arbitrary radii for clarity.
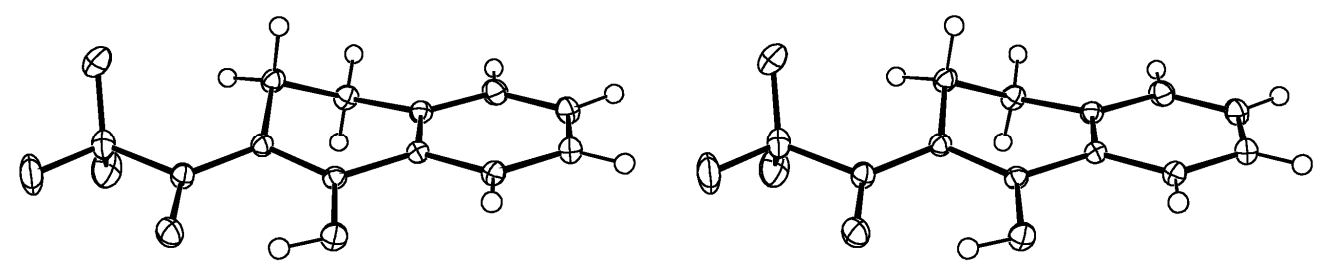

Table 22. Summary of Crystal Data for $4 c$.

\begin{tabular}{ll}
\hline Formula & $\mathrm{C}_{12} \mathrm{H}_{9} \mathrm{~F}_{3} \mathrm{O}_{2}$ \\
Formula Weight $(\mathrm{g} / \mathrm{mol})$ & 242.19 \\
Crystal Dimensions $(\mathrm{mm})$ & $0.38 \times 0.28 \times 0.04$ \\
Crystal Color and Habit & colourless plate \\
Crystal System & triclinic \\
Space Group & $\mathrm{P}-1$ \\
\hline
\end{tabular}


Table 22. Cont.

\begin{tabular}{|c|c|}
\hline Temperature, $\mathrm{K}$ & 110 \\
\hline$a, \AA$ & $7.3528(2)$ \\
\hline$b, \AA$ & $7.9165(2)$ \\
\hline$c, \AA$ & $9.7991(2)$ \\
\hline$\alpha,{ }^{\circ}$ & $73.0533(11)$ \\
\hline$\beta,^{\circ}$ & $85.3968(12)$ \\
\hline$\gamma,{ }^{\circ}$ & 68.3581(11) \\
\hline $\mathrm{V}, \AA^{3}$ & $506.92(2)$ \\
\hline Reflections to determine final unit cell & 6416 \\
\hline Min and Max $2 \theta$ for cell determination, ${ }^{\circ}$ & $5.78,71.38$ \\
\hline $\mathrm{Z}$ & 2 \\
\hline $\mathrm{F}(000)$ & 248 \\
\hline$\rho(\mathrm{g} / \mathrm{cm})$ & 1.587 \\
\hline$\lambda, \AA,(\mathrm{MoK} \quad)$ & 0.71073 \\
\hline$\mu,\left(\mathrm{cm}^{-1}\right)$ & 0.143 \\
\hline Number of reflections measured & 20479 \\
\hline Unique reflections measured & 4691 \\
\hline $\mathrm{R}_{\text {merge }}$ & 0.0265 \\
\hline Number of reflections included in refinement & 4691 \\
\hline Cut off Threshold Expression & $>2 \operatorname{sigma}(\mathrm{I})$ \\
\hline Structure refined using & $\begin{array}{l}\text { full matrix least-squares using } \\
\mathrm{F}^{2}\end{array}$ \\
\hline Weighting Scheme & $\begin{array}{l}\mathrm{w}=1 /\left[\operatorname{sigma}^{2}\left(\mathrm{Fo}^{2}\right)+\right. \\
\left.(0.0707 \mathrm{P})^{2}+0.0436 \mathrm{P}\right] \text { where } \\
\mathrm{P}=\left(\mathrm{Fo}^{2}+2 \mathrm{Fc}^{2}\right) / 3\end{array}$ \\
\hline $\mathrm{R}_{1}$ & 0.0382 \\
\hline$w_{2}$ & 0.1082 \\
\hline $\mathrm{R}_{1}$ (all data) & 0.0525 \\
\hline $\mathrm{wR}_{2}$ (all data) & 0.1220 \\
\hline GOF & 1.048 \\
\hline
\end{tabular}

Where:

$\mathrm{R}_{1}=\Sigma\left(\left|\mathrm{F}_{\mathrm{O}}\right|-\left|\mathrm{F}_{\mathrm{C}}\right|\right) / \Sigma \mathrm{F}_{\mathrm{O}}$

$\mathrm{wR}_{2}=\left[\Sigma\left(w\left(\mathrm{~F}_{\mathrm{O}}^{2}-\mathrm{F}_{\mathrm{c}^{2}}\right)^{2}\right) / \Sigma\left(w \mathrm{~F}_{\mathrm{O}}{ }^{4}\right)\right]^{1 / 2}$

$\mathrm{GOF}=\left[\Sigma\left(w\left(\mathrm{~F}_{\mathrm{O}}{ }^{2}-\mathrm{F}_{\mathrm{c}}{ }^{2}\right)^{2}\right) /(\text { No. of reflns. }- \text { No. of params. })\right]^{1 / 2}$

Table 23. Atomic Coordinates for $4 c$.

\begin{tabular}{lllll}
\hline Atom & $\mathrm{x}$ & $\mathrm{y}$ & $\mathrm{z}$ & $\mathrm{U}_{\text {iso/equiv }}$ \\
$\mathrm{O} 1$ & $0.77448(8)$ & $0.28007(9)$ & $0.27345(6)$ & $0.01748(12)$ \\
$\mathrm{O} 2$ & $0.99446(9)$ & $0.28522(9)$ & $0.06442(6)$ & $0.02064(13)$ \\
$\mathrm{C} 1$ & $0.92164(10)$ & $0.26838(10)$ & $0.34926(7)$ & $0.01305(12)$ \\
$\mathrm{C} 2$ & $1.10003(10)$ & $0.26974(10)$ & $0.29126(8)$ & $0.01358(12)$ \\
$\mathrm{C} 3$ & $1.25154(11)$ & $0.27188(11)$ & $0.38557(8)$ & $0.01584(13)$ \\
$\mathrm{C} 4$ & $1.24786(11)$ & $0.15172(11)$ & $0.53827(8)$ & $0.01618(13)$ \\
\hline
\end{tabular}


Table 23. Cont.

\begin{tabular}{lllll}
\hline C5 & $1.04451(11)$ & $0.19875(10)$ & $0.59451(8)$ & $0.01444(13)$ \\
C6 & $1.00916(12)$ & $0.18008(12)$ & $0.73914(8)$ & $0.01899(15)$ \\
C7 & $0.82002(13)$ & $0.21517(12)$ & $0.78875(9)$ & $0.02070(15)$ \\
C8 & $0.66361(12)$ & $0.26962(12)$ & $0.69526(9)$ & $0.01971(15)$ \\
C9 & $0.69574(11)$ & $0.28853(11)$ & $0.55100(8)$ & $0.01598(13)$ \\
C10 & $0.88579(10)$ & $0.25358(10)$ & $0.50052(7)$ & $0.01326(12)$ \\
C11 & $1.12232(11)$ & $0.27815(10)$ & $0.14448(8)$ & $0.01590(13)$ \\
C12 & $1.31898(12)$ & $0.27354(12)$ & $0.07494(9)$ & $0.02008(15)$ \\
F1 & $1.37562(8)$ & $0.40737(8)$ & $0.09309(6)$ & $0.02557(13)$ \\
F2 & $1.46211(8)$ & $0.10631(8)$ & $0.12997(6)$ & $0.03004(14)$ \\
F3 & $1.30731(9)$ & $0.29835(10)$ & $-0.06471(6)$ & $0.03180(15)$ \\
H1 & $0.818(3)$ & $0.282(3)$ & $0.190(2)$ & $0.066(5)$ \\
H3A & $1.2210(17)$ & $0.4028(17)$ & $0.3866(12)$ & $0.018(3)$ \\
H3B & $1.386(2)$ & $0.2261(18)$ & $0.3516(13)$ & $0.026(3)$ \\
H4A & $1.3333(19)$ & $0.1700(17)$ & $0.5989(13)$ & $0.021(3)$ \\
H4B & $1.2933(18)$ & $0.0209(17)$ & $0.5436(13)$ & $0.020(3)$ \\
H6 & $1.120(2)$ & $0.1395(19)$ & $0.8020(14)$ & $0.030(3)$ \\
H7 & $0.806(2)$ & $0.204(2)$ & $0.8859(17)$ & $0.041(4)$ \\
H8 & $0.526(2)$ & $0.304(2)$ & $0.7231(14)$ & $0.033(3)$ \\
H9 & $0.5882(18)$ & $0.3326(17)$ & $0.4836(13)$ & $0.019(3)$ \\
\hline
\end{tabular}

Table 24. Anisotropic Displacement Parameters for $\mathbf{4 c}$.

\begin{tabular}{lllllll}
\hline Atom & $\mathrm{u}^{11}$ & $\mathrm{u}^{22}$ & $\mathrm{u}^{33}$ & $\mathrm{u}^{12}$ & $\mathrm{u}^{13}$ & $\mathrm{u}^{23}$ \\
$\mathrm{O} 1$ & $0.0149(2)$ & $0.0246(3)$ & $0.0147(2)$ & $-0.0091(2)$ & $-0.00183(19)$ & $-0.0048(2)$ \\
$\mathrm{O} 2$ & $0.0229(3)$ & $0.0269(3)$ & $0.0145(2)$ & $-0.0113(2)$ & $-0.0001(2)$ & $-0.0061(2)$ \\
$\mathrm{C} 1$ & $0.0127(3)$ & $0.0135(3)$ & $0.0133(3)$ & $-0.0052(2)$ & $-0.0005(2)$ & $-0.0035(2)$ \\
$\mathrm{C} 2$ & $0.0129(3)$ & $0.0155(3)$ & $0.0131(3)$ & $-0.0059(2)$ & $0.0007(2)$ & $-0.0042(2)$ \\
$\mathrm{C} 3$ & $0.0137(3)$ & $0.0189(3)$ & $0.0166(3)$ & $-0.0081(2)$ & $0.0007(2)$ & $-0.0046(2)$ \\
$\mathrm{C} 4$ & $0.0134(3)$ & $0.0184(3)$ & $0.0162(3)$ & $-0.0059(2)$ & $-0.0019(2)$ & $-0.0035(2)$ \\
$\mathrm{C} 5$ & $0.0151(3)$ & $0.0148(3)$ & $0.0143(3)$ & $-0.0062(2)$ & $0.0003(2)$ & $-0.0044(2)$ \\
$\mathrm{C} 6$ & $0.0226(4)$ & $0.0212(3)$ & $0.0144(3)$ & $-0.0091(3)$ & $-0.0007(3)$ & $-0.0051(3)$ \\
$\mathrm{C} 7$ & $0.0270(4)$ & $0.0225(3)$ & $0.0156(3)$ & $-0.0115(3)$ & $0.0055(3)$ & $-0.0078(3)$ \\
$\mathrm{C} 8$ & $0.0210(4)$ & $0.0215(3)$ & $0.0203(3)$ & $-0.0104(3)$ & $0.0077(3)$ & $-0.0097(3)$ \\
$\mathrm{C} 9$ & $0.0142(3)$ & $0.0171(3)$ & $0.0185(3)$ & $-0.0069(2)$ & $0.0030(2)$ & $-0.0068(2)$ \\
$\mathrm{C} 10$ & $0.0133(3)$ & $0.0143(3)$ & $0.0136(3)$ & $-0.0061(2)$ & $0.0012(2)$ & $-0.0047(2)$ \\
$\mathrm{C} 11$ & $0.0174(3)$ & $0.0162(3)$ & $0.0140(3)$ & $-0.0067(2)$ & $0.0021(2)$ & $-0.0038(2)$ \\
$\mathrm{C} 12$ & $0.0204(3)$ & $0.0226(4)$ & $0.0166(3)$ & $-0.0077(3)$ & $0.0049(3)$ & $-0.0058(3)$ \\
$\mathrm{F} 1$ & $0.0244(3)$ & $0.0283(3)$ & $0.0279(3)$ & $-0.0162(2)$ & $0.0068(2)$ & $-0.0065(2)$ \\
$\mathrm{F} 2$ & $0.0215(3)$ & $0.0254(3)$ & $0.0345(3)$ & $-0.0013(2)$ & $0.0080(2)$ & $-0.0070(2)$ \\
$\mathrm{F} 3$ & $0.0341(3)$ & $0.0473(4)$ & $0.0169(2)$ & $-0.0181(3)$ & $0.0108(2)$ & $-0.0115(2)$ \\
\hline
\end{tabular}


Table 25. Bond Lengths for $4 c$.

\begin{tabular}{llll}
\hline O1-C1 & $1.3215(9)$ & $\mathrm{C} 5-\mathrm{C} 10$ & $1.4016(10)$ \\
$\mathrm{O} 1-\mathrm{H} 1$ & $0.855(19)$ & $\mathrm{C} 6-\mathrm{C} 7$ & $1.3903(12)$ \\
$\mathrm{O} 2-\mathrm{C} 11$ & $1.2476(10)$ & $\mathrm{C} 6-\mathrm{H} 6$ & $0.960(14)$ \\
$\mathrm{C} 1-\mathrm{C} 2$ & $1.3895(10)$ & $\mathrm{C} 7-\mathrm{C} 8$ & $1.3860(12)$ \\
$\mathrm{C} 1-\mathrm{C} 10$ & $1.4626(10)$ & $\mathrm{C} 7-\mathrm{H} 7$ & $0.931(15)$ \\
$\mathrm{C} 2-\mathrm{C} 11$ & $1.4193(10)$ & $\mathrm{C} 8-\mathrm{C} 9$ & $1.3877(11)$ \\
$\mathrm{C} 2-\mathrm{C} 3$ & $1.5112(10)$ & $\mathrm{C} 8-\mathrm{H} 8$ & $0.984(14)$ \\
$\mathrm{C} 3-\mathrm{C} 4$ & $1.5255(11)$ & $\mathrm{C} 9-\mathrm{C} 10$ & $1.3992(10)$ \\
$\mathrm{C} 3-\mathrm{H} 3 \mathrm{~A}$ & $0.979(12)$ & $\mathrm{C} 9-\mathrm{H} 9$ & $0.964(12)$ \\
$\mathrm{C} 3-\mathrm{H} 3 \mathrm{~B}$ & $0.984(13)$ & $\mathrm{C} 11-\mathrm{C} 12$ & $1.5408(11)$ \\
$\mathrm{C} 4-\mathrm{C} 5$ & $1.5016(10)$ & $\mathrm{C} 12-\mathrm{F} 3$ & $1.3298(10)$ \\
$\mathrm{C} 4-\mathrm{H} 4 \mathrm{~A}$ & $0.972(12)$ & $\mathrm{C} 12-\mathrm{F} 1$ & $1.3322(10)$ \\
$\mathrm{C} 4-\mathrm{H} 4 \mathrm{~B}$ & $0.950(12)$ & $\mathrm{C} 12-\mathrm{F} 2$ & $1.3410(10)$ \\
$\mathrm{C} 5-\mathrm{C} 6$ & $1.3946(10)$ & & \\
\hline
\end{tabular}

Table 26. Bond Angles for $4 c$.

\begin{tabular}{llll}
\hline C1-O1-H1 & $105.2(13)$ & C7-C6-H6 & $122.1(8)$ \\
O1-C1-C2 & $123.08(7)$ & C5-C6-H6 & $117.4(8)$ \\
O1-C1-C10 & $115.65(6)$ & C8-C7-C6 & $120.54(7)$ \\
C2-C1-C10 & $121.28(6)$ & C8-C7-H7 & $123.4(9)$ \\
C1-C2-C11 & $116.88(7)$ & C6-C7-H7 & $116.1(9)$ \\
C1-C2-C3 & $118.29(6)$ & C7-C8-C9 & $119.86(7)$ \\
C11-C2-C3 & $124.76(6)$ & C7-C8-H8 & $124.2(8)$ \\
C2-C3-C4 & $111.06(6)$ & C9-C8-H8 & $115.9(8)$ \\
C2-C3-H3A & $108.3(7)$ & C8-C9-C10 & $119.82(7)$ \\
C4-C3-H3A & $108.5(7)$ & C8-C9-H9 & $121.1(7)$ \\
C2-C3-H3B & $113.2(7)$ & C10-C9-H9 & $119.0(7)$ \\
C4-C3-H3B & $108.2(8)$ & C9-C10-C5 & $120.59(7)$ \\
H3A-C3-H3B & $107.4(10)$ & C9-C10-C1 & $120.17(7)$ \\
C5-C4-C3 & $112.07(6)$ & C5-C10-C1 & $119.22(6)$ \\
C5-C4-H4A & $110.3(7)$ & O2-C11-C2 & $125.09(7)$ \\
C3-C4-H4A & $109.1(7)$ & O2-C11-C12 & $115.47(7)$ \\
C5-C4-H4B & $105.9(7)$ & C2-C11-C12 & $119.42(7)$ \\
C3-C4-H4B & $111.1(7)$ & F3-C12-F1 & $107.53(7)$ \\
H4A-C4-H4B & $108.2(10)$ & F3-C12-F2 & $107.30(7)$ \\
C6-C5-C10 & $118.70(7)$ & F1-C12-F2 & $107.24(7)$ \\
C6-C5-C4 & $121.98(7)$ & F3-C12-C11 & $110.83(7)$ \\
C10-C5-C4 & $119.24(6)$ & F1-C12-C11 & $112.56(6)$ \\
C7-C6-C5 & $120.50(8)$ & F2-C12-C11 & $111.13(6)$ \\
\hline
\end{tabular}

Table 27. Torsion Angles for $4 c$.

\begin{tabular}{llll}
\hline O1-C1-C2-C11 & $-2.04(11)$ & C4-C5-C10-C9 & $176.58(7)$ \\
C10-C1-C2-C11 & $177.93(6)$ & C6-C5-C10-C1 & $-178.26(7)$ \\
O1-C1-C2-C3 & $175.03(7)$ & C4-C5-C10-C1 & $-1.57(10)$ \\
\hline
\end{tabular}


Table 27. Cont.

\begin{tabular}{llll}
\hline C10-C1-C2-C3 & $-4.99(10)$ & O1-C1-C10-C9 & $-12.24(10)$ \\
C1-C2-C3-C4 & $36.71(9)$ & C2-C1-C10-C9 & $167.79(7)$ \\
C11-C2-C3-C4 & $-146.47(7)$ & O1-C1-C10-C5 & $165.92(6)$ \\
C2-C3-C4-C5 & $-49.62(8)$ & C2-C1-C10-C5 & $-14.06(10)$ \\
C3-C4-C5-C6 & $-149.82(7)$ & C1-C2-C11-O2 & $0.34(11)$ \\
C3-C4-C5-C10 & $33.60(9)$ & C3-C2-C11-O2 & $-176.52(7)$ \\
C10-C5-C6-C7 & $0.04(11)$ & C1-C2-C11-C12 & $-178.03(6)$ \\
C4-C5-C6-C7 & $-176.56(7)$ & C3-C2-C11-C12 & $5.11(11)$ \\
C5-C6-C7-C8 & $-0.13(12)$ & O2-C11-C12-F3 & $6.60(10)$ \\
C6-C7-C8-C9 & $0.30(12)$ & C2-C11-C12-F3 & $-174.87(7)$ \\
C7-C8-C9-C10 & $-0.37(11)$ & O2-C11-C12-F1 & $127.07(8)$ \\
C8-C9-C10-C5 & $0.28(11)$ & C2-C11-C12-F1 & $-54.40(10)$ \\
C8-C9-C10-C1 & $178.41(7)$ & O2-C11-C12-F2 & $-112.62(8)$ \\
C6-C5-C10-C9 & $-0.11(11)$ & C2-C11-C12-F2 & $65.91(9)$ \\
\hline
\end{tabular}

(C) 2012 by the authors; licensee MDPI, Basel, Switzerland. This article is an open access article distributed under the terms and conditions of the Creative Commons Attribution license (http://creativecommons.org/licenses/by/3.0/). 